\title{
Energy and Environmental (JSR) Research Emphasizing Low-Rank Coal
}

\section{Topical Report}

Laura L. Sharp

December 1994

Work Performed Under Contract No.: DE-FC21-93MC30098

For

U.S. Department of Energy

Office of Fossil Energy

Morgantown Energy Technology Center

Morgantown, West Virginia

By

University of North Dakota Grand Forks, North Dakota 


\section{DISCLAIMER}

This report was prepared as an account of work sponsored by an agency of the United States Government. Neither the United States Government nor any agency thereof, nor any of their employees, makes any warranty, express or implied, or assumes any legal liability or responsibility for the accuracy, completeness, or usefulness of any information, apparatus, product, or process disclosed, or represents that its use would not infringe privately owned rights. Reference herein to any specific commercial product, process, or service by trade name, trademark, manufacturer, or otherwise does not necessarily constitute or imply its endorsement, recommendation, or favoring by the United States Government or any agency thereof. The views and opinions of authors expressed herein do not necessarily state or reflect those of the United States Government or any agency thereof.

This report has been reproduced directly from the best available copy.

Available to DOE and DOE contractors from the Office of Scientific and Technical Information, 175 Oak Ridge Turnpike, Oak Ridge, TN 37831; prices available at (615) 576-8401.

Available to the public from the National Technical Information Service, U.S. Department of Commerce, 5285 Port Royal Road, Springfield, VA 22161; phone orders accepted at (703) 487-4650. 


\section{DISCLAIMER}

Portions of this document may be illegible in electronic image products. Images are produced from the best available original document. 


\title{
Energy and Environmental (JSR) Research Emphasizing Low-Rank Coal
}

\author{
Topical Report
}

Laura L. Sharp

Work Performed Under Contract No.: DE-FC21-93MC30098

\author{
For \\ U.S. Department of Energy \\ Office of Fossil Energy \\ Morgantown Energy Technology Center \\ P.O. Box 880 \\ Morgantown, West Virginia 26507-0880 \\ By \\ University of North Dakota \\ P.O. Box 9018 \\ Grand Forks, North Dakota 58292-9018
}

December 1994 


\section{ACKNOWLEDGMENT}

This report describes work performed at the Energy \& Environmental Research Center (EERC) over the period June 1993 to December 1994. Sponsors of the work were the U.S. Department of Energy (DOE), the 3M Corporation, and the American Plastics Council (APC). The following personnel contributed to the completion of the project:

\section{EERC}

Laura L. Sharp - Principal Investigator and primary author

Robert O. Ness, Jr. - Project Manager

Ted R. Aulich - Analytical coordinator and contributing author

$\underline{\mathrm{APC}}$

George A. Mackey - DOW Chemical Co., Granville, OH v4,33 APC technical advisor James C. Randall - Exxon Chemical Co., Houston, TX

Jose M. Sosa - FINA Oil and Chemical Co., Houston, TX

Dave Warner - Mobil Chemical Co., Houston, TX

John Forgac - Amoco Chemical Co., Napperville, IL

$\underline{3 \mathrm{M}}$

Donald Eaton - 3M Corporation, St. Paul, MN - Project monitor

Tim Hebrink - 3M Corporation, St. Paul, MN

Fred Kelly - 3M Corporation, Brownwood, TX

DOE

Rodney Geisbrecht - Contracting Officer's Representative

EERC Research Staff

Greg Anderson

Don Cox

David Hassett

Steve Hawthorne

Ray Johnson

Timothy Kujawa

Yufu Li

John Lutheran

Lorne McEwen

David Miller

Edward Olson

Willis Palmer

Jerry Petersburg

William Sukalski

Miranda Timpe

Ronald Timpe

EERC Office Services

Mary Jo Sturman

Mary Pringle 


\section{INTRODUCTION}

Recycling of plastics on a significant scale is in the future of the United States. With a realization of this fact, plastics manufacturers in the U.S. have begun to support research aimed at finding the most practicable technology to achieve higher levels of plastics recycling, at minimal cost to the consumer. This goal presents many challenges. Already quite heterogeneous, postconsumer plastic streams composition varies with location, season, and time. Because of the many applications of plastics, numerous additives, both inorganic and organic, are present in the plastic products. Contaminants from use by the consumer will be mixed with the plastics (e.g., paint, paint thinner, food, metals, paper, adhesives, etc). Processes to recycle plastics will need to account for all of these factors.

Presently, some types of plastics (mainly polyethylene terephthalate [PET] and highdensity polyethylene [HDPE]) are collected and recycled back to plastics of that same type by chemical or mechanical methods. These methods of recycling require relatively clean, homogeneous streams. Processes to recycle PET or HDPE exist mainly because large enough quantities of feed are available at a sufficiently low price to make the process economical. For most types of plastics, delivery of sufficient quantities (considering collection, sortation, preparation, and transportation) to a process dedicated solely to the recycling of that plastic is economically prohibitive. In order to recycle large quantities of plastics, processes that are able to accept mixed streams are necessary. Methods to form usable products with minimal processing of plastics also exist, such as plastic lumber manufacturing, but have limited markets. Traditional recycling processes, such as those to mechanically recycle PET or to form plastic lumber, trash bags, or trash cans, are an important part of the overall recycling effort, but cannot process all types of plastics streams collected and do not accept sufficient quantities of material to achieve significantly higher recycling levels. As an additional recycling option, several groups around this country and in Europe are examining methods of thermal decomposition (sometimes referred to as thermal depolymerization or feedstock recycling) of mixed plastics streams. A range of hydrocarbon liquid and gaseous products are available from this type of process, many of which have potentially large markets. The products of thermal depolymerization can be used for the manufacture of new plastics or various other hydrocarbon-based products. One thermal depolymerization development effort is ongoing at the Energy \& Environmental Research Center (EERC) of the University of North Dakota, under joint sponsorship of the American Plastics Council, the 3M corporation, and the Department of Energy.

Thermal depolymerization process development began at the EERC with a benchscale program that ran from $9 / 92$ to $6 / 93$ (1). Testing was conducted in a $1-4-\mathrm{lb} / \mathrm{hr}$ continuous fluid-bed reactor (CFBR) unit using individual virgin resins and resin blends and was intended to determine rough operating parameters and product yields and to identify product stream components. Process variables examined included temperature and bed material, with a lesser emphasis on gas fluidization velocity and feed material mix. The following work was performed: 1) a short program to determine the suitability of using $\mathrm{CaO}$ in a postreactor, fixed bed for chlorine remediation, 2) thermal depolymerization of postconsumer plastics, and 3) testing of industrial (3M) products and wastes to determine their suitability as feed to a thermal depolymerization process.

(1) "Thermal Recycling of Plastics," Sharp, L.L. final report to the American Plastics Council; EERC publication, March 1994. 
The involvement of DOE in the development of the plastics thermal depolymerization process has helped to facilitate the transfer of coal conversion technology to a new and growing technology area-waste conversion. These two technology areas are complementary. The application of known coal conversion technology has accelerated the development of plastics conversion technology, and findings from the plastics depolymerization process development, such as the development of chlorine remediation techniques and procedures for measurement of organically associated chlorine, can be applied to new generations of coal conversion processes. 
CHLORINE REMOVAL FROM THE PRODUCTS OF THERMAL DEPOLYMERIZATION OF PLASTICS 


\section{TABLE OF CONTENTS}

LIST OF FIGURES $\ldots \ldots \ldots \ldots \ldots \ldots \ldots \ldots \ldots \ldots \ldots \ldots \ldots \ldots \ldots \ldots \ldots \ldots$

LIST OF TABLES $\ldots \ldots \ldots \ldots \ldots \ldots \ldots \ldots \ldots \ldots \ldots \ldots \ldots \ldots \ldots \ldots \ldots \ldots \ldots$

EXECUTIVE SUMMARY $\ldots \ldots \ldots \ldots \ldots \ldots \ldots \ldots \ldots \ldots \ldots \ldots \ldots \ldots$ iii

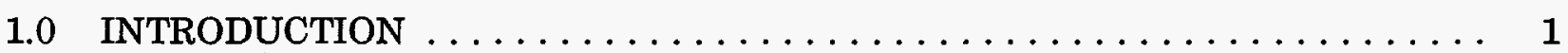

$2.0 \quad$ PP/PVC FIXED-BED TESTS $\ldots \ldots \ldots \ldots \ldots \ldots \ldots \ldots \ldots \ldots \ldots \ldots \ldots$

3.0 CONTINUOUS FLUID-BED REACTOR $\ldots \ldots \ldots \ldots \ldots \ldots \ldots \ldots \ldots$

4.0 PARAMETRIC TESTING RESULTS $\ldots \ldots \ldots \ldots \ldots \ldots \ldots \ldots \ldots \ldots$

4.1 Product Liquid Chlorine Concentrations $\ldots \ldots \ldots \ldots \ldots \ldots \ldots \ldots$

4.2 Nonfilter Product Liquids $\ldots \ldots \ldots \ldots \ldots \ldots \ldots \ldots \ldots \ldots \ldots$

4.2.1 Effect of Depolymerization Temperature on Chlorine

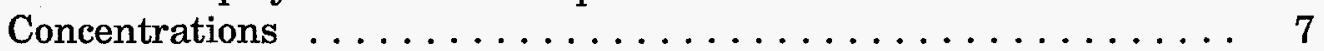

4.2.2 Effect of PVC Concentration on Chlorine Concentrations . . . . . 8

4.3 Filtered Product Liquids $\ldots \ldots \ldots \ldots \ldots \ldots \ldots \ldots \ldots . \ldots \ldots$

4.3.1 Effect of Filter Temperature at $440^{\circ} \mathrm{C}$ on Chlorine Concentrations . 8

4.3.2 Effect of Filter Temperature at $540^{\circ} \mathrm{C} \ldots \ldots \ldots \ldots \ldots \ldots \ldots$

4.3.3 Effect of Sorbent Particle Size at $540^{\circ} \mathrm{C} \ldots \ldots \ldots \ldots \ldots \ldots 12$

4.3.4 Effect of PVC Concentration in Feed on CaO Chlorine Removal

Effectiveness ........................ 13

4.4 Material Balance Results . . . . . . . . . . . . . . . . . . 14

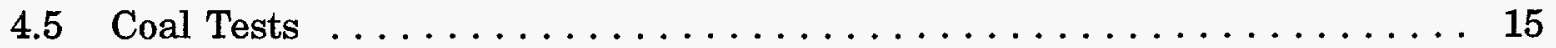

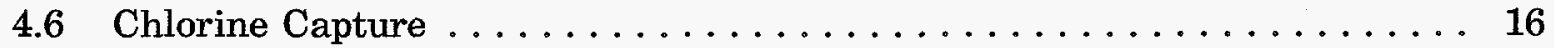

5.0 CONCLUSIONS AND RECOMMENDATIONS $\ldots \ldots \ldots \ldots \ldots \ldots \ldots \ldots$

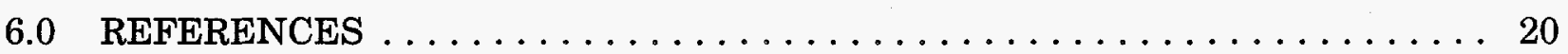

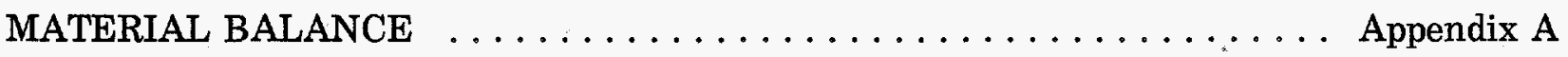

TOTAL AND ORGANIC CHLORINE DETERMINATION $\ldots \ldots \ldots \ldots$ Appendix B

GC/AED ORGANIC CHLORINE ANALYSIS OF PLASTICS DECOMPOSITION

LIQUIDS DETECTION LIMIT/QUALITY CONTROL STUDY . . . . . . . Appendix C

CHLORINE CONCENTRATION DETERMINATION $\ldots \ldots \ldots \ldots \ldots$ Appendix D 


\section{LIST OF FIGURES}

1 1- to $4-\mathrm{lb} / \mathrm{hr}$ continuous fluid-bed reactor $\ldots \ldots \ldots \ldots \ldots \ldots \ldots \ldots$

2 Chlorine capture effectiveness of $\mathrm{CaO}$ filter at $440^{\circ} \mathrm{C} \ldots \ldots \ldots \ldots$

3 Chlorine capture effectiveness of $\mathrm{CaO}$ filter at $540^{\circ} \mathrm{C} \ldots \ldots \ldots \ldots$

\section{LIST OF TABLES}

$1 \quad$ Run Conditions $\ldots \ldots \ldots \ldots \ldots \ldots \ldots \ldots \ldots \ldots \ldots \ldots \ldots \ldots$

2 Product and Bed Material Chlorine Concentrations . . . . . . . . . . 7

3 Effect of Filter Temperature at a Decomposition Temperature of $440^{\circ} \mathrm{C} \ldots \ldots$

4 Chlorine Capture Effectiveness of $\mathrm{CaO}$ at a Reactor Temperature of $440^{\circ} \mathrm{C} \ldots \ldots$

5 Effect of Filter Temperature at a Decomposition Temperature of $540^{\circ} \mathrm{C} \ldots \ldots$

6 Chlorine Capture Effectiveness of $\mathrm{CaO}$ at a Reactor Temperature of $540^{\circ} \mathrm{C} \ldots \ldots$

7 Effect of Sorbent Particle Size on Product and Bed Material Chlorine

Concentrations . . . . . . . . . . . . . . . . . . . . . . . 12

8 Effect of Sorbent Particle Size on Chlorine Capture Effectiveness . . . . . . . 13

9 Effect of PVC Concentration on Product and Bed Material Chlorine

Concentrations .......................... 13

10 Effect of PVC Concentration on Chlorine Capture Effectiveness . . . . . . . . 14

11 Material Balance Results . . . . . . . . . . . . . . . . . . . 14

12 Product Gas Analyses PP/PVC Tests $\ldots \ldots \ldots \ldots \ldots \ldots \ldots \ldots$

13 Coal Test Conditions $\ldots \ldots \ldots \ldots \ldots \ldots \ldots \ldots \ldots \ldots \ldots$

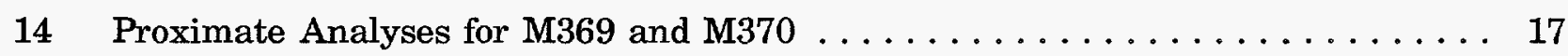

15 Chlorine Analyses for Coal Tests $\ldots \ldots \ldots \ldots \ldots \ldots \ldots \ldots$

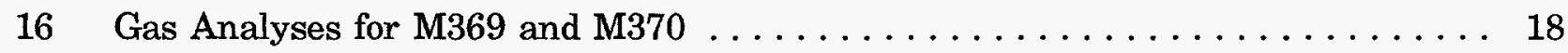




\section{EXECUTIVE SUMMARY}

Thermal depolymerization of mixed-plastics streams will necessarily include some method of removing chlorine, present primarily from the decomposition of polyvinyl chloride (PVC). Chlorine removal can take place before the depolymerization step (feed pretreatment), during depolymerization (in situ), or after depolymerization (postreactor scrubbers). The first phase of this study investigated the feasibility of chlorine removal in a fixed-bed, postdepolymerization scrubber using calcium oxide as a sorbent. Tests using polypropylene (PP) and PVC were performed at three filter temperatures, two depolymerization reactor temperatures, two sorbent particle sizes, and two ratios of $P P$ to PVC in the feed material. The qualitative effects of these variables on total and organic chlorine levels in the product liquids were determined. Concurrent with the evaluation of the feasibility to use a fixed bed of $\mathrm{CaO}$ to remove chlorine, a study was conducted to determine the detection limits of organically associated chlorine using the GC/AED technique. Additionally, a quality control procedure was implemented for the technique.

For the PP/PVC tests, $\mathrm{CaO}$ was found to capture between approximately $43 \%$ and essentially $100 \%$ of the chlorine introduced to the system. The greatest effect on capture efficiency is filter temperature. At both depolymerization temperatures examined $\left(440^{\circ} \mathrm{C}\right.$ and $540^{\circ} \mathrm{C}$ ), tests in which filter temperatures were maintained at the depolymerization temperatures (prohibiting any condensation of the product liquids) resulted in nearly $100 \%$ capture of chlorine by the $\mathrm{CaO}$ and prevention of organochloride formation in the product liquids. At a depolymerization temperature of $440^{\circ} \mathrm{C}$, organic chlorine formation in the product liquids was observed only when the filter temperature was set at $340^{\circ} \mathrm{C}$. No organic chlorine formation in the liquid products was observed in the $440^{\circ} \mathrm{C}$ depolymerization test at a filter temperature as low as $390^{\circ} \mathrm{C}$.

One PP/PVC test was performed using $\mathrm{CaO}$ with a smaller particle size than was used in all other tests to observe the effect of particle size on chlorine capture. Calculated captures of the two tests were similar, as were chlorine levels in the two liquid samples.

In all PP/PVC tests but one, a 5\% PVC and 95\% $\mathrm{PP}$ mix was used as the feed material. One test was performed using a 10\% PVC and 90\% PP mix to examine the influence of PVC concentration on filter effectiveness. The resulting chlorine levels in the product liquids were similar, with a slightly higher total chlorine concentration in the $10 \%$ test product liquid. The chlorine capture efficiencies of the two tests were the same.

While conditions were identified for very good chlorine capture, some chlorine remained in all PP/PVC test product liquids. At best, product liquids contained approximately 100-ppm chlorine. Chlorine levels in liquids obtained without a $\mathrm{CaO}$ filter were found to be approximately $5000 \mathrm{ppm}$ (the test was performed without a filter at a depolymerization temperature of $540^{\circ} \mathrm{C}$ ). This method of chlorine capture will need to be used in combination with some other method, possibly a second $\mathrm{CaO}$ filter in series with the first, in situ removal, or a polishing step. It is not yet known if two filters placed in series (or a deeper bed) or other combinations of chlorine removal methods placed in series would drop the chlorine level down to acceptable levels (1-2 ppm). These possibilities are areas for future investigation.

Two tests were completed with the fixed bed of $\mathrm{CaO}$ using coal as a feed material to the pyrolysis reactor. Significant chlorine capture was observed by $\mathrm{CaO}$.

The organic chlorine detection limits/quality control study determined a detection limit of approximately $4 \mathrm{ppm}$ per component for chlorinated organic species. 


\section{CHLORINE REMOVAL FROM THE PRODUCTS OF THERMAL DEPOLYMERIZATION OF PLASTICS}

\subsection{INTRODUCTION}

Plastics currently account for about $20 \%$ by volume of the material entering a landfill. Landfilling and, to a lesser extent, incineration have been the traditional means of waste disposal in this country. With increasingly stringent requirements on material entering a landfill and the desire to recycle more products, an effort to reduce the amount of material disposed of in these traditional manners is under way. Although many products can be recycled directly back to their starting roles (e.g., paper, aluminum cans, high-density polyethylene [HDPE] bottles), others must be recycled through alternate means to be economically pragmatic. Because of the high cost associated with separating and cleaning, it is not practical to separate all types of plastics to recycle. Some products, which are combinations of polymers, cannot be separated manually. Fluid-bed thermal depolymerization with the purpose of producing liquids suitable for feed to a petroleum refinery is being considered as a means of recycling waste plastics. A yearlong study, recently completed at the Energy \& Environmental Research Center (EERC), examined the variables of a fluid-bed thermal decomposition process, including the effects of temperature, bed material, gas residence time, and feed material composition, on product yields (1).

Plastics streams targeted for recycling will contain some level of chlorine, primarily in the form of PVC. This chlorine will need to be removed, at some point, in all of the mixed-plastics recycling process options envisioned. Several removal options have been suggested, including the following:

- Feed pretreatment (in an extruder or retort)

- In situ (using bed material as a sorbent)

- Postreactor scrubbers (wet or dry)

Each of these options has its advantages and disadvantages. In the case of plastics, feed pretreatment in either a retort or extruder involves heating the feed material to around $200^{\circ}-300^{\circ} \mathrm{C}$ to drive off $\mathrm{HCl}$. This option would remove chlorine early, relieving downstream process equipment of corrosion potential. Disadvantages to this option are that a chlorine guard bed might still be needed (depending on the efficiency of chlorine removal), so that an extra unit operation would be added to the process. The most appropriate use of such technology is as a retrofit application.

In situ removal, using a chlorine-absorbing bed material, has been used in an earlier American Plastics Council (APC)-sponsored project at the EERC (1). This method has been demonstrated successfully on the bench scale and has been shown not only to greatly reduce the amount of total chlorine in the product liquids, but also to prevent organochloride formation. The testing done thus far was under similar conditions. It is not yet known how this method responds to potential variables, such as chlorine loading levels and reactor conditions (particularly temperature), if the sorbent used is the most effective available, and if salt removal from the bed is practicable. Bed material longevity is also a question that must be addressed. Additionally, testing to date has included only select and pure polymers. Postconsumer plastics streams will likely contain high levels of 
metals, PET, and some water. PET decomposition will yield some amount of $\mathrm{CO}_{2}$, although the temperature dependence of $\mathrm{CO}_{2}$ evolution is unknown or if it will exist in high enough partial pressures to be of concern in an industrial-scale process.

Postreactor scrubbers can be either wet or dry systems. A wet scrubber is a proven, simple, available technology. The main disadvantage to wet scrubbers is that they generate wastewater. Since a wet scrubber is placed after the condensation step, organochlorides have already formed and most likely cannot be removed. If placed before the condensation step (spray quench), there are potential separation problems (organic liquids from a water phase). Although it is theorized that organochlorides form during the condensation process, it is not known for certain if this is the case, or if formation occurs during PVC decomposition. Dry scrubbers have the advantage that they can be in a variety of places in the process, if the right sorbent is used, and generate no wastewater. If the sorbent is not regenerated, solid disposal will need to be addressed. The fixed-bed dry scrubber under consideration has the potential disadvantage of adsorbing organics and other undesirable materials, creating high pressure drops across the bed. 


\subsection{PP/PVC FIXED-BED TESTS}

A series of eight tests was performed to determine the effectiveness of a postreactor filter in chlorine capture and to identify the temperature region where organochlorides can be removed. This was to be accomplished by varying the temperature of a fixed-bed, postreactor filter, from an upper limit of the fluid-bed reactor temperature $\left(540^{\circ}\right.$ or $\left.440^{\circ} \mathrm{C}\right)$ down to $340^{\circ} \mathrm{C}$, where a portion of the product liquid is condensed. The conditions for these eight tests are shown in Table 1 (note the run durations). Since runs were carried out over different lengths of time, chlorine concentrations in their sorbent filter materials should not be compared. Depolymerization temperatures of $440^{\circ}$ and $540^{\circ} \mathrm{C}$ were chosen because they cover the range of temperatures that maximize liquid yield in a thermal decomposition process. Two mesh sizes of $\mathrm{CaO}$ were used. The $-1 / 4^{\prime \prime} \times+8$-mesh material produced an acceptable (less than 1 psi) pressure drop across the 8-in.-deep fixed-bed cartridge and was used for most of the tests. $\mathrm{A}-12 \times+60$-mesh $\mathrm{CaO}$ was used in the earlier EERC in situ experiments, so this size was used in a 4-in.-deep filter to make comparisons between the two methods possible, as well as to determine if any surface area differences occurred. One test was performed to determine if an effect was observed from PVC concentration in the feed material.

Testing was completed in the EERC 1- to 4-lb/hr CFBR (described in Section 3.0). The feed material consisted of 90\%-95\% PP and 5\%-10\% PVC. Sand was used as the bed material in the reactor. The $\mathrm{CaO}$ used in the filter device was approximately $1 \%-1.5 \%$ carbonates.

For each set of test conditions, a 2-hour "prerun" period established steady-state conditions. After the achievement of steady state, a "balance period" was performed in which material balance information and products were collected. Balance periods lasted from 2-4 hours. In addition to the conditions listed in Table 1, liquid product was collected at each of the conditions (M357, M359, M364) without a filter to establish baseline chlorine concentrations. Material balance sheets for the eight tests are provided in Appendix A.

Total chlorine concentration of the product liquids was determined by a modified version of ASTM D808-91. Total chlorine concentration for the solids (bed material) was determined by an acid wash to remove chlorine, followed by chlorine quantitation by ion chromatography. Organically associated chlorine content and distribution were determined by gas chromatography/atomic emission detection (GC/AED). Total and organic chlorine analytical procedures are explained in Appendix B. Appendix B also contains simulated boiling point distributions for the organically associated chlorine. Appendix $\mathrm{C}$ details a detection limit quality control procedure developed for use in GC/AED organic chlorine determinations. 


\section{TABLE 1}

Run Conditions

\begin{tabular}{cccccc}
\hline $\begin{array}{c}\text { Run } \\
\text { Number }\end{array}$ & $\begin{array}{c}\text { Decomposition } \\
\text { Temp., }\end{array}{ }^{\circ} \mathrm{C}$ & $\begin{array}{c}\text { Filter } \\
\text { Temp., }\end{array}{ }^{\circ} \mathrm{C}$ & $\begin{array}{c}\text { PVC in } \\
\text { Feed, }{ }^{1} \%\end{array}$ & CaO Size & $\begin{array}{c}\text { Run } \\
\text { Duration, hr }\end{array}$ \\
\hline M357 & 540 & 340 & 5 & $-1 / 4^{\prime \prime} \times+8$ mesh & 2 \\
M358 & 540 & 440 & 5 & $-1 / 4^{\prime \prime} \times+8$ mesh & 4 \\
M359 & 440 & 390 & 5 & $-1 / 4^{\prime \prime} \times+8$ mesh & 2 \\
M360 & 440 & 340 & 5 & $-1 / 4^{\prime \prime} \times+8$ mesh & 4 \\
M361 & 440 & 440 & 5 & $-1 / 4^{\prime \prime} \times+8$ mesh & 3 \\
M362 & 540 & 540 & 5 & $-1 / 4^{\prime \prime} \times+8$ mesh & 3 \\
M363 & 540 & 540 & 5 & $-12 \times+60$ mesh & 3 \\
M364 & 540 & 440 & 10 & $-1 / 4^{\prime \prime} \times+8$ mesh & 2 \\
\hline
\end{tabular}

${ }^{1}$ Remaining feed material was PP from Lyondell. 


\subsection{CONTINUOUS FLUID-BED REACTOR}

Figure 1 is a schematic of a 1- to $4-\mathrm{lb} / \mathrm{hr}$ continuous fluid-bed reactor (CFBR) benchscale test unit previously used to pyrolyze/gasify coal, plastics, automotive shredder residue, and wood chips. The unit has also been used in combustion tests and in the processing of lunar soil simulant. The system is rated to $815^{\circ} \mathrm{C}\left(1500^{\circ} \mathrm{F}\right)$ and $170 \mathrm{psi}$. The reactor consists of a 33-in.-high bed, with a nominal 3-in. ID. The freeboard section is 17 in. high, with a nominal 4-in. ID. Any liquid used in the fluidization gas mix is first preheated, then mixed with heated fluidization gas, and finally heated to reaction temperature in a superheater. Because plastics have a very low density, an inert bed material can be used to facilitate adequate fluidization. Free flowing solids are fed into the reactor either through a dual auger arrangement or a modified ball valve "star feeder." In the dual auger arrangement, the first auger, horizontally situated, meters out the feed material. The metered feed drops to the second auger. The second auger, at a $30^{\circ}$ angle from horizontal, delivers the feed material quickly into the hot reactor. When using the modified ball valve feed system, a cup cut into a solid ball drops a metered amount of material onto an auger, which delivers the material quickly into the reactor. Because plastics soften and get sticky at a fairly low temperature, it is important to keep the feed at a low temperature until it enters the reactor.

Spent solids are collected from the reactor through a top-bed drain leg. Material is collected in a lock hopper-type pot. Gas, volatiles, and fines leave the top of the reactor and enter a 3-in.-ID cyclone where fines are removed. The gas stream enters one of two condensation trains. A fixed-bed filter cartridge is located prior to one of the condensation trains. The cartridge is made of 3-in., Sch. 10, 304 SS pipe. Two cartridges were available for use: one $4 \mathrm{in}$. long and one $8 \mathrm{in}$. long. The cartridge and the lines leading to it are externally heated. The two condensation trains are identical, each consisting of a water-cooled indirect heat exchanger, followed by two glycol-cooled indirect heat exchangers. The stream is then depressurized, sampled by GC, and metered. In this set of experiments, the product gas stream was not monitored for $\mathrm{HCl}$ or chlorinated organics. Data collection and process control are achieved with a Genesis software package. Sixtytwo data points are stored on disk every 30 seconds and are updated on the screen every 2 seconds. 


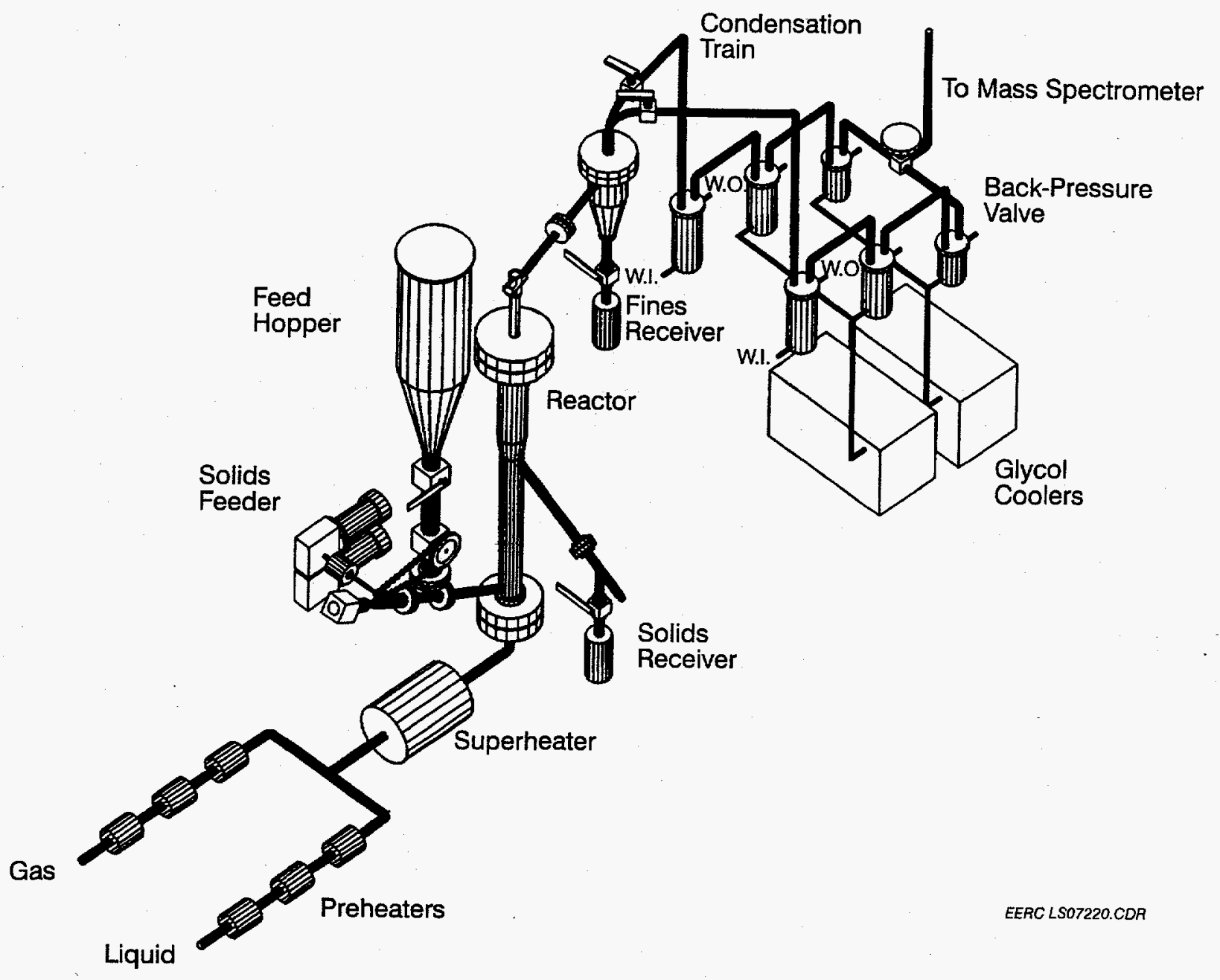

Figure 1. 1- to 4-lb/hr continuous fluid-bed reactor. 


\subsection{PARAMETRIC TESTING RESULTS}

\subsection{Product Liquid Chlorine Concentrations}

Table 2 shows the total and organic chlorine concentrations for the product liquids, as well as total chlorine concentrations for the $\mathrm{CaO}$ filter materials. Since tests were carried out over different lengths of time, chlorine content of the spent filter materials should not be compared.

TABLE 2

Product and Bed Material Chlorine Coneentrations

\begin{tabular}{|c|c|c|c|c|c|c|c|}
\hline \multirow[t]{2}{*}{$\begin{array}{c}\text { Run } \\
\text { Number }\end{array}$} & \multirow[t]{2}{*}{$\begin{array}{c}\text { Decomposition } \\
\text { Temp., }{ }^{\circ} \mathrm{C} \text {. }\end{array}$} & \multirow[t]{2}{*}{$\begin{array}{c}\text { Filter } \\
\text { Temp., }{ }^{\circ} \mathrm{C}\end{array}$} & \multirow[t]{2}{*}{$\begin{array}{l}\text { PVC in } \\
\text { Feed, } \%\end{array}$} & \multirow[t]{2}{*}{$\mathrm{CaO}$ Size } & \multicolumn{2}{|c|}{ Liquids } & \multirow{2}{*}{$\begin{array}{c}\text { Solids } \\
\begin{array}{c}\text { Total Cl, } \\
\text { ppm }\end{array}\end{array}$} \\
\hline & & & & & $\begin{array}{c}\text { Total Cl, } \\
\text { ppm }\end{array}$ & $\begin{array}{l}\text { Organic } \\
\text { Cl, ppm }\end{array}$ & \\
\hline M357 & 540 & 340 & 5 & $-1 / 4^{\prime \prime} \times+8$ mesh & 370 & 140 & 144,000 \\
\hline M358 & 540 & 440 & 5 & $-1 / 4^{\prime \prime} \times+8$ mesh & 130 & $\mathrm{ND}^{1}$ & 148,000 \\
\hline M359 & 440 & 390 & 5 & $-1 / 4^{\prime \prime} \times+8$ mesh & 150 & ND & 89,700 \\
\hline M360 & 440 & 340 & 5 & $-1 / 4^{\prime \prime} \times+8$ mesh & 850 & 760 & 63,400 \\
\hline M361 & 440 & 440 & 5 & $-1 / 4 " \times+8$ mesh & 110 & ND & 117,000 \\
\hline M362 & 540 & 540 & 5 & $-1 / 4^{\prime \prime} \times+8$ mesh & 91 & ND & 119,000 \\
\hline M363 & 540 & 540 & 5 & $-12 \times+60$ mesh & 100 & ND & 239,000 \\
\hline M364 & 540 & 440 & 10 & $-1 / 4^{11} \times+8$ mesh & 170 & ND & 147,000 \\
\hline \multicolumn{8}{|c|}{ Nonfiltered Material } \\
\hline & 540 & -- & 5 & -- & 4700 & 5400 & -- \\
\hline & 440 & --- & 5 & -- & 1100 & 300 & - \\
\hline & 540 & -- & 10 & -- & 6400 & 4500 & --- \\
\hline
\end{tabular}

1 Not detected-indicates that if any organic chlorine exists, it is below detection limits.

\subsection{Nonfilter Product Liquids}

\subsubsection{Effect of Depolymerization Temperature on Chlorine Concentrations}

As seen in Table 2 , a test with no filter at $540^{\circ} \mathrm{C}$ produced liquids with a much higher total chlorine $(4700 \mathrm{ppm})$ and organically associated chlorine concentration $(5400 \mathrm{ppm})$ than did a test at $440^{\circ} \mathrm{C}(1100$ and $300 \mathrm{ppm})$. This result was also observed in the earlier in situ work (1): relatively small increases in temperature produced large increases in chlorine concentrations of the product liquids. About one-quarter of the chlorine in the liquids produced at $440^{\circ} \mathrm{C}$ was organically associated, while essentially all of the chlorine in the liquids produced at $540^{\circ} \mathrm{C}$ was organically associated. 
The $540^{\circ} \mathrm{C}$ test shows a higher organic chloride concentration than total chlorine concentration. This discrepancy is most likely due to analytical error. Both the organic and total chlorine determinations used for the liquids analyses are accurate to approximately $15 \%$.

\subsubsection{Effect of PVC Concentration on Chlorine Concentrations}

A test was performed at a reactor temperature of $540^{\circ} \mathrm{C}$ using $10 \% \mathrm{PVC}$ in the feed to examine the relationship of PVC concentration in the feed to chlorine concentrations in the liquids. Organic chlorine concentration in the 10\% PVC test was roughly the same as that in the 5\% PVC test, and total chlorine in the 10\% test was slightly higher than that of the 5\% test. Essentially all of the chlorine in the 5\% test was organically associated, while only about $70 \%$ of the chlorine in the liquids produced from the $10 \%$ test was organically associated.

\subsection{Filtered Product Liquids}

Results of the tests using a chlorine-capturing, fixed-bed $\mathrm{CaO}$ filter are given in the following sections. Methods used for determining chlorine capture are detailed in Appendix D.

\subsubsection{Effect of Filter Temperature at $440^{\circ} \mathrm{C}$ on Chlorine Concentrations}

Three tests were performed at a reactor temperature of $440^{\circ} \mathrm{C}$, with filter temperatures of $340^{\circ}, 390^{\circ}$, and $440^{\circ} \mathrm{C}$. The results of these tests, along with those of the test without a filter, are shown in Table 3.

As can be seen from Table 3, total chlorine concentration increases with decreasing filter temperature. Organochlorines appear between $340^{\circ}$ and $390^{\circ} \mathrm{C}$. Although total chlorine for the unfiltered material at $440^{\circ} \mathrm{C}$ is higher than Run $\mathrm{M} 360\left(440^{\circ} \mathrm{C}\right.$ decomposition temperature, $340^{\circ} \mathrm{C}$ filter temperature), the organic chlorine for the unfiltered material is higher than the filtered material at $340^{\circ} \mathrm{C}$. Since only these two data points exist, it is not known for certain why a higher percentage of the chlorine in the filtered material is organically associated, relative to the unfiltered material.

Table 4 shows chlorine captured by $\mathrm{CaO}$ for the three tests run at a reactor temperature of $440^{\circ} \mathrm{C}$. Some tests show captures greater than $100 \%$. This is most likely because of analytical variability. As mentioned previously, the techniques used for chlorine analysis are good to approximately $10 \%-15 \%$. Figure 2 shows the percent capture for each test, as well as $15 \%$ error bars. Chlorine not captured by the $\mathrm{CaO}$ filter is captured by a caustic scrubber. Previous tests in this unit have indicated very high efficiency for chlorine capture by the caustic solutions in the scrubber. To verify the assumption that most chlorine is absorbed from the gas stream by the caustic solution, a sample from Run M360 was analyzed for chlorine. The analysis revealed a chlorine concentration of $4900 \mathrm{mg} / \mathrm{L}$. This translates to approximately $58.6 \mathrm{~g}$ of chlorine captured in the scrubber (weight of the solution in the caustic scrubber was 11,960 g). Taking into account the analytical accuracy of this number $(15 \%)$, the chlorine content of the scrubber water lies between 49.8 and $67.4 \mathrm{~g}$. $53.4 \mathrm{~g}$ of chlorine were assumed to have gone to the gas stream. This assumed value lies well within the reasonable range of possible values (49.8 to $67.4 \mathrm{~g})$. Although good chlorine capture is experienced in the caustic scrubber, 
trace amounts of the chlorine will possibly still be present in the gas stream. The association and concentration of this chlorine should be determined.

TABLE 3

Effect of Filter Temperature at a Decomposition Temperature of $440^{\circ} \mathrm{C}$

\begin{tabular}{|c|c|c|c|c|c|c|c|}
\hline \multirow[t]{2}{*}{$\begin{array}{c}\text { Run } \\
\text { Number }\end{array}$} & \multirow[t]{2}{*}{$\begin{array}{c}\text { Decomposition } \\
\text { Temp., }{ }^{\circ} \mathrm{C} \\
\end{array}$} & \multirow[t]{2}{*}{$\begin{array}{c}\text { Filter Temp., } \\
{ }^{\circ} \mathrm{C} \\
\end{array}$} & \multirow[t]{2}{*}{$\begin{array}{l}\text { PVC in } \\
\text { Feed, } \%\end{array}$} & \multirow[t]{2}{*}{$\mathrm{CaO}$ Size } & \multicolumn{2}{|c|}{ Liquids } & \multirow{2}{*}{$\begin{array}{c}\text { Solids } \\
\begin{array}{c}\text { Total } \mathrm{Cl} \\
\text { ppm }\end{array}\end{array}$} \\
\hline & & & & & $\begin{array}{c}\text { Total } \\
\text { Cl, ppm }\end{array}$ & $\begin{array}{l}\text { Organic } \\
\mathrm{Cl} \text {, ppm }\end{array}$ & \\
\hline M360 & 440 & 340 & 5 & $-1 / 4^{\prime \prime} \times+8$ mesh & 850 & 760 & 63,400 \\
\hline M359 & 440 & 390 & 5 & $-1 / 4^{\prime \prime} \times+8$ mesh & 150 & $\mathrm{ND}^{1}$ & 89,700 \\
\hline M361 & 440 & 440 & 5 & $-1 / 4^{\prime \prime} \times+8$ mesh & 110 & ND & 117,000 \\
\hline \multicolumn{8}{|c|}{ Nonfiltered Material } \\
\hline & 440 & -- & 5 & -- & 1100 & 300 & --- \\
\hline
\end{tabular}

1 Not detected.

TABLE 4

Chlorine Capture Effectiveness of $\mathrm{CaO}$ at a Reactor Temperature of $440^{\circ} \mathrm{C}$

\begin{tabular}{lccc}
\hline Run Number: & M360 & M359 & M361 \\
\hline Filter Temperature, ${ }^{\circ} \mathrm{C}$ & 340 & 390 & 440 \\
$\mathrm{Cl}$ in Feed, g & 81.6 & 40.8 & 61.2 \\
$\mathrm{Cl}$ in CaO Filter, g & 35.1 & 43.7 & 63.1 \\
$\mathrm{Cl}$ in Liquids, g & 2.9 & 0.8 & 0.3 \\
$\mathrm{Cl}$ Captured by CaO, \% & 43.0 & 107 & 103 \\
$\mathrm{Cl}$ in Liquids, \% & 3.6 & 2.0 & 0.5 \\
$\mathrm{Cl}$ in Gas (by diff.), ${ }^{1} \%$ & 53.4 & --- & -- \\
\hline
\end{tabular}

${ }^{1}$ This material (chlorine assumed to be in the form of $\mathrm{HCl}$ ) is captured in a caustic scrubber. 


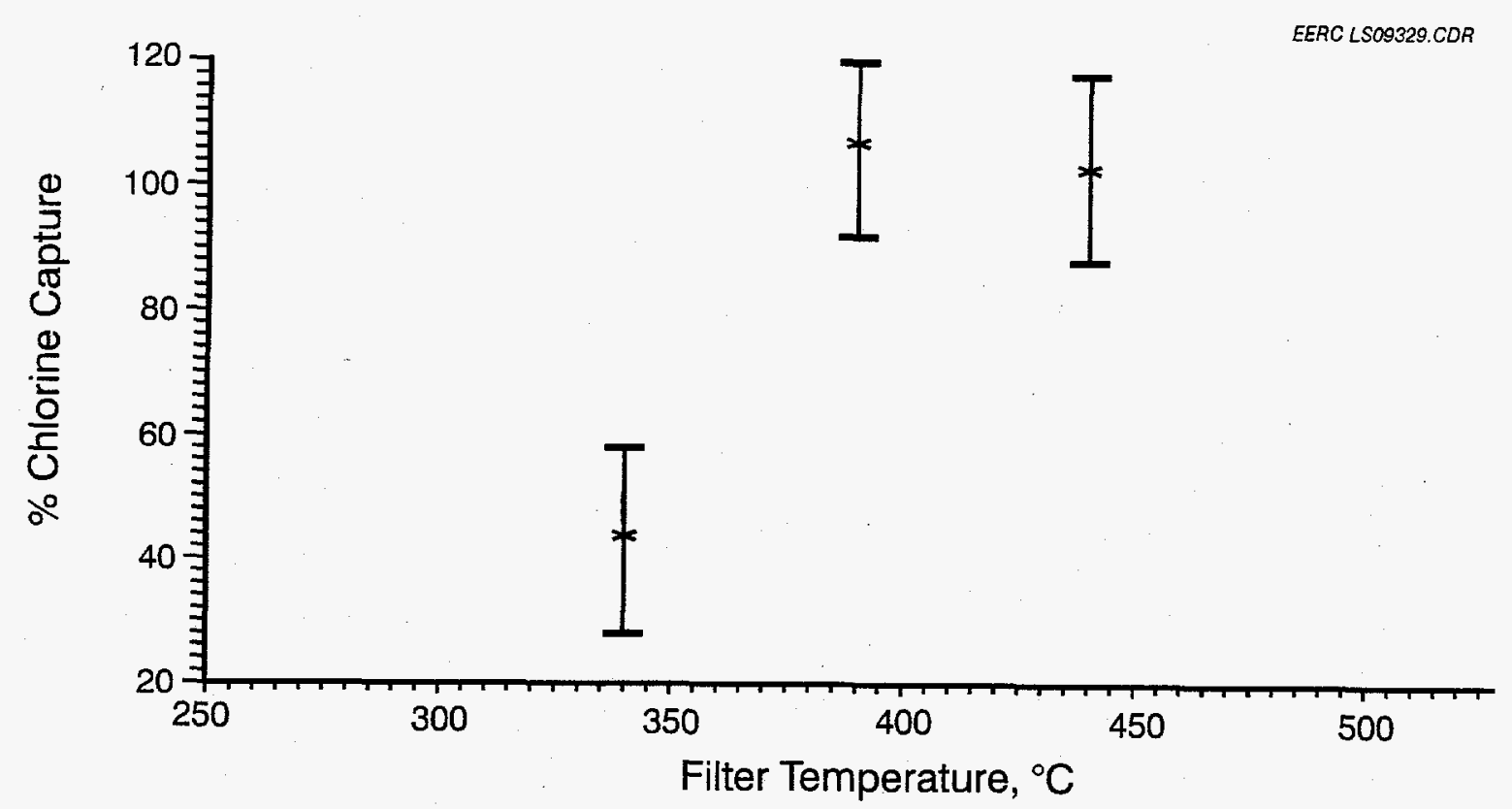

Figure 2. Chlorine capture effectiveness of $\mathrm{CaO}$ filter at $440^{\circ} \mathrm{C}$.

\subsubsection{Effect of Filter Temperature at $540^{\circ} \mathrm{C}$}

Table 5 indicates a trend of increased total and organic chlorine concentrations with decreased temperature. Organochlorine species appear somewhere between $340^{\circ}$ and $440^{\circ} \mathrm{C}$.

Table 6 indicates the chlorine capture effectiveness of $\mathrm{CaO}$ at removing chlorine from a stream of gas and vaporized liquids produced at a reactor temperature of $540^{\circ} \mathrm{C}$, and Figure 3 graphically shows percent capture for each test, along with $15 \%$ error bars. As with the set of tests at a reactor temperature of $440^{\circ} \mathrm{C}$, chlorine capture is much more efficient at high filter temperatures. The test at a depolymerization temperature of $540^{\circ} \mathrm{C}$ and a filter temperature of $440^{\circ} \mathrm{C}$ (Run M358) has a lower capture rate than its counterpart produced at a depolymerization temperature of $440^{\circ} \mathrm{C}$ (Run M361). This is most likely due to the great increase in both the concentration of chlorine and the number and concentration of chlorinated species produced at the higher depolymerization temperature. 


\section{TABLE 5}

Effect of Filter Temperature at a Decomposition Temperature of $540^{\circ} \mathrm{C}$

\begin{tabular}{|c|c|c|c|c|c|c|c|}
\hline \multirow[t]{2}{*}{$\begin{array}{c}\text { Run } \\
\text { Number }\end{array}$} & \multirow[t]{2}{*}{$\begin{array}{c}\text { Decomposition } \\
\text { Temp., }{ }^{\circ} \mathrm{C}\end{array}$} & \multirow[t]{2}{*}{$\begin{array}{c}\text { Filter } \\
\text { Temp., }{ }^{\circ} \mathrm{C}\end{array}$} & \multirow[t]{2}{*}{$\begin{array}{l}\text { PVC in } \\
\text { Feed, } \%\end{array}$} & \multirow[t]{2}{*}{$\mathrm{CaO}$ Size } & \multicolumn{2}{|c|}{ Liquids } & \multirow{2}{*}{$\begin{array}{c}\text { Solids } \\
\begin{array}{c}\text { Total Cl, } \\
\text { ppm }\end{array}\end{array}$} \\
\hline & & & & & $\begin{array}{c}\text { Total } \\
\text { Cl, ppm }\end{array}$ & $\begin{array}{l}\text { Organic } \\
\mathrm{Cl} \text {, ppm }\end{array}$ & \\
\hline M357 & 540 & 340 & 5 & $-1 / 4^{\prime \prime} \times+8$ mesh & 370 & 140 & 144,000 \\
\hline M358 & 540 & 440 & 5 & $-1 / 4 " \times+8$ mesh & 130 & $\mathrm{ND}^{1}$ & 148,000 \\
\hline M362 & 540 & 540 & 5 & $-1 / 4^{\prime \prime} \times+8$ mesh & 91 & ND & 119,000 \\
\hline \multicolumn{8}{|c|}{ Nonfiltered Material } \\
\hline & 540 & $\ldots$ & 5 & - & 4700 & 5400 & $\ldots$ \\
\hline
\end{tabular}

${ }^{1}$ Not detected.

TABLE 6

Chlorine Capture Effectiveness of $\mathrm{CaO}$ at a Reactor Temperature of $540^{\circ} \mathrm{C}$

\begin{tabular}{lccc}
\hline Run Number: & M357 & M358 & M362 $^{1}$ \\
\hline Filter Temperature, ${ }^{\circ} \mathrm{C}$ & 340 & 440 & 540 \\
$\mathrm{Cl}$ in Feed, g & 40.8 & 81.6 & 61.2 \\
$\mathrm{Cl}$ in CaO Filter, g & 33.7 & 76.1 & 55.8 \\
$\mathrm{Cl}$ in Liquids, g & 0.3 & 0.3 & 0.1 \\
$\mathrm{Cl}$ Captured by CaO, \% & 83 & 93 & 91 \\
$\mathrm{Cl}$ in Liquids, \% & 0.7 & 0.4 & 0.2 \\
$\mathrm{Cl}$ in Gas (by diff.), $\%$ & 17 & 6 & 9 \\
\hline
\end{tabular}

${ }^{1} \mathrm{~A}$ final bed material weight was unavailable for this test. A calcium balance was used to estimate bed weight and capture.

2 This material is captured in a caustic scrubber. 


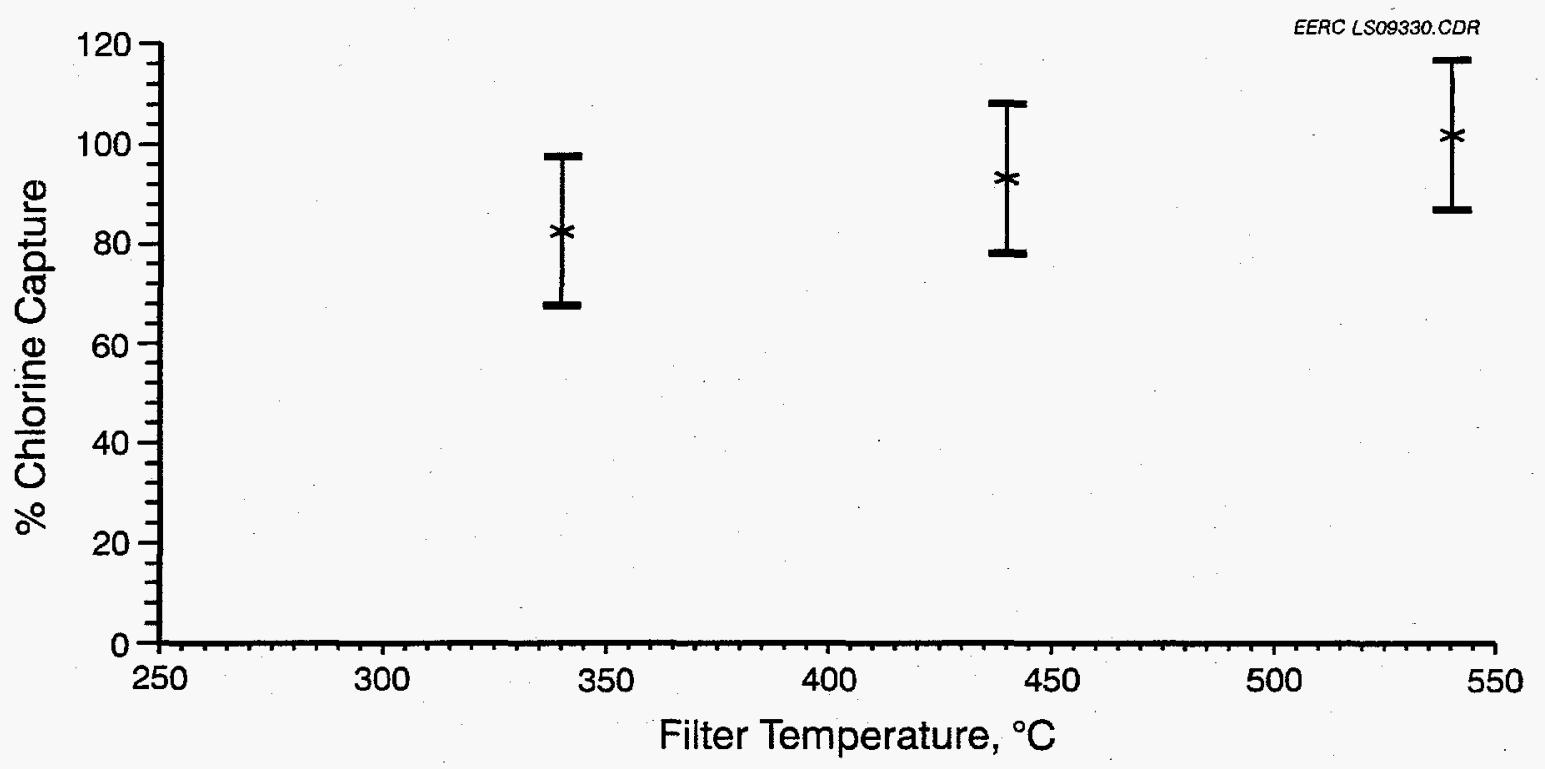

Figure 3. Chlorine capture effectiveness of $\mathrm{CaO}$ filter at $540^{\circ} \mathrm{C}$.

\subsubsection{Effect of Sorbent Particle Size at $540^{\circ} \mathrm{C}$}

A test with $-12 \times+60$-mesh $\mathrm{CaO}$ (Table 7) indicates that particle size of the $\mathrm{CaO}$ is not a significant variable for chlorine capture. Total chlorine content of the $-12 \times+60$-mesh $\mathrm{CaO}(100 \mathrm{ppm})$ is within analytical error of the test using $-1 / 4^{\prime \prime} \times+8$-mesh $\mathrm{CaO}(91 \mathrm{ppm})$. Organic chlorine for both tests was undetected.

Table 8, which shows the chlorine capture effectiveness of these two tests, indicates that both have high rates of capture, $91 \%$ for Run M362 and 90\% for Run M363.

\section{TABLE 7}

Effect of Sorbent Particle Size on Product and Bed Material Chlorine Concentrations

\begin{tabular}{|c|c|c|c|c|c|c|c|}
\hline $\begin{array}{c}\text { Run } \\
\text { Number }\end{array}$ & $\begin{array}{c}\text { Decomposition } \\
\text { Temp., }{ }^{\circ} \mathrm{C}\end{array}$ & $\begin{array}{c}\text { Filter } \\
\text { Temp., }{ }^{\circ} \mathrm{C}\end{array}$ & $\begin{array}{l}\text { PVC in } \\
\text { Feed, \% }\end{array}$ & CaO Size & \multicolumn{2}{|c|}{ Liquids } & Solids \\
\hline & & & & & \multicolumn{2}{|c|}{$\begin{array}{c}\text { Total } \mathrm{Cl} \text {, } \\
\text { ppm } \\
\text { Organic } \mathrm{Cl} \\
\mathrm{ppm}\end{array}$} & $\begin{array}{l}\text { Total } \\
\mathrm{Cl}, \mathrm{ppm}\end{array}$ \\
\hline M362 & 540 & 540 & 5 & $-1 / 4^{\prime \prime} \times+8$ mesh & 91 & $\mathrm{ND}^{1}$ & 119,000 \\
\hline M363 & 540 & 540 & 5 & $-12 \times+60$ mesh & 100 & ND & 239,000 \\
\hline \multicolumn{8}{|c|}{ Nonfiltered Material } \\
\hline & 540 & ... & 5 & ... & 4700 & 5400 & $\ldots$ \\
\hline
\end{tabular}

${ }^{1}$ Not detected. 
TABLE 8

Effect of Sorbent Particle Size on Chlorine Capture Effectiveness

\begin{tabular}{lcc}
\hline Run Number & M362 & M363 \\
\hline Filter Temperature, ${ }^{\circ} \mathrm{C}$ & 540 & 540 \\
$\mathrm{CaO}$ Size & $-1 / 4^{\prime \prime} \times+8$ mesh & $-12 \times+60$ mesh \\
$\mathrm{Cl}$ in Feed, g & 61.2 & 61.2 \\
$\mathrm{Cl}$ in CaO Filter, g & 55.8 & 55.2 \\
$\mathrm{Cl}$ in Liquids, g & 0.1 & 0.1 \\
$\mathrm{Cl}$ Captured by CaO, $\%$ & 91.2 & 90.2 \\
$\mathrm{Cl}$ in Liquids, $\%$ & 0.2 & 0.2 \\
$\mathrm{Cl}$ in Gas (by diff.), ${ }^{1} \%$ & 8.6 & 9.6 \\
\hline
\end{tabular}

${ }^{1}$ This material is captured in a caustic scrubber.

\subsubsection{Effect of PVC Concentration in Feed on CaO Chlorine Removal Effectiveness}

Two tests were run for the purpose of determining the effect of PVC concentration in the feed material on chlorine levels in the product liquids. No organic chlorine was detected in either product liquid, and although the $10 \%$ test produced a slightly higher total liquid chlorine content, the total chlorine levels for the two samples were within analytical error of each other (Table 9). This suggests that PVC concentration within the range of 5\%-10\% of the feed material does not have a significant effect on resulting chlorine concentration in the product liquids. Effectiveness of capture by the $\mathrm{CaO}$ sorbent is similar for the two tests, as seen in Table 10.

\section{TABLE 9}

Effect of PVC Concentration on Product and Bed Material Chlorine Concentrations

\begin{tabular}{|c|c|c|c|c|c|c|c|}
\hline $\begin{array}{c}\text { Run } \\
\text { Number }\end{array}$ & $\begin{array}{c}\text { Decomposition } \\
\text { Temp., }{ }^{\circ} \mathrm{C}\end{array}$ & $\begin{array}{c}\text { Filter } \\
\text { Temp., }{ }^{\circ} \mathrm{C}\end{array}$ & $\begin{array}{l}\text { PVC in } \\
\text { Feed, \% }\end{array}$ & $\mathrm{CaO}$ Size & \multicolumn{2}{|c|}{ Liquids } & \multirow{2}{*}{$\begin{array}{c}\text { Solids } \\
\text { Total } \\
\text { Cl, ppm }\end{array}$} \\
\hline & & & & & $\begin{array}{c}\text { Total Cl, } \\
\text { ppm }\end{array}$ & $\begin{array}{l}\text { Organic } \\
\mathrm{Cl} \text {, ppm }\end{array}$ & \\
\hline M358 & 540 & 440 & 5 & $-1 / 4^{\prime \prime} \times+8$ mesh & 130 & $\mathrm{ND}^{1}$ & 148,000 \\
\hline M364 & 540 & 440 & 10 & $-1 / 4^{\prime \prime} \times+8$ mesh & 170 & ND & 147,000 \\
\hline \multicolumn{8}{|c|}{ Nonfiltered Material } \\
\hline & 540 & --- & 5 & $\cdots$ & 4700 & 5400 & --- \\
\hline & 540 & $\cdots$ & 10 & $\ldots$ & 6400 & 4500 & --- \\
\hline
\end{tabular}

${ }^{1}$ Not detected. 
TABLE 10

Effect of PVC Concentration on Chlorine Capture Effectiveness

\begin{tabular}{lcc}
\hline Run Number & M358 & M364 \\
\hline Filter Temperature, ${ }^{\circ} \mathrm{C}$ & 440 & 440 \\
PVC in Feed, \% & 5 & 10 \\
Cl in Feed, g & 81.6 & 81.6 \\
Cl in CaO Filter, g & 76.1 & 76.7 \\
Cl in Liquids, g & 0.3 & 0.1 \\
Cl Captured by CaO, \% & 93.2 & 94.0 \\
Cl in Liquids. \% & 0.4 & 0.1 \\
Cl in Gas (by diff.), $\%$ & 6.4 & 5.9 \\
\hline
\end{tabular}

This material is captured in a caustic scrubber.

\subsection{Material Balance Results}

Material balance results for the eight tests completed, based on weight percent of the feed material, are shown in Table 11. An explanation of the methods used to calculate these yields and other calculations is given in Appendix A. The average material balance closure for the tests was 96.7 , and the standard deviation was 14.5. Two standard deviations include the interval 82.3, 111.2.

Since the tests were run at fixed reactor temperatures and filter temperature varied, two gas analyses from each reactor temperature $\left(440^{\circ}\right.$ and $\left.540^{\circ} \mathrm{C}\right)$ were taken, compared, and used for all tests at that temperature. These analyses are given in Table 12.

\section{TABLE 11}

Material Balance Results

\begin{tabular}{cccccc}
\hline $\begin{array}{c}\text { Run } \\
\text { Number }\end{array}$ & $\begin{array}{c}\text { Depolymerization } \\
\text { Temp., }\end{array}{ }^{\circ} \mathrm{C}$ & $\begin{array}{c}\text { Filter Temp., } \\
{ }^{\circ} \mathrm{C}\end{array}$ & $\begin{array}{c}\text { Liquid Yield, } \\
\text { wt\% }\end{array}$ & $\begin{array}{c}\text { Gas Yield, } \\
\text { wt\% }\end{array}$ & $\begin{array}{c}\text { Material } \\
\text { Balance }\end{array}$ \\
\hline M357 & 540 & 340 & 54.5 & 45.5 & 92.3 \\
M358 & 540 & 440 & 53.8 & 46.2 & 99.6 \\
M359 & 440 & 390 & 92.9 & 7.1 & 88.0 \\
M360 & 440 & 340 & 92.9 & 7.1 & 93.1 \\
M361 & 440 & 440 & 92.8 & 7.2 & 88.0 \\
M362 & 540 & 540 & 53.8 & 46.2 & 102.5 \\
M363 & 540 & 540 & 53.7 & 46.3 & 100.3 \\
M364 & 540 & 440 & 53.8 & 46.2 & 110.1 \\
\hline
\end{tabular}


TABLE 12

Product Gas Analyses PP/PVC Tests

\begin{tabular}{lrc}
\hline Gas Component, $\mathrm{mol} \%$ & $440^{\circ} \mathrm{C}$ & $540^{\circ} \mathrm{C}$ \\
\hline Hydrogen & 0.07 & 0.43 \\
Carbon Dioxide & 0.34 & \\
Propane & 0.04 & 0.47 \\
Propylene & 0.18 & 5.26 \\
iso-Butane & & 0.19 \\
iso-Butylene $^{1}$ & 0.04 & 1.99 \\
$n$-Butane & & 0.02 \\
Butadiene $^{1}$ & & 0.19 \\
1-Butene & & 0.12 \\
$t-2$-Butene & & 0.04 \\
$c-2$-Butene & & 0.02 \\
$n$-Pentane & & 0.76 \\
Ethylene & 0.19 & 1.12 \\
Ethane & & 2.77 \\
Nitrogen & 0.07 & 78.65 \\
Methane & 96.61 & 3.81 \\
\hline
\end{tabular}

${ }^{1}$ Unconfirmed.

\subsection{Coal Tests}

Two tests using $\mathrm{CaO}$ in the fixed bed were performed using coal as a pyrolysis feed material to assess the applicability of this technology to coal. In the first of these tests, Wyodak was pyrolyzed at $440^{\circ} \mathrm{C}$. After 4 hours, the fixed-bed filter material and product liquids, collected both prior to and after the fixed bed, were analyzed for chlorine content. In the second test with Wyodak, also performed at $440^{\circ} \mathrm{C}$, a sodium chloride salt was mixed with the coal to elevate the chlorine level in the feed material to a higher level, ensuring that the chlorine levels would be within a range of greater analytical confidence.

While coal has a much lower chlorine content than most postconsumer plastics streams, the removal techniques are anticipated to be similar. Differences between coal and plastics might have some effect on the relative effectiveness of $\mathrm{CaO}$ in chlorine removal though. Thermal decomposition of plastics can produce liquids that range from highly aromatic to highly aliphatic/olefinic. The higher the temperature, the more aromatic the character of the liquids. Since is desirous to produce the highest liquid yield, the least severe temperatures (yielding predominantly aliphatics/olefinics) will most likely be used in the thermal depolymerization of plastics process. Liquids produced from the thermal decomposition of coal may contain higher or lower amounts of aromatic liquids than liquids produced from the thermal decomposition of plastics, depending on 
the decomposition temperature used for the plastics processing. Chlorine attached to aromatics is more difficult to remove than if attached to aliphatics or olefins. One possible explanation as to why $\mathrm{CaO}$ is successful in removing chlorine during plastics processing is that calcium acts as a cracking agent, helping to break apart molecules, combining with chlorine in the process.

\subsection{Chlorine Capture}

To evaluate the ability of a fixed bed of $\mathrm{CaO}$ to remove chlorine from the products of coal pyrolysis, two tests were run in the CFBR described in Section 3.0. Liquids were collected from both before and after the fixed-bed unit. These liquids were analyzed for total and organic chlorine, using methods described in Appendix B. Material from the fixed-bed cartridge was also collected and analyzed for chlorine content. Since this was a scoping study, to determine the applicability of this technique, sections of the filter were not analyzed for chlorine. Instead, a composite sample was analyzed.

Table 13 lists conditions for the two tests completed. Wyodak coal was used in both instances. In the second test, M370, salt ( $\mathrm{NaCl})$ was added to the feed coal. This was done to bring chlorine levels up to reasonable levels for detection. Table 14 shows composite proximate analyses for the two fixed-bed filter samples, feed coal, and char products, and Table 15 shows chlorine levels for the feed coal, filter material, and the product liquids resulting from these tests.

As observed in Table 15, M369 shows some removal with the fixed bed of CaO. Chlorine levels for the liquids that have not passed through the $\mathrm{CaO}$ bed are $1200 \mathrm{ppm}$. Those that have passed through the $\mathrm{CaO}$ fixed bed have a chlorine content of $410 \mathrm{ppm}$. The filter section composite sample contains $1900 \mathrm{ppm}$ chlorine, indicating that chlorine was absorbed by the filter material. Without the $\mathrm{CaO}, 10.0 \%$ of the chlorine in the coal was in the product liquids. After passing through the $\mathrm{CaO}, 3.3 \%$ of the chlorine from the feed coal was found in the product liquids. This test was performed at a relatively low pyrolysis temperature. It may be of interest in the future to repeat this test at a higher pyrolysis temperature.

For Run M370, the chlorine level of the liquids collected after passing through the filter was higher than that of the liquids not passing through the $\mathrm{CaO}$ bed. It may be that the $\mathrm{NaCl}$ particles are small and passed through the filter, or that the $\mathrm{NaCl}$ salt is facilitating combination of chlorine with the organic liquids. It is not possible to identify the reason for this higher level, since the association of the chlorine in the liquids is not known (organic or inorganic). The chlorine content of the $\mathrm{CaO}$ in the filter was not very high, $12,000 \mathrm{ppm}$, compared to the earlier plastics tests. Only about $1.6 \%$ of the chlorine fed in M370 was captured by the CaO. It should be recalled that most (99\%) of the chlorine fed in M370 was due to the inorganic salt added to the system, so it may be that the chlorine prefers to stay with the sodium. More chlorine was found with the $\mathrm{CaO}$ than came in with the coal, however, indicating that some of the chlorine from $\mathrm{NaCl}$ combined with the $\mathrm{CaO}$. Since most of the incoming chlorine from M370 was due to the addition of $\mathrm{NaCl}$, caution must be used when making comparisons between $\mathrm{M} 369$ and $\mathrm{M} 370$.

Although the chlorine content of the feed from M370 was two orders of magnitude higher than M369, the chlorine level of the nonfiltered liquids from M370 was approximately half that of M369. It may be speculated that the chloride salt added to 
M370 affected some amount of chlorine capture or the presence of $\mathrm{NaCl}$ influenced the form chlorine took during decomposition in the coal liquids.

Gas analyses for M369 and M370 are given in Table 16.

TABLE 13

Coal Test Conditions

\begin{tabular}{ccccc}
\hline Run Number & $\begin{array}{c}\text { Decomposition } \\
\text { Temperature, }^{\circ} \mathrm{C}\end{array}$ & $\begin{array}{c}\text { Pressure, } \\
\text { psig }\end{array}$ & $\begin{array}{c}\text { Feed Rate, } \\
\text { grams/hr }\end{array}$ & $\begin{array}{c}\text { Duration of Test, } \\
\text { hr }\end{array}$ \\
\hline M367 & 440 & 10 & 590 & $4^{1}$ \\
M368 & 440 & 10 & 590 & $6^{2}$ \\
\hline
\end{tabular}

${ }^{1}$ All 4 hours with $\mathrm{CaO}$ filter on-line.

${ }^{2} 4$ hours with $\mathrm{CaO}$ filter on-line and 2 hours without $\mathrm{CaO}$ filter on-line.

TABLE 14

Proximate Analyses for M369 and M370, wt\%

\begin{tabular}{|c|c|c|c|c|}
\hline & Moisture & Volatile Matter & Fixed Carbon & Ash \\
\hline \multicolumn{5}{|l|}{$\mathrm{M} 369$} \\
\hline Feed Material & 22.10 & 36.00 & 35.37 & 6.53 \\
\hline Top Char & 0.30 & 38.26 & 48.54 & 12.90 \\
\hline Bottom Char & 0.00 & 32.40 & 0.00 & 13.32 \\
\hline Filter Material & 0.10 & 12.43 & 0.02 & 87.45 \\
\hline \multicolumn{5}{|l|}{$\mathrm{M3} 70$} \\
\hline Feed Material & 25.70 & 30.89 & 27.68 & 15.73 \\
\hline Top Char & 0.40 & 36.57 & 46.05 & 16.98 \\
\hline Bottom Char & 0.10 & 28.03 & 46.12 & 25.75 \\
\hline Filter Material & 0.30 & 13.42 & 0.00 & 86.44 \\
\hline
\end{tabular}


TABLE 15

Chlorine Analyses for Coal Tests

\begin{tabular}{lr}
\hline Sample & Total Chlorine, $\mu \mathrm{g} / \mathrm{g}$ \\
\hline Feed Coal & \\
Wyodak & 1,000 \\
Wyodak + NaCl & 72,000 \\
Composite Liquid Samples & \\
M369 prior to fixed bed & 1,200 \\
M369 after fixed bed & 410 \\
M370 prior to fixed bed & 610 \\
M370 after fixed bed & 1,000 \\
Sorbent Sections & \\
M369, Sections 1-4 Composite (412 grams CaO in filter) & 1,900 \\
M370, Sections 1-4 Composite (454.5 grams CaO in filter) & 12,000 \\
\hline
\end{tabular}

TABLE 16

Gas Analyses for M369 and M370

\begin{tabular}{lccccc}
\hline Component & \multicolumn{2}{c}{ M369 } & \multicolumn{2}{c}{ M370 } \\
& $\begin{array}{c}\text { On Filter } \\
\text { Side }\end{array}$ & $\begin{array}{c}\text { Off Filter } \\
\text { Side }\end{array}$ & $\begin{array}{c}\text { On Filter } \\
\text { Side }\end{array}$ & $\begin{array}{c}\text { On Filter } \\
\text { Side }\end{array}$ & $\begin{array}{c}\text { Off Filter } \\
\text { Side }\end{array}$ \\
\cline { 2 - 6 } $\mathrm{H}_{2}$ & 0.03 & 0.02 & 0.02 & 0.01 & 0.01 \\
$\mathrm{CO}_{2}$ & 0.59 & 0.52 & 0.44 & 0.38 & 0.41 \\
$\mathrm{C}_{3}=$ & 0.01 & 0.01 & & 0.01 & \\
$\mathrm{n}^{-} \mathrm{C}_{5}$ & 0.02 & 0.02 & & & \\
$\mathrm{~N}_{2}$ & 99.07 & 99.14 & 99.49 & 99.60 & 99.49 \\
$\mathrm{CH}_{4}$ & 0.07 & 0.07 & 0.05 & & 0.08 \\
$\mathrm{CO}$ & 0.12 & 0.11 & & & \\
\hline
\end{tabular}




\subsection{CONCLUSIONS AND RECOMMENDATIONS}

It should be stated again that this study was intended as a screening study, in which $\mathrm{CaO}$ in a hot, fixed-bed postreactor filter was evaluated for its ability to capture chlorine. The conclusions put forth are tentative. A more balanced study should be performed before hard conclusions are made.

Chlorine resulting from the decomposition of PVC can be successfully captured by $\mathrm{CaO}$ in a postdepolymerization reactor scrubber. Indications are that removal efficiency depends predominantly on the temperature of the postreactor filter. $\mathrm{CaO}$ was found to capture between $43 \%$ and almost $100 \%$ of the chlorine introduced into the system. The highest chlorine removal was observed when the filter temperature was maintained at or close to the depolymerization temperature (before any condensation of the product liquids occurred).

While capture efficiency for the smaller-particle-size $\mathrm{CaO}$ appears to be slightly higher, the test with smaller-sized $\mathrm{CaO}$ (larger surface area) resulted in product liquids with chlorine levels within analytical error of those produced under similar conditions, with larger (smaller surface area) $\mathrm{CaO}$.

A test with higher (10\%) PVC concentration in the feed material resulted in a total chlorine concentration in the product liquids equivalent to a similar test using a 5\% PVC concentration in the feed. The chlorine capture effectiveness of these two tests was nearly identical.

While use of $\mathrm{CaO}$ in a fixed-bed scrubber results in significant chlorine capture, all product liquid samples still contain unacceptably high levels of chlorine (although not organically associated chlorine) for most envisioned end-use applications. It is recommended that a combination of chlorine removal techniques be employed in a mixed-plastics recycling process. This could include in situ removal, postreactor filters, and polishing steps or simply multiple postreactor scrubbers in series.

Although very high chlorine capture is achieved, some trace amounts of chlorine will most likely remain in the product gas. The concentration of this chlorine, as well as its form, should be determined, since product gas will either be flared or used for process heat. Combustion of chlorinated organics under the proper conditions has the potential to form dioxins and other undesirable compounds. Identification of possible chlorine associations in the product gas stream will flag potential problem compounds.

Two tests with coal were run to explore the applicability of this technology to coal pyrolysis systems. In the first test, performed at $440^{\circ} \mathrm{C}$, some chlorine capture was seen by the $\mathrm{CaO}$ sorbent. Approximately $10 \%$ of the chlorine entering with the feed coal associated with the organic liquids when no $\mathrm{CaO}$ was used, while $3.3 \%$ of the entering chlorine was associated with the organic liquids that passed through the bed of $\mathrm{CaO}$. This is a marginal improvement, but should be extended to include higher pyrolysis temperatures. 


\subsection{REFERENCES}

1. Sharp, L.L.; Ness, R.O., Jr.; Aulich, T.A.; Randall, J.C. "Thermal Recycling of Plastics," final report to the American Plastics Council; EERC publication, Aug. 1993. 
APPENDIX A

\section{MATERIAL BALANCE CALCULATION METHODS}




\section{MATERIAL BALANCE CALCULATION METHODS}

Figure A-1 is a material balance sheet for M357. This sheet will be used to help to explain how yields were calculated.

Components listed in the first column of the material balance sheet are "polymer/solids" (a generic reference to the component fed), "water," or "cond." (organic liquids), and "gas." The organic liquid section is broken down further as boiling point cuts. The gas section is also broken down further, by components. The first column, marked "grams in," contains the grams of material fed to the process broken down by component. For example, 5442.0 g of PP/PVC and $4743.0 \mathrm{~g}$ of nitrogen were fed over the material balance period for Run M357. The next column is grams out, again broken down by component. The third column is yields. Yields for each component are calculated by dividing "grams out" minus "grams in" of a component by the grams of polymer fed. For example, the calculation of total liquid ("Cond.") yield for this run would be:

$$
\frac{(2477.0-0)}{5442.0}=45.5 \%
$$

All columns are totaled at the bottom of the sheet. In this case, 10,185.0 $\mathrm{g}$ of total material were fed to the process, and $9398.2 \mathrm{~g}$ of total material were collected. This corresponds to a $92.3 \%$ material closure, shown below the grams out total. The yields do not add up to $100 \%$ since the material balance is not $100 \%$. These two numbers are not the same (92.3 and 85.5) because the yield calculation is based on polymer fed and the material balance number is based on total material fed and collected. The last column is labeled "N Yields." This column takes the difference between the material fed and the material collected and distributes it to one or more of the three product streams based on tie elements. The only tie element in these balances is nitrogen. Nitrogen into the system must equal nitrogen out of the system. No significant solid material or unreacted polymer was collected, so it was not available for use as a tie. In the case of Run M357, the difference between total material fed and total material collected is $786.8 \mathrm{~g}$. $38 \%$ of this "missing" mass is assigned to the gas stream and $62 \%$ to the liquid stream. This $38 \%$ was based on the nitrogen balance in the gas stream. 38\%, or $299.0 \mathrm{~g}$, is distributed to the gas stream on a molar, or volume, basis. Since this is distributed on a molar basis, the mass assigned to the gas stream must be put on a molar basis by dividing by the average molecular weight of the gas, 33.5:

$$
\frac{299.0}{33.5}=8.92 \text { moles }
$$

Propylene is 5.26\% of the product gas stream, so $5.26 \%$ of the 8.92 moles is given to propylene:

8.92 moles $\times 5.26 \%=0.469$ moles propylene

0.469 moles $\times 42 \mathrm{~g} / \mathrm{g}$-mole $=19.7 \mathrm{~g}$ propylene

The normalized $(\mathrm{N})$ yield for propylene is:

$([456.2-0]+[19.7])=8.7 \%$

5442.0 
For the product liquids, $2447.0 \mathrm{~g}$ were collected. This equates to a yield of $45.5 \%$ :

$$
\frac{(2477.0-0)}{5442.0} \times 100 \%=45.5 \%
$$

$62 \%$ of the "missing mass," or 487.8 , was added to the liquid stream. The normalized yield becomes:

$$
\frac{([2477.0-0]+487.8)}{5442.0} \times 100 \%=54.5 \%
$$

The assignment of percentages to streams is shown in the lower left corner of the yields summary sheet. 


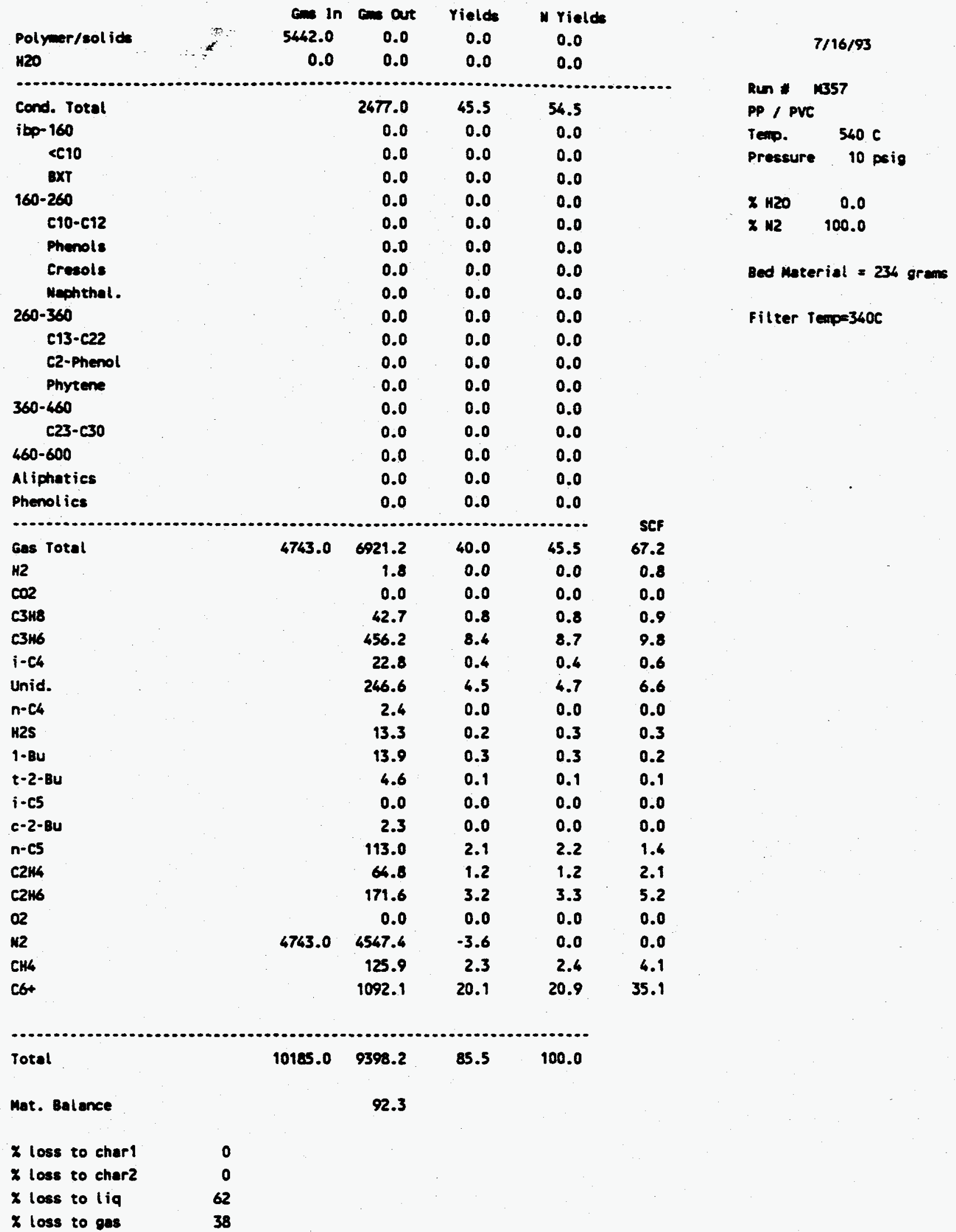

Figure A-1. Run M357. 


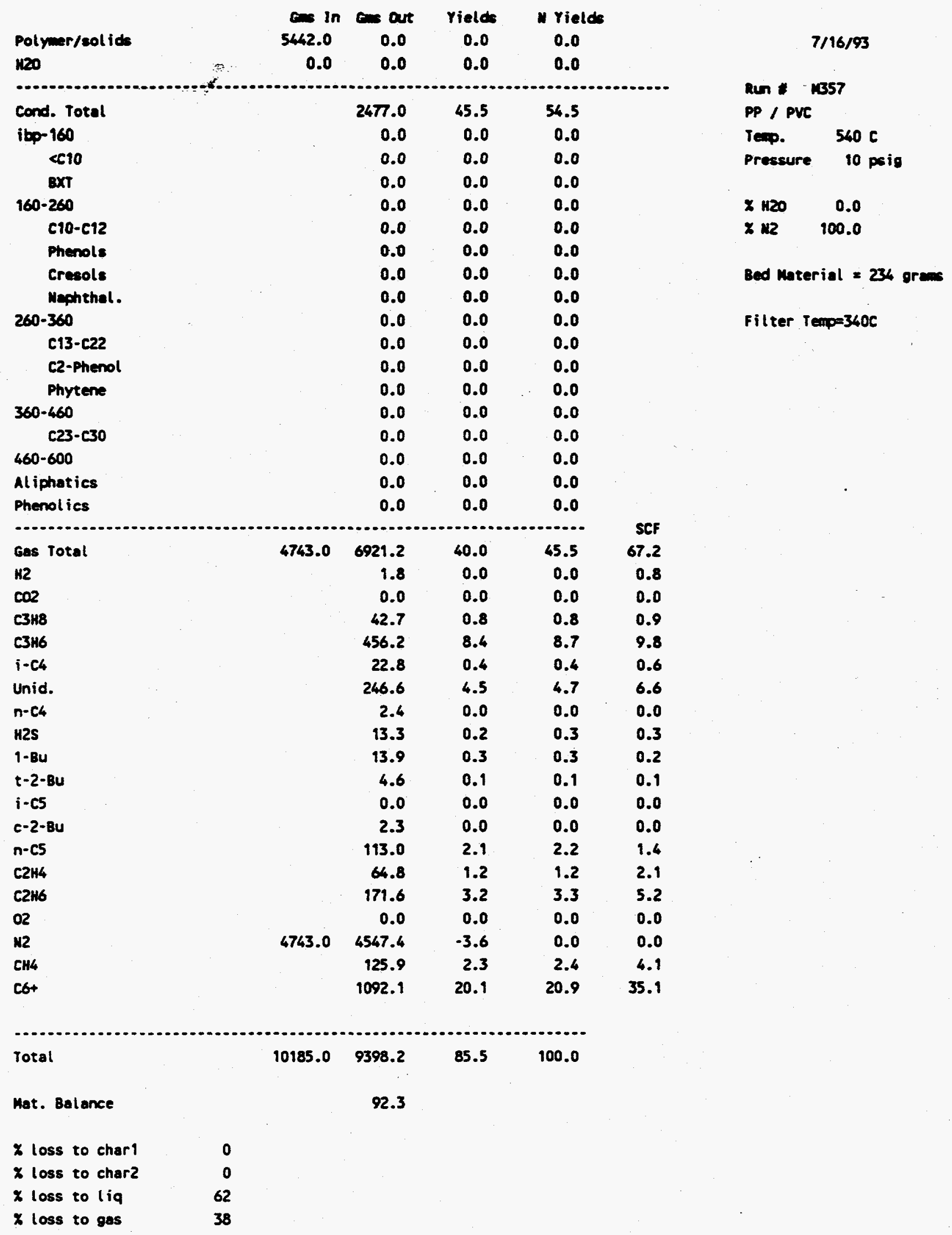




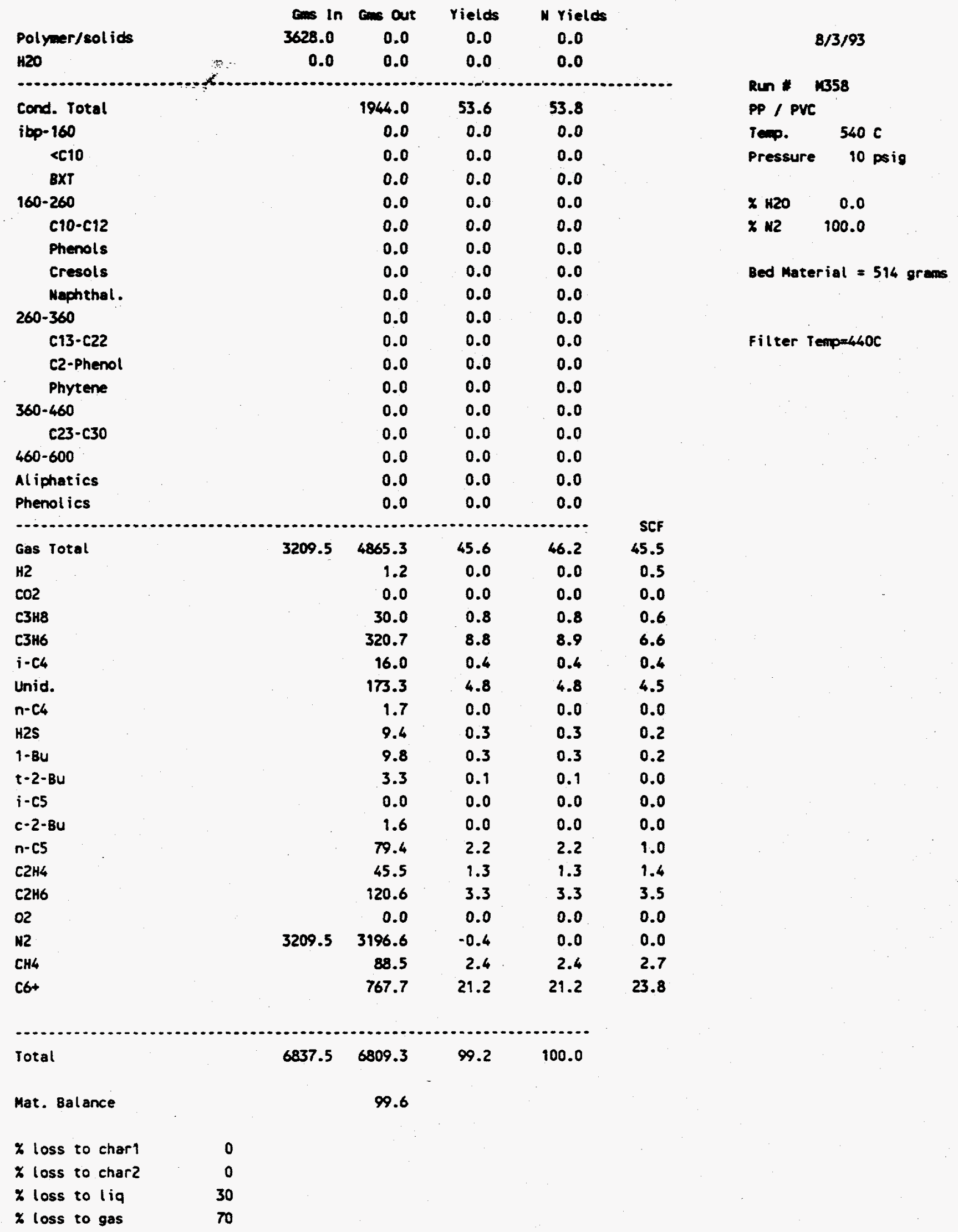




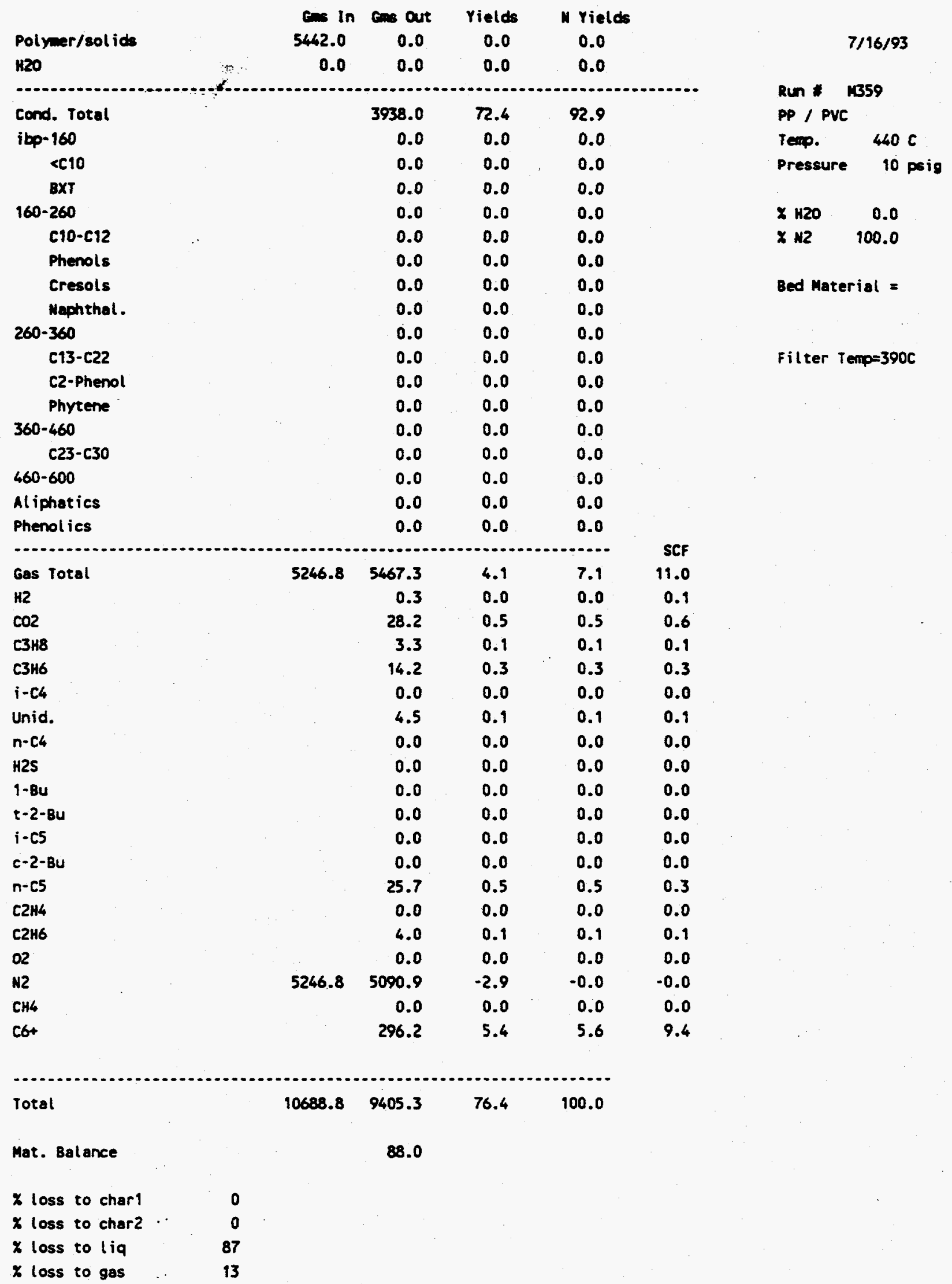




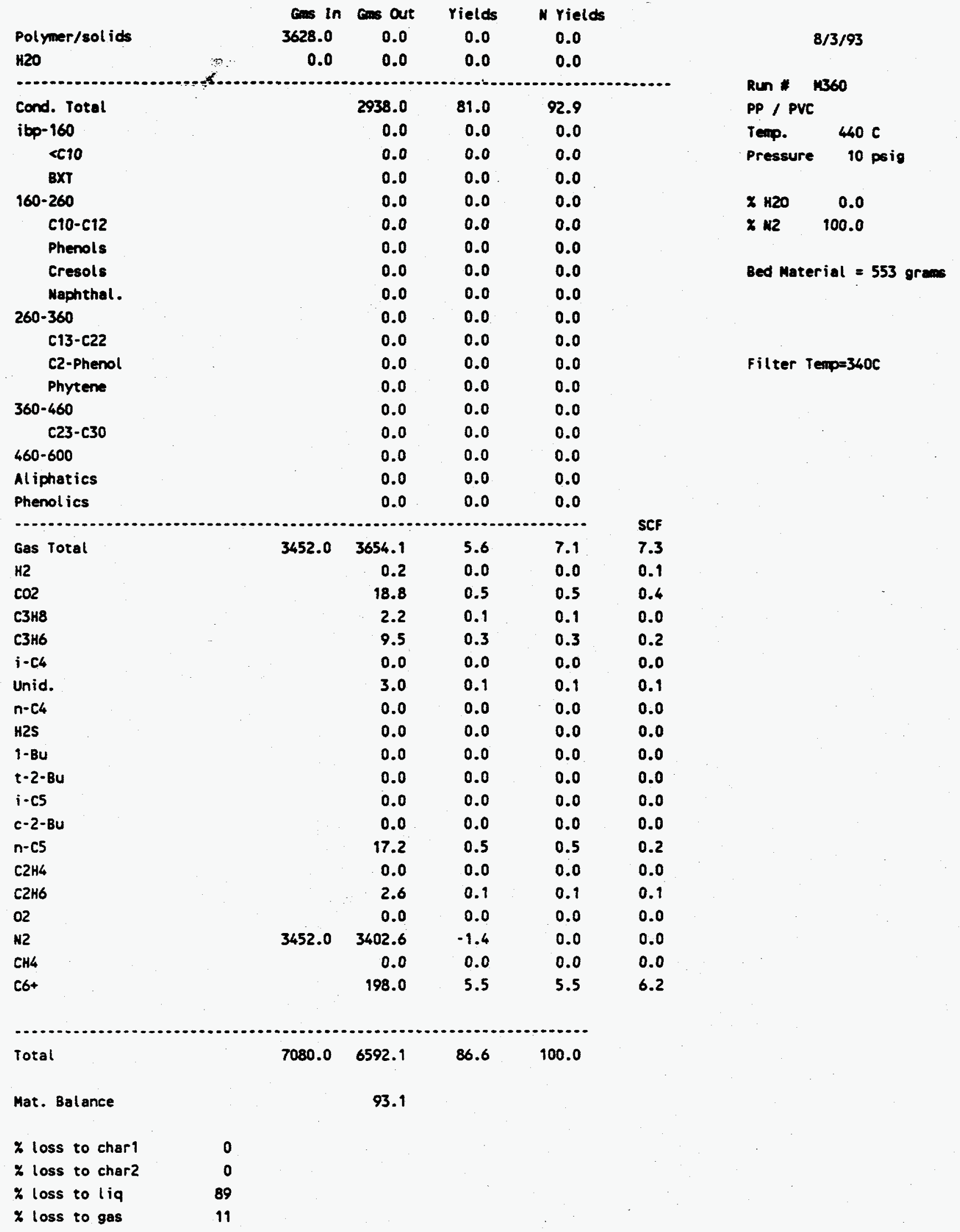




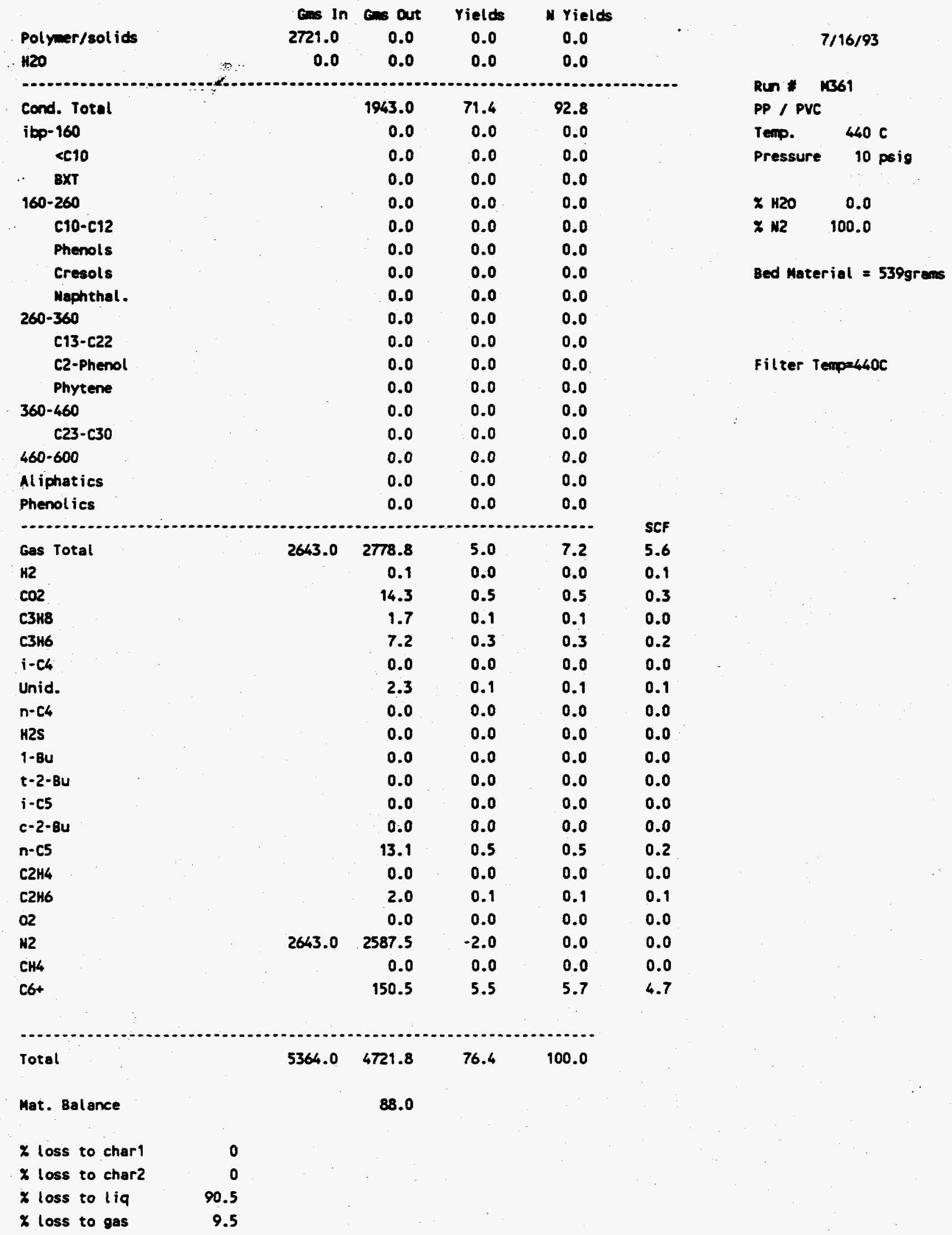




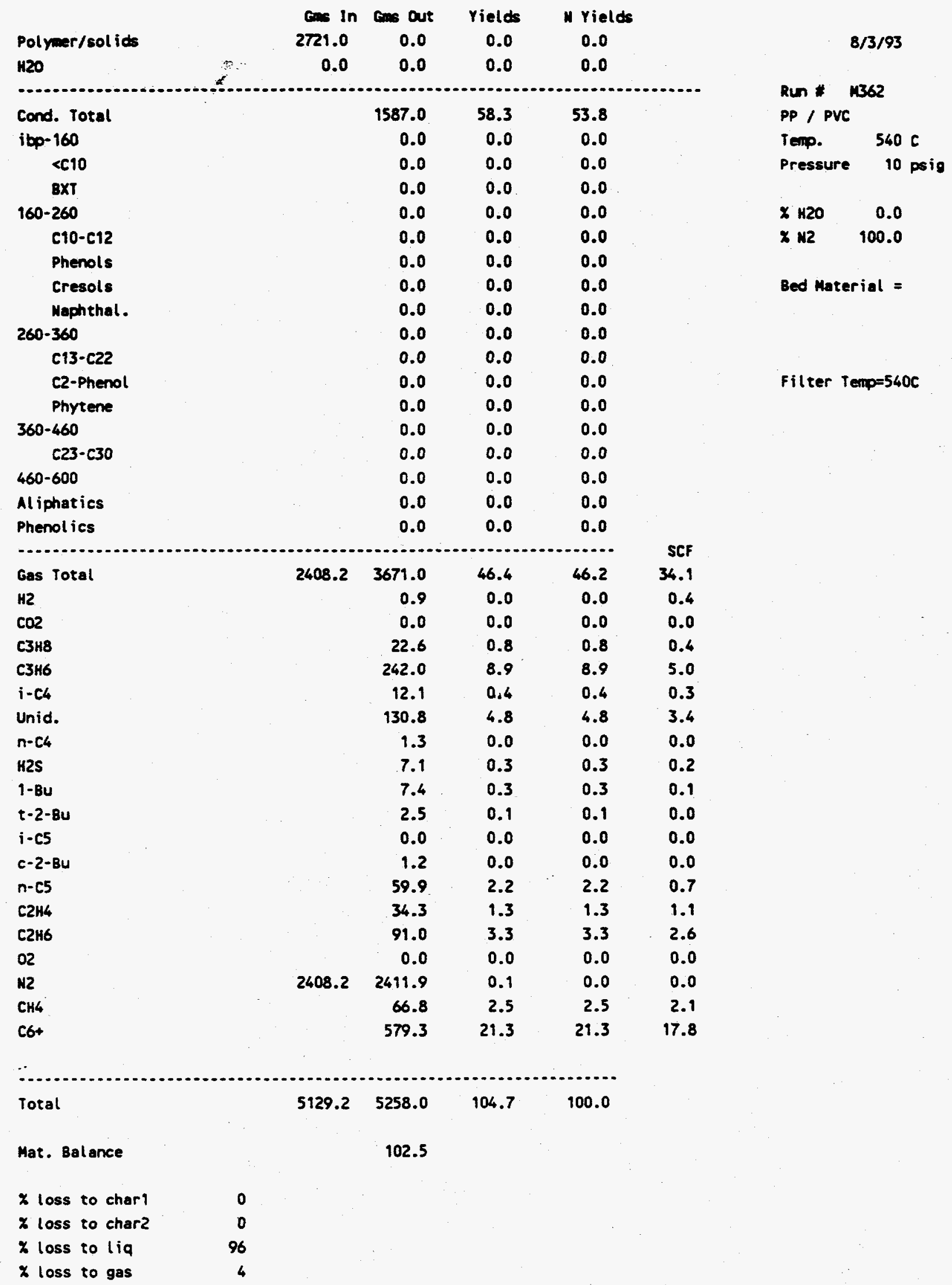




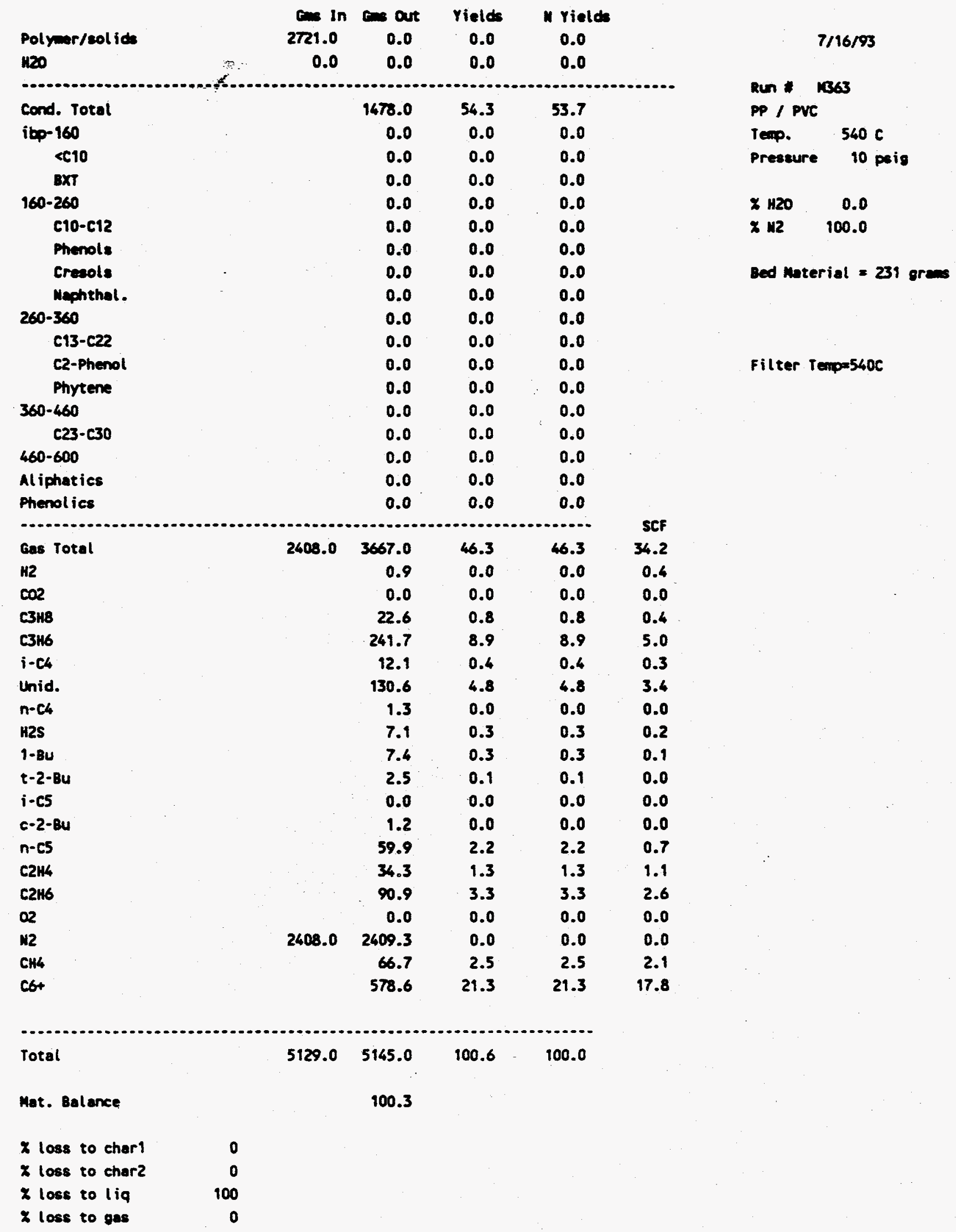




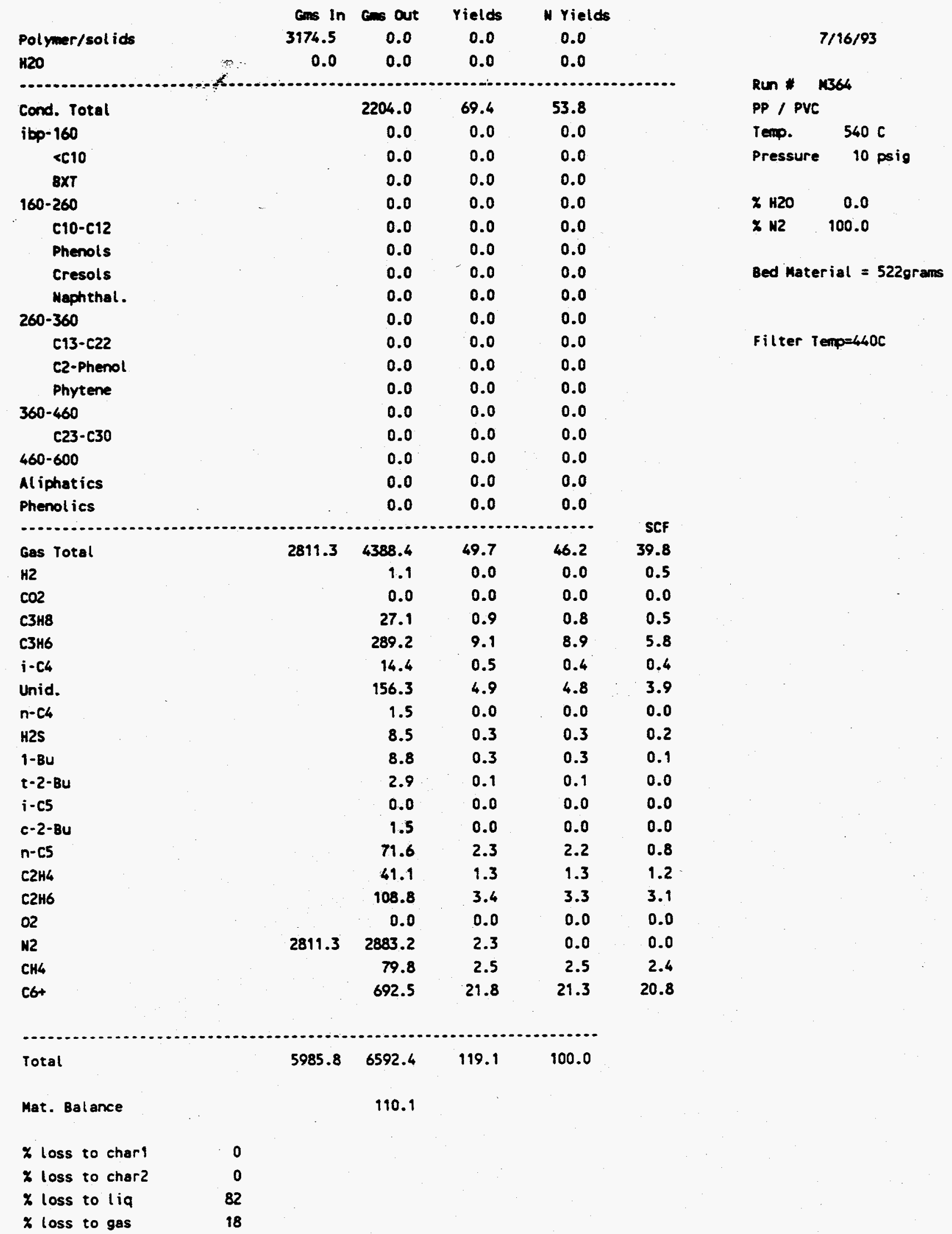


APPENDIX B

\section{TOTAL AND ORGANIC CHLORINE DETERMINATION}




\section{TOTAL AND ORGANIC CHLORINE DETERMINATION}

To determine chlorine distribution, total chlorine and organic chlorine are determined by analyses, while inorganic chlorine is calculated by their difference.

\section{Total Chlorine Content of Liquid Products}

The method used in product liquid total chlorine determination is based on ASTM Method D808-91, "Standard Test Method for Chlorine in New and Used Petroleum Products (Bomb Method)." The primary difference between the method used and ASTM D808-91 is that the ASTM method utilizes precipitation of chloride from solution for chloride quantitation. Chloride quantitation by ion chromatography is less labor-intensive and provides accurate, reproducible results. Total chlorine is determined as follows: An approximate 0.5-g sample is obtained for combustion in a Parr bomb apparatus. The weighed sample is sealed in the bomb along with a solution of $\mathrm{Na}_{2} \mathrm{CO}_{3}$ and $\mathrm{NaHCO}_{3}$, and the bomb is pressurized with oxygen to 28 atmospheres. The sample is then ignited electronically with a platinum firing wire and combusted. After a cooldown period for condensation of vapors, the bomb is opened, and the sample is removed for chloride analysis by ion chromatography.

Table B-1 is a list of several other ASTM chlorine analysis methods. After review of these methods, ASTM Method D808-91 was deemed most appropriate for these samples.

\section{Total Chlorine Content of Solid Products}

Total chlorine determination of solids ( $\mathrm{CaO}$ filter sorbent) was determined by first washing the sorbent with acid to remove chlorine. Chlorine is then quantified with ion

\section{TABLE B-1}

\section{ASTM Chlorine/Chloride Analysis Methods}

D 2384-83 Standard Test Methods for Traces of Volatile Chlorides in Butane-Butene Mixtures

E 776-87 Standard Test Method for Forms of Chlorine in Refuse-Derived Fuel

E442-91 Standard Test Method for Chlorine/Bromine/Iodine in Organic Compounds, by Oxygen Flask Combustion

E256-91 Standard Test Method for Chlorine in Organic Compounds, by Sodium Peroxide Bomb Ignition

D1726 Standard Test Method for Hydrolyzable Chlorine Content of Liquid Epoxy Resins

D1847 Standard Test Method for Total Chlorine Content of Liquid Epoxy Resins 
chromatography. Chlorine-containing salts, such as calcium chloride, sodium chloride, and potassium chloride, are easily solubilized in water. Quantitation of chlorine in samples of the calcium oxide sorbent used to capture chlorine generated during the decomposition of PVC was performed as follows:

- Weigh out about $1 \mathrm{~g}$ of sample into a 100 -mL volumetric flask.

- Fill the flask to the $100-\mathrm{mL}$ line with distilled, deionized water.

- Sonicate at room temperature for about 30 minutes.

- Gently swirl, then filter, the mixture.

- Analyze the filtered liquid for total chlorine content using ion chromatography.

- If the chlorine content of the liquid is above the accurate detection level of the instrument, repeat Steps 1-5 using about $100 \mathrm{mg}$ of sample.

\section{Organic Chlorine Content of Liquid Products}

Organic chlorine concentrations were determined using gas chromatography/atomic emission detection (GC/AED) analysis. GC/AED can identify and quantitate chloride in compounds as they elute from a GC column. When a compound leaves the GC column and enters the atomic emission detector, electrons in the atoms that make up the compound are energized by a microwave-induced plasma and excited to higher energy levels. When the electrons return to their stable state, they emit light, which passes into a spectrophotometer. The light is separated by a diffraction grating into wavelengths characteristic of the element selected for analysis (in this case, chlorine, but the instrument can also analyze for hydrogen, carbon, nitrogen, sulfur, oxygen, and several metals and other halogens) and transmit to a photodiode array detector, which can be tuned to monitor a specific range of wavelengths, depending on the element(s) of interest.

To quantitate chlorine, the photodiode array is tuned to monitor the 479-nanometer wavelength, which is characteristic of the energy emission from chlorine atoms. When energy of this wavelength is detected, it is converted into an electrical signal, the intensity of which is proportional to a specific quantity of chlorine atoms. The electrical signal intensity of each detected chlorine-containing compound is directly related to the amount of chlorine contained in the total amount of the compound present. For this reason, GC/AED (by itself) is useful in providing accurate total "gas chromatographable" chloride concentration values, but may or may not provide accurate concentration values for chloride-containing compounds, depending on how many chloride atoms a compound has. For example, if only GC/AED data are used, a compound with two chloride atoms will appear twice as concentrated as an equal amount of a compound with one chloride atom. Quantitating the concentrations of individual chloride-containing species can be done using GC/AED analysis in conjunction with GC/mass spectrometry (GC/MS) analysis to determine a species' degree of chloride substitution. This does not mean the organic chloride level will be inaccurate using GC/AED alone, but rather that a compound with one chlorine will appear less concentrated than a compound with two or more chlorine 
atoms. Therefore GC/AED alone cannot be used to quantify the chlorinated compound, but can be used to quantify organically associated chlorine of the liquid, overall. In this work, in which GC/AED alone was used to quantitate total organic chloride, 1-chloronaphthalene was used to calibrate the detector's chloride response.

Because GC/AED is a chromatographic technique, its use in determining organic chloride concentrations is valid for samples that contain no significant quantities of nonchromatographable organic species. Use of the technique in this work is probably worthwhile, since the plastics decomposition liquids analyzed appear to be composed primarily of volatile species.

Chlorine distributions for runs that contained measurable organic chloride are shown in Figures B-1 through B-5.

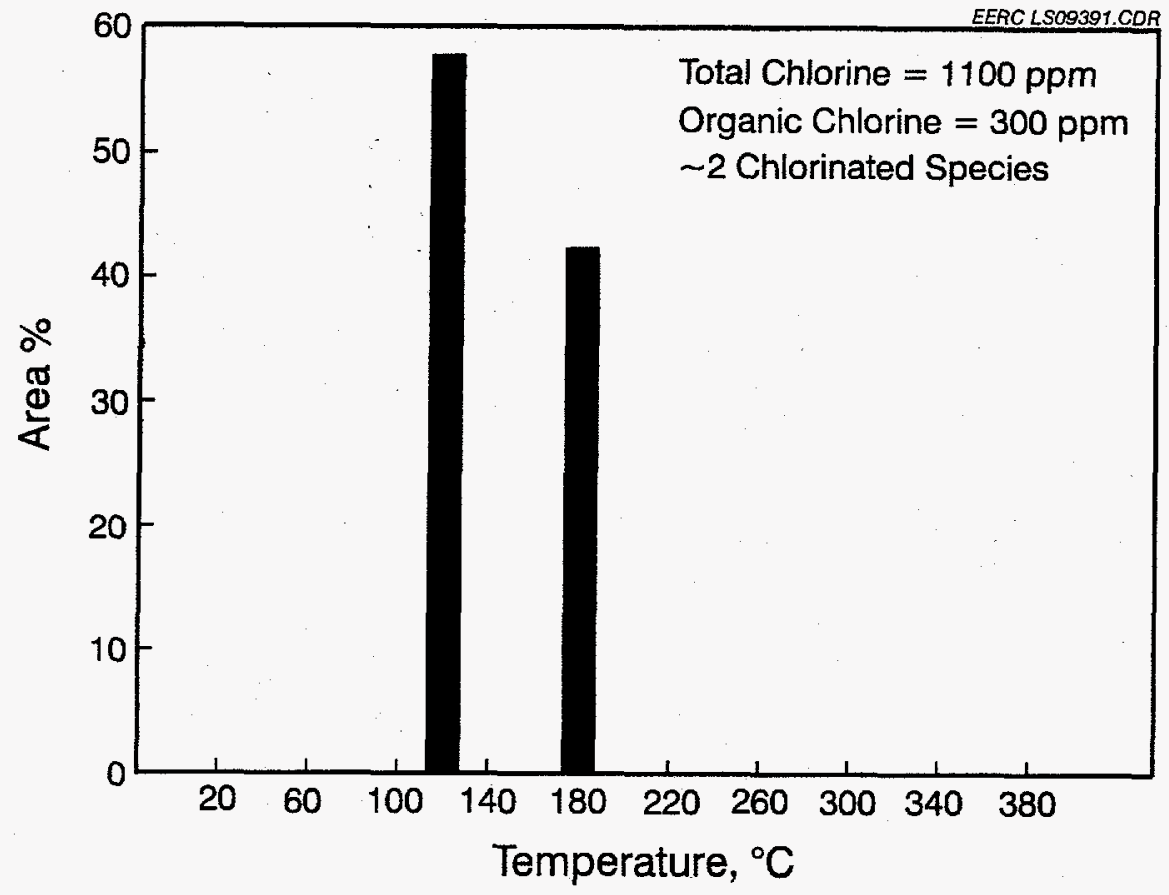

Figure B-1. Organic chlorine distribution for liquids produced at a depolymerization temperature of $440^{\circ} \mathrm{C}$ (M359). 


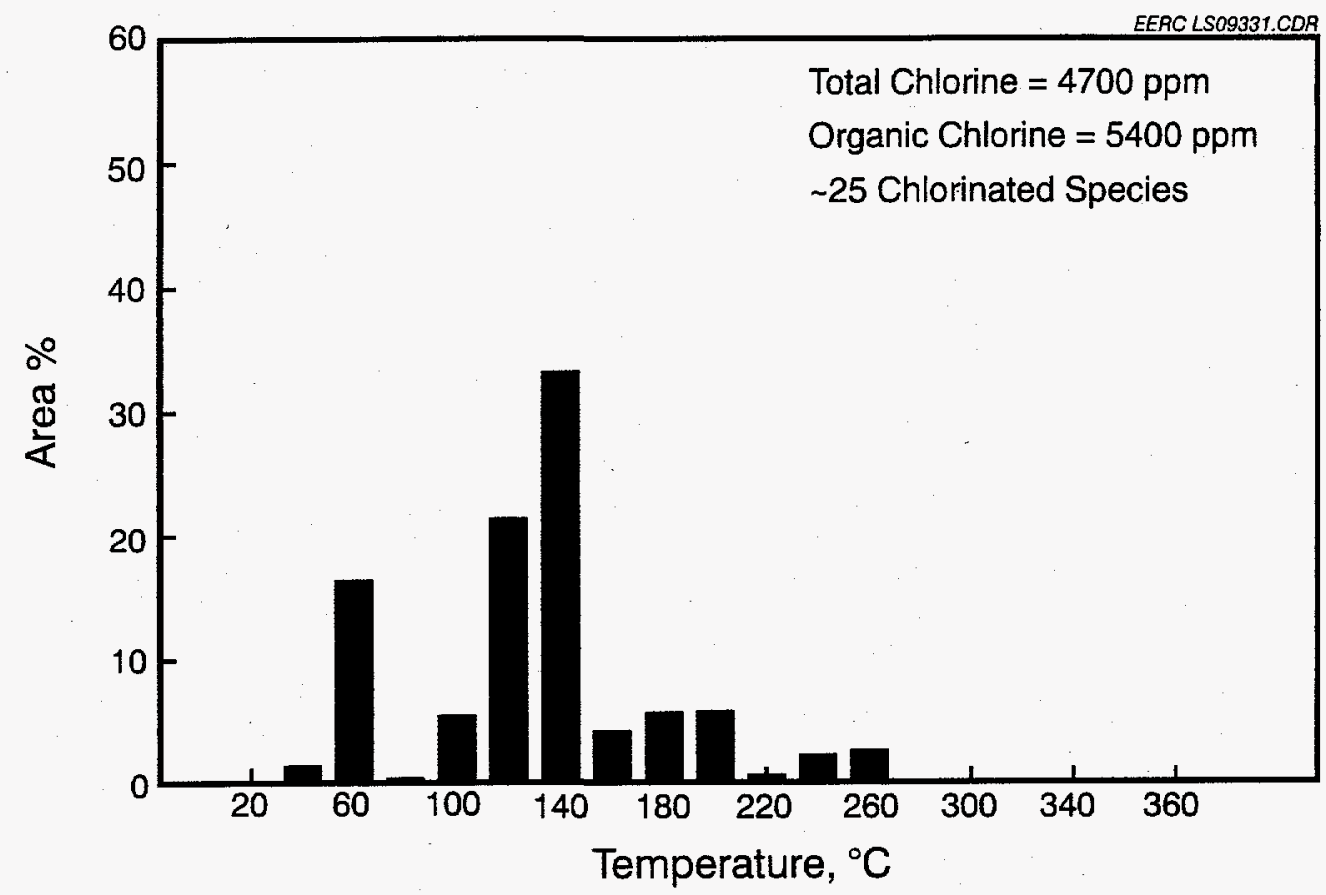

Figure B-2. Organic chlorine distribution for liquids produced at a depolymerization temperature of $540^{\circ} \mathrm{C}$ (M357).

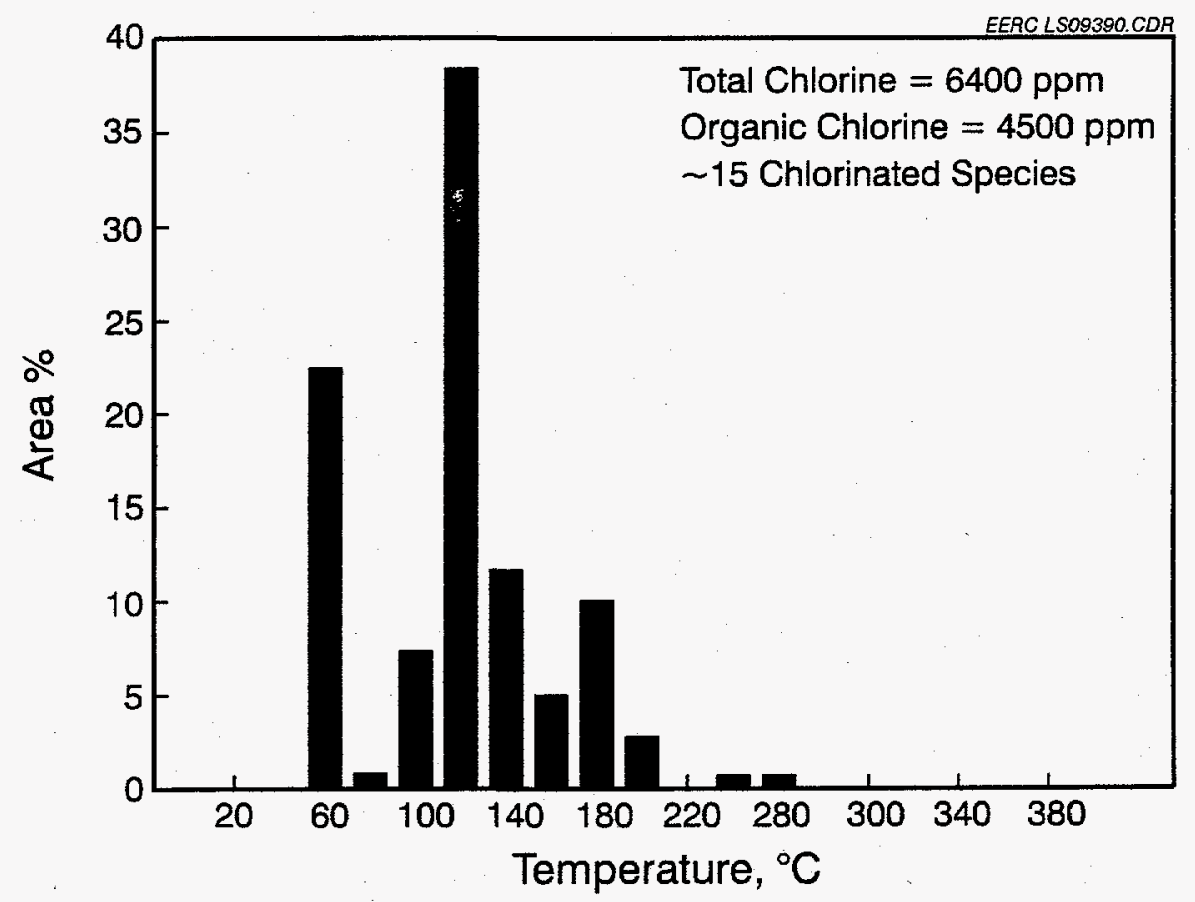

Figure B-3. Organic chlorine distribution for liquids produced at a depolymerization temperature of $540^{\circ} \mathrm{C}$ (M364). 


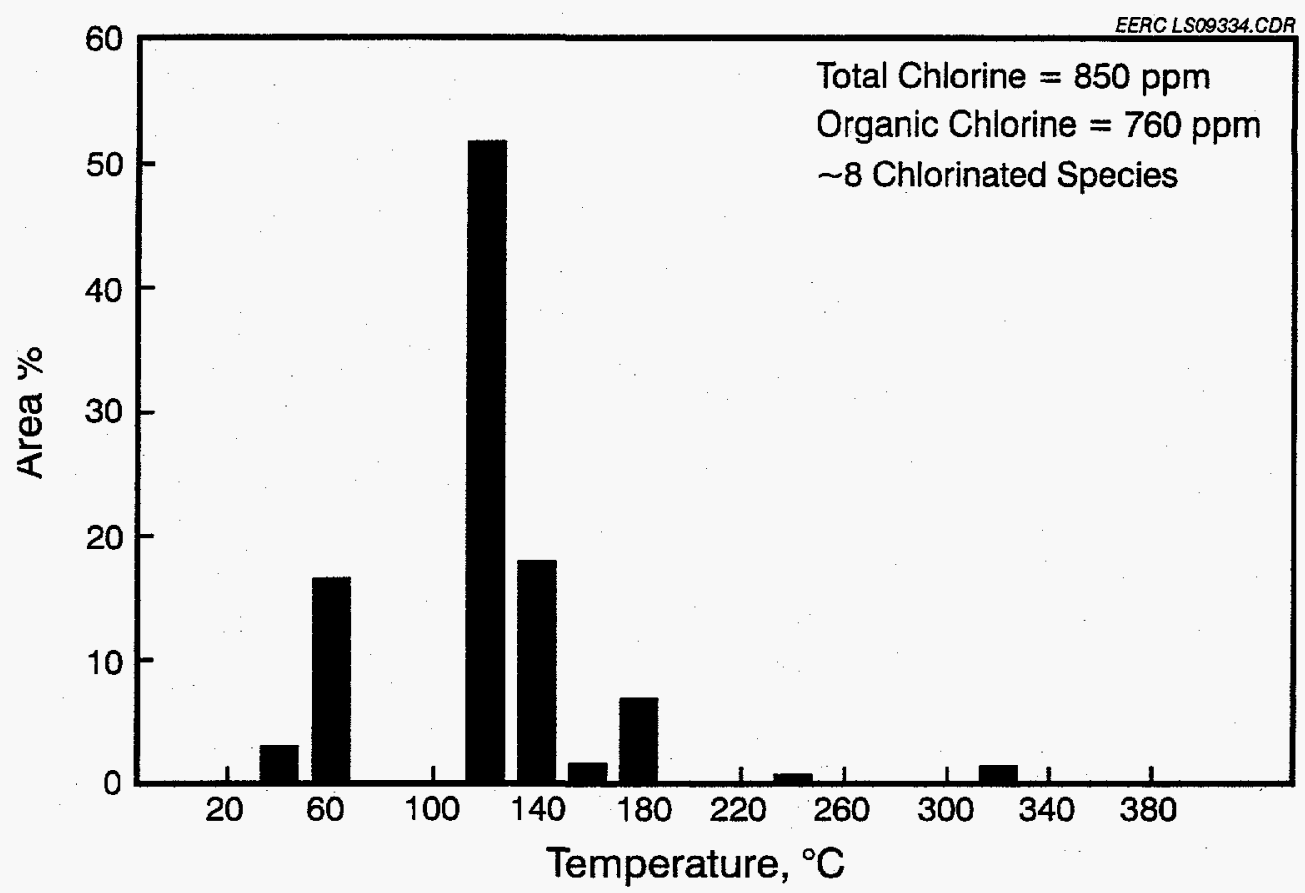

Figure B-4. Organic chlorine distribution for liquids produced at a depolymerization temperature of $440^{\circ} \mathrm{C}$ and a filter temperature of $340^{\circ} \mathrm{C}$ (M360).

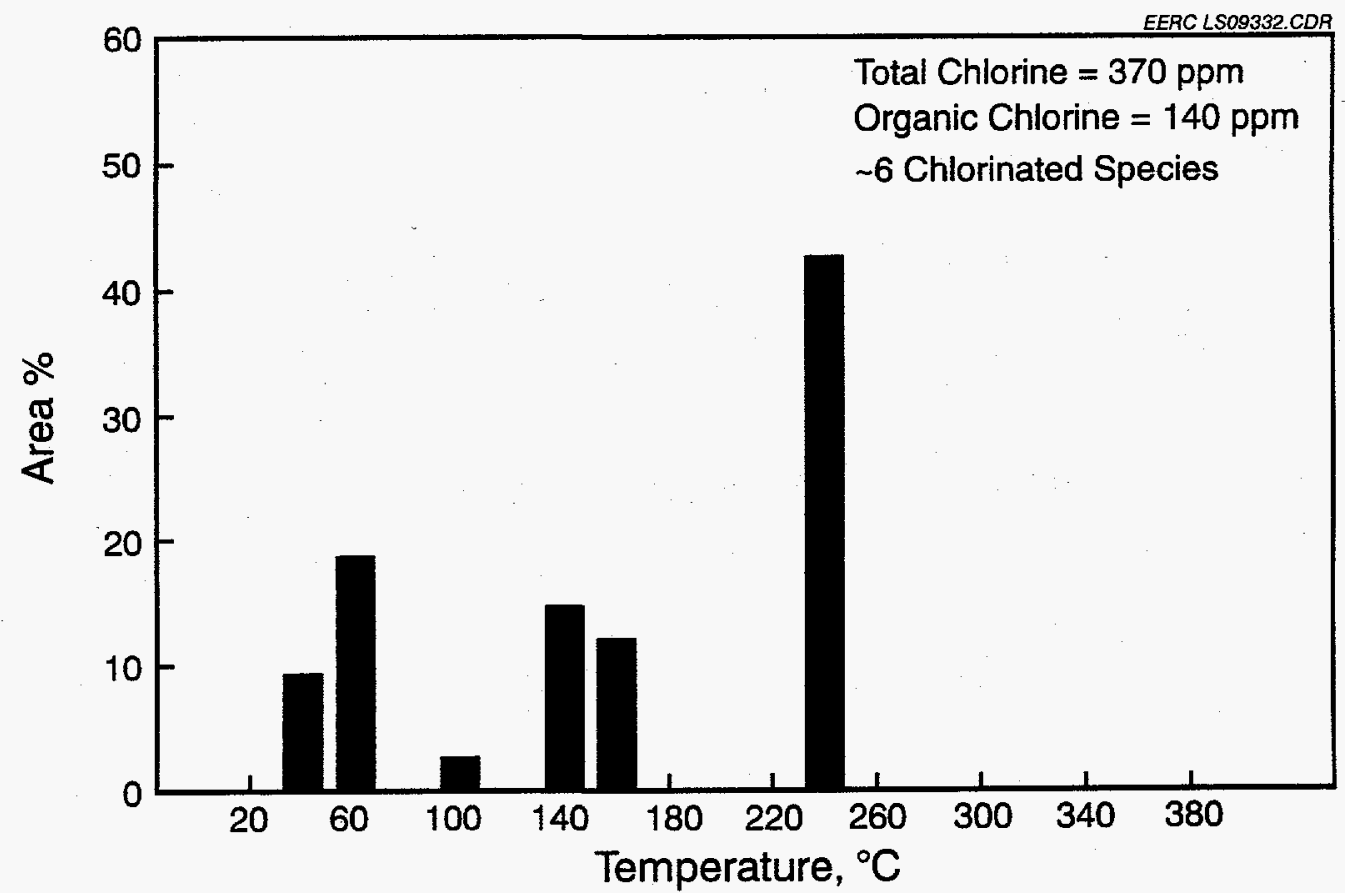

Figure B-5. Organic chlorine distribution for liquids produced at a depolymerization temperature of $540^{\circ} \mathrm{C}$ and a filter temperature of $340^{\circ} \mathrm{C}$ (M357). 
APPENDIX C

GC/AED ORGANIC CHLORINE ANALYSIS OF PLASTICS DECOMPOSITION LIQUIDS DETECTION LIMIT/QUALITY CONTROL STUDY 


\section{GC/AED ORGANIC CHLORINE ANALYSIS OF PLASTICS DECOMPOSITION LIQUIDS DETECTION LIMIT/QUALITY CONTROL STUDY}

A study was conducted at the Energy \& Environmental Research Center (EERC) in Grand Forks, North Dakota, to determine the detection limit (lowest detectable concentration) of organic chlorine in plastics decomposition liquids using gas chromatography coupled with atomic emission detection (GC/AED). The study consisted of analyzing a base material and three successively less concentrated dilutions of the base material. The results of this limited study indicate a per-compound detection limit of about 4 parts per million (ppm) organic chlorine. It must be stressed that the 4-ppm value is an indication of a detection limit and that a more comprehensive study would be required to establish a statistically valid detection limit.

Several decomposition products from both the EERC and the Energy \& Environmental Research (EER) Corporation in Irvine, California, were considered as a base material for the study. APC-106 from EER was chosen for the following reasons:

- While many decomposition products are waxy, sludgy materials at room temperature, APC-106 is a liquid with the approximate viscosity of a heavy fuel oil. Liquids can be accurately sampled, mixed, and solubilized without heat, which eliminates the possibility of boiling away volatile chlorine species.

- APC-106 has been analyzed for organic chlorine twice at the EERC and at least once at Core Laboratories in California; all three analyses provided similar results:

EERC 1 11,300 ppm EERC $210,300 \mathrm{ppm}$ Core $1 \quad 11,000 \mathrm{ppm}$

- APC-106 has a wide concentration range of chlorine-containing species. In the two EERC analyses, APC-106 was found to be composed of about 30 organic chlorinecontaining species, ranging in concentration from less than $1.0 \%$ to about $24 \%$ of the total organic chlorine content.

Table C-1 provides results of the two EERC analyses of APC-106, and the following table provides results of triplicate analyses of the three APC-106 dilutions. The following definitions apply to both tables:

IS1/IS2 Area counts of Internal Standard 1 (2-chloronaphthalene) divided by area counts of Internal Standard 2 (1-chloronaphthalene)

IS1+IS2 Area counts of Internal Standard 1 plus area counts of Internal Standard 2

Total-IS Total area counts minus IS1+IS2

ISTD, $g$ Weight of Internal Standard in grams 


\begin{abstract}
$\mathrm{Sx}, \mathrm{g} \quad$ Weight of sample in grams
$\mathrm{Cl}, \mathrm{ppm} \quad$ Organic chlorine content in parts per million

BPI, ${ }^{\circ} \mathrm{C} \quad$ Boiling point index (calculated boiling point based on relationship of GC retention time to boiling point for the series of normal alkanes from $\mathrm{C}_{5}$ to $\mathrm{C}_{15}$ )
\end{abstract}

RT GC retention time

AC GC area counts

Table C-1 indicates the reproducibility of the analysis technique. In both analyses, the same five compounds (with boiling point indices of $47^{\circ}, 86^{\circ}, 113^{\circ}, 126^{\circ}$, and $153^{\circ} \mathrm{C}$ ) accounted for about $70 \%$ of the total organic chlorine. Regarding the internal standard (ISTD), the original intent was to use 1-chloronaphthalene, but analysis revealed that 2-chloronaphthalene was present as an impurity in the 1-chloronaphthalene. This turned out to be advantageous, because it enabled calculation of an area count ratio (IS1/IS2) for the two compounds. If this ratio is consistent over the course of a series of analyses, it indicates that 1) neither species is present in the samples (this is required for overall quantitative accuracy-if chloronaphthalene is found in a sample, a different ISTD must be used in the analysis of that sample) and 2) the instrument is providing accurate and reproducible area count data.

In Table C-1, the two analyses are merged to allow easy comparison of area count data. Gaps in the columns indicate that the instrument detected a compound in one analysis but did not find the same compound in the other analysis. These errors are because of judgement differences in establishing a baseline from which to integrate the AED response for chlorine-containing compounds. As shown in the table, none of these inconsistently present compounds accounts for more than $2 \%$ of the total organic chlorine content, and the cumulative effect of all of them is $3.1 \%$ for APC-106a and $4.8 \%$ for APC$106 \mathrm{~b}$. Also of significance in the analysis of the base material are the ISTD area count values of 399 and 297 for APC-106a and APC-106b, respectively, and the weight ratio of ISTD to sample $(0.011 / 1.010=0.011)$. These numbers will be compared to their counterparts in the analysis of the base material dilutions.

In order to prepare dilutions of the base material, a liquid was needed in which the base material was soluble at room temperature. Because the base material was produced from a feedstock containing $10 \%$ PVC in a mixture of polyethylene (PE), polypropylene (PP), and polystyrene (PS), it was determined that a dilution liquid made from a similar feedstock would have the best solubilization capability. The dilution liquid (DL) was prepared by mixing $6 \mathrm{~mL}$ of a PP decomposition product (EERC-M269) with $14 \mathrm{~mL}$ of a 50\% PE/50\% PS decomposition product (EERC-M291). The three base material dilutions were prepared as follows:

No. $1 \quad 0.5 \mathrm{~mL}(0.418 \mathrm{~g})$ APC-106 was added to $4.5 \mathrm{~mL}(3.743 \mathrm{~g}) \mathrm{DL}$.

No. 2 About $0.05 \mathrm{~mL}(0.056 \mathrm{~g})$ APC-106 was added to $5.0 \mathrm{~mL}(4.121 \mathrm{~g}) \mathrm{DL}$.

No. $3 \quad 0.010 \mathrm{~g}$ APC-106 was added to about $8 \mathrm{~mL}(6.890 \mathrm{~g}) \mathrm{DL}$. 
Based on the average of the three base material analyses, the chlorine content of the base material is about $10,900 \mathrm{ppm}$. Therefore, assuming good mixing and solubilization of the base material in the DL (which seems reasonable because of lack of visual evidence of precipitation or cloudiness), the chlorine content of the three dilutions should be about $1100 \mathrm{ppm}, 150 \mathrm{ppm}$, and $16 \mathrm{ppm}$, respectively, for No. 1, No. 2, and No. 3 ( $\mu \mathrm{g} / \mathrm{g}$ and ppm are equivalent-see Table C-2). Table $\mathrm{C}-2$ shows the merged results of the triplicate analyses of the three dilutions. To avoid any effects of analysis repetition, the dilutions were analyzed in the order shown in the table (APC-1 through APC-9).

The table shows that in all three analyses of No. 1 and No. 2, the analyzed chlorine content was higher than the calculated value. The reason for this is unknown and would require more testing to determine, but comparison of the three analyses of No. 1 and the three analyses of No. 2 shows that in both cases the greatest chlorine content error is associated with the smallest ISTD area count value. This indicates valid relationship between the accuracy of analyzed chlorine content and the magnitude of the ISTD area count value and the establishment of a minimum ISTD area count value. Based on the available data, it appears that reasonable accuracy should be possible, provided the ISTD area count value for an analysis exceeds 1800 . This does not mean that if the ISTD area count is below 1800 the analysis will not be accurate; it means that the chance for inaccuracy is greater. In the case of the base material analyses, it must be remembered that the ISTD-to-sample ratio was about 0.011 , whereas with the dilution analyses, the ISTD-to-sample ratios were about $0.013(0.011 / 0.824)$, a difference of about $22 \%$. Also, three separate analyses of the base material, using two different samples, yielded three similar chlorine content values.

Of the three analyses of Dilution No. 3 (the least concentrated), only APC-4 detected a response for a compound other than the two ISTDs. The ISTD area count for APC-4 was 1868, while the other two area count values were less than 500. A small ISTD area count is indicative of a small GC injection volume, the reason for which may involve sample viscosity and the small inside diameter of the injection needle. However, this should not be a problem-if an injection size is small, the analysis can be repeated until a representative sample (as defined by an ISTD area count of over 1800) is injected.

The following rationale was used to yield an indication of the detection limit of the GC/AED method for organic chlorine analysis:

Based on the average base material total organic chlorine content of 10,900 , the concentration of the most concentrated component (BPI of $47^{\circ} \mathrm{C}$ ) of the base material was calculated to be $2600 \mathrm{ppm}$. The concentration of this component in Dilution No. 3 (assuming proper mixing and solubilization) was calculated to be about $4 \mathrm{ppm}$. Because this 4-ppm component was detected in a representative sample injection, it seems reasonable to assume that the detection limit is at least $4 \mathrm{ppm}$ (per component), provided an adequate sample volume is injected (as defined by an ISTD area count value of at least 1800 ).

Concerning the use of GC/AED to quantitate organic chlorine in APC plastics decomposition liquids, the primary implication of this limited study is that the technique will detect chlorine-containing species present at concentrations of $4 \mathrm{ppm}$ or higher. Hence, the possibility exists that if a product contains 100-ppm organic chlorine distributed among 40 compounds, none of which individually comprise more than $3 \mathrm{ppm}$ 
of the total organic chlorine content, the technique may yield an organic chlorine content of zero for this product. However, this is unlikely, because in analyses of products from both the EERC and EER Corporation, the same five components normally account for about $50 \%$ to $70 \%$ of the organic chlorine content. In products with lower chlorine contents (from 200 to $1000 \mathrm{ppm}$ ), these same five components appear to account for about $70 \%$ to $90 \%$. While it is possible that product liquids with lower organic chlorine contents have lower degrees of chlorine compound speciation, it is more likely that at lower organic chlorine levels, fewer species are present in above-detection-limit concentrations. In a hypothetical analysis, if only the above-mentioned five compounds were detected, all at concentrations of $4 \mathrm{ppm}$, the analyzed organic chlorine content of $20 \mathrm{ppm}$ would probably account for less than the actual content, which would probably range from about 25 to $50 \mathrm{ppm}$.

In addition to enabling quantitation of total organic chlorine, GC/AED data provides useful information regarding product volatility. In comparing samples analyzed at different times, it is important to remember that GC boiling point indices can vary by about $3^{\circ} \mathrm{C}$, because of differences in chromatographic conditions and the use of different alkane mixtures for boiling point calibration. 
TABLE C-1

Analytical Reproducibility

\begin{tabular}{ccc}
\hline & Base Material & \\
\hline IS1/IS2 & APC-106a & APC-106b \\
IS1+IS2 & 0.140 & 0.142 \\
Total-IS & 399 & 297 \\
ISTD, g & 1833 & 1245 \\
Sx, g & 0.011 & 0.011 \\
Cl, ppm & 1.010 & 1.010 \\
& 11307 & 10318
\end{tabular}

Organic Chlorine Boiling Point Distribution APC-106a

\begin{tabular}{ccccccc}
\hline BPI, ${ }^{\circ} \mathrm{C}$ & $\mathrm{RT}$ & $\mathrm{AC}$ & $\mathrm{A} \%$ & $\mathrm{RT}$ & $\mathrm{AC}$ & $\mathrm{A} \%$ \\
\hline & & & & & & \\
47 & 1.33 & 447 & 24.4 & 1.28 & 303 & 24.3 \\
53 & 1.47 & 6 & 0.3 & & & 0.0 \\
64 & & & 0.0 & 1.71 & 13 & 1.0 \\
68 & & & 0.0 & 1.82 & 22 & 1.8 \\
73 & & & 0.0 & 1.96 & 6 & 0.5 \\
81 & 2.65 & 14 & 0.8 & 2.55 & 15 & 1.2 \\
86 & 2.99 & 151 & 8.2 & 2.89 & 111 & 8.9 \\
91 & & & 0.0 & 3.20 & 6 & 0.5 \\
102 & & & 0.0 & 4.09 & 9 & 0.7 \\
104 & 4.35 & 67 & 3.7 & 4.24 & 55 & 4.4 \\
113 & 5.12 & 280 & 15.3 & 5.00 & 209 & 16.8 \\
118 & 5.59 & 84 & 4.6 & 5.48 & 59 & 4.7 \\
119 & 5.73 & 10 & 0.5 & & & 0.0 \\
126 & 6.37 & 288 & 15.7 & 6.25 & 151 & 12.1 \\
129 & 6.59 & 44 & 2.4 & 6.47 & 27 & 2.2 \\
133 & 6.97 & 16 & 0.9 & 6.87 & 11 & 0.9 \\
133 & 7.05 & 12 & 0.7 & 6.93 & 10 & 0.8 \\
136 & 7.27 & 23 & 1.3 & 7.15 & 13 & 1.0 \\
139 & 7.57 & 42 & 2.3 & 7.45 & 20 & 1.6 \\
139 & 7.64 & 6 & 0.3 & 7.51 & 4 & 0.3 \\
140 & 7.65 & 8 & 0.4 & & & 0.0 \\
146 & 8.25 & 22 & 1.2 & 8.13 & 10 & 0.8 \\
150 & 8.66 & 17 & 0.9 & 8.54 & 16 & 1.3 \\
153 & 8.92 & 126 & 6.9 & 8.79 & 93 & 7.5 \\
154 & 9.06 & 33 & 1.8 & 8.94 & 21 & 1.7 \\
164 & 10.01 & 13 & 0.7 & 9.88 & 6 & 0.5
\end{tabular}


TABLE C-1 (continued)

\begin{tabular}{ccclccc}
\hline \multicolumn{7}{c}{ Base Material } \\
BPI, ${ }^{\circ} \mathrm{C}$ & $\mathrm{RT}$ & $\mathrm{AC}$ & $\mathrm{A} \%$ & $\mathrm{RT}$ & $\mathrm{AC}$ & $\mathrm{A} \%$ \\
\hline 165 & 10.10 & 8 & 0.4 & & & 0.0 \\
173 & 10.81 & 17 & 0.9 & & & 0.0 \\
173 & 10.83 & 14 & 0.8 & 10.68 & 5 & 0.4 \\
175 & 10.99 & 11 & 0.6 & 10.86 & 8 & 0.6 \\
180 & 11.54 & 8 & 0.4 & & & 0.0 \\
184 & 11.85 & 4 & 0.2 & & & 0.0 \\
187 & 12.15 & 15 & 0.8 & 12.02 & 16 & 1.3 \\
194 & & & 0.0 & 12.68 & 4 & 0.3 \\
199 & 13.23 & 47 & 2.6 & 13.10 & 22 & 1.8 \\
247 & 17.80 & 49 & IS & 17.65 & 37 & IS \\
247 & 17.87 & 350 & IS & 17.72 & 260 & IS \\
\hline
\end{tabular}


TABLE C-2

Dilution Analyses

\begin{tabular}{|c|c|c|c|c|c|c|c|c|c|c|}
\hline \multirow{3}{*}{$\begin{array}{c}\text { Dilution: } \\
\text { Name: } \\
\text { IS1/IS2 }\end{array}$} & \multicolumn{3}{|c|}{ No. $1,1100 \mu \mathrm{g} / \mathrm{g}$} & \multicolumn{4}{|c|}{ No. 2, $150 \mu \mathrm{g} / \mathrm{g}$} & \multicolumn{3}{|c|}{ No. $3,16 \mu \mathrm{g} / \mathrm{g}$} \\
\hline & \multirow{2}{*}{$\frac{\text { APC3-3 }}{0.137}$} & \multirow{2}{*}{$\frac{\mathrm{APC} 3-6}{0.136}$} & \multirow{2}{*}{$\frac{\text { APC3-9 }}{0.141}$} & \multirow{2}{*}{$\frac{\mathrm{APC} 3-2}{0.133}$} & \multirow[t]{2}{*}{ APC3.5 } & \multicolumn{2}{|r|}{ APC3-8 } & \multirow{2}{*}{$\frac{\mathrm{APC} 3-1}{0.128}$} & \multirow{2}{*}{$\frac{\mathrm{APC} 3-4}{0.140}$} & \multirow{2}{*}{$\begin{array}{r}\text { APC3-7 } \\
\begin{array}{c}0.13 \\
5\end{array}\end{array}$} \\
\hline & & & & & & 0.135 & 0.139 & & & \\
\hline IS1+IS2 & 2485 & 301 & 2393 & 2076 & & 4928 & 654 & 132 & 1868 & 487 \\
\hline Total-IS & 1087 & 170 & 1029 & 131 & & 296 & 48 & 0 & 6 & 0 \\
\hline ISTD, $\mathbf{g}$ & 0.012 & 0.012 & 0.012 & 0.011 & & 0.011 & 0.011 & 0.011 & 0.011 & $\begin{array}{c}0.01 \\
1\end{array}$ \\
\hline Sx, g & 0.825 & 0.825 & 0.825 & 0.808 & & 0.808 & 0.808 & 0.838 & 0.838 & $\begin{array}{c}0.83 \\
8\end{array}$ \\
\hline $\mathrm{Cl}, \mathrm{ppm}$ & 1341 & 1732 & 1319 & 194 & & 185 & 226 & 0 & 10 & 0 \\
\hline $\mathrm{BPI},{ }^{\circ} \mathrm{C}$ & $\mathrm{AC}$ & $\mathrm{AC}$ & $\mathbf{A C}$ & $\mathrm{AC}$ & RT & $\mathrm{AC}$ & $\mathrm{AC}$ & $\mathrm{AC}$ & $\mathrm{AC}$ & $\mathrm{RT}$ \\
\hline
\end{tabular}

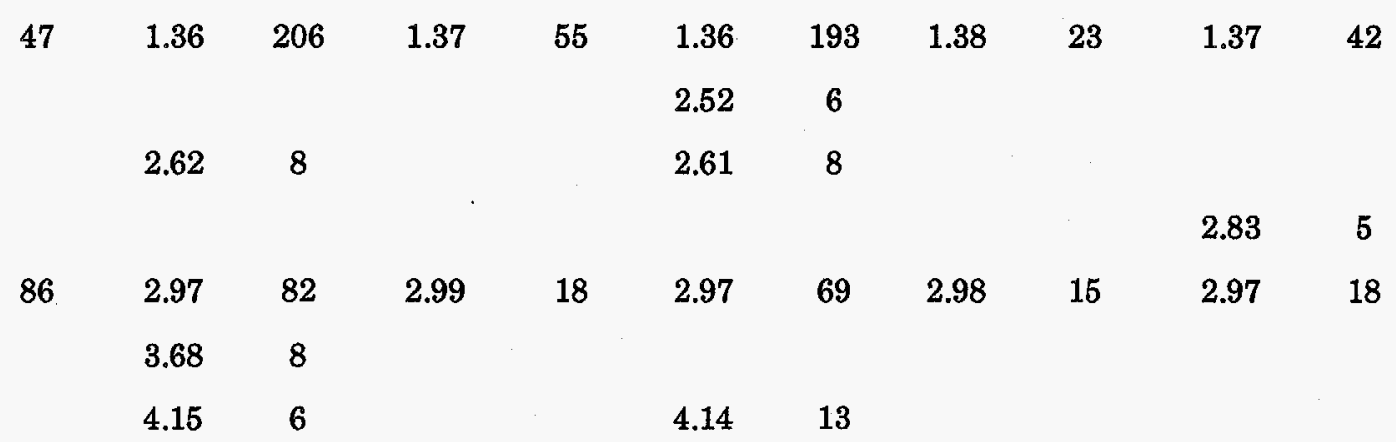

(continued...) 
TABLE C-2 (continued)

\begin{tabular}{|c|c|c|c|c|c|c|c|c|c|c|c|c|c|c|c|c|c|c|c|}
\hline \multirow{2}{*}{$\frac{\text { Dilution: }}{\text { BPI, }{ }^{\circ} \mathrm{C}}$} & \multicolumn{6}{|c|}{ No. $1,1100 \mu \mathrm{g} / \mathrm{g}$} & \multicolumn{7}{|c|}{ No. $2,150 \mu \mathrm{g} / \mathrm{g}$} & \multicolumn{6}{|c|}{ No. $3,16 \mu \mathrm{g} / \mathrm{g}$} \\
\hline & $\mathrm{RT}$ & $\mathrm{AC}$ & $\mathrm{RT}$ & $\mathrm{AC}$ & $\mathrm{RT}$ & $\mathrm{AC}$ & $\mathrm{RT}$ & $\mathrm{AC}$ & $\mathrm{RT}$ & $\mathrm{AC}$ & RT & $\mathrm{AC}$ & RT & $\mathrm{AC}$ & $\mathrm{RT}$ & $\mathrm{AC}$ & $\mathrm{RT}$ & $\mathrm{AC}$ & $\mathrm{RT}$ \\
\hline \multirow[t]{2}{*}{104} & 4.31 & 49 & 4.34 & 12 & 4.30 & 56 & & & 4.32 & 11 & & & & & & & & & \\
\hline & 4.61 & 10 & & & & & & & & & & & & & & & & & \\
\hline \multirow[t]{4}{*}{113} & 5.08 & 154 & 5.10 & & 5.07 & 145 & 5.11 & 24 & 5.10 & 49 & 5.12 & 14 & & & & & & & \\
\hline & 5.21 & 9 & & & & & & & & & & & & & & & & & \\
\hline & 5.27 & 4 & & & & & & & 5.26 & 8 & & & & & & & & & \\
\hline & & & & & & & & & 5.32 & 2 & & & & & & & & & \\
\hline \multirow[t]{2}{*}{118} & 5.53 & 51 & 5.55 & 7 & 5.52 & 46 & 5.54 & 7 & 5.54 & 10 & & & & & & & & & \\
\hline & 5.65 & 2 & & & 5.64 & 5 & & & & & & & & & & & & & \\
\hline \multirow[t]{3}{*}{126} & 6.32 & 126 & 6.34 & 28 & 6.31 & 123 & 6.35 & 18 & 6.33 & 34 & 6.36 & 8 & & & & & & & \\
\hline & 6.52 & 14 & & & 6.51 & 12 & & & 6.52 & 2 & & & & & & & & & \\
\hline & & & & & 6.88 & 9 & & & & & & & & & & & & & \\
\hline & 7.20 & 12 & & & 7.19 & 14 & & & & & & & & & & & & & \\
\hline & 7.50 & 31 & 7.51 & 6 & 7.50 & 18 & 7.51 & 3 & & & & & & & & & & & \\
\hline & 7.79 & 11 & & & & & & & & & & & & & & & & & \\
\hline & 8.19 & 10 & & & & & & & & & & & & & & & & & \\
\hline & 8.61 & 13 & & & 8.60 & 16 & & & & & & & & & & & & & \\
\hline \multirow[t]{5}{*}{153} & 8.86 & 86 & 8.87 & 10 & 8.85 & 83 & 8.89 & 16 & 8.88 & 26 & 8.88 & 15 & & & & & & & \\
\hline & 8.99 & 21 & & & 8.99 & 25 & 9.01 & 5 & 9.00 & 14 & & & & & & & & & \\
\hline & 9.92 & 36 & & & 9.91 & 23 & & & & & & & & & & & & & \\
\hline & & & & & 10.01 & 13 & & & & & & & & & & & & & \\
\hline & 10.74 & 22 & & & 10.73 & 20 & & & 10.74 & 22 & & & & & & & & & \\
\hline
\end{tabular}

(continued...) 
TABLE C-2 (continued)

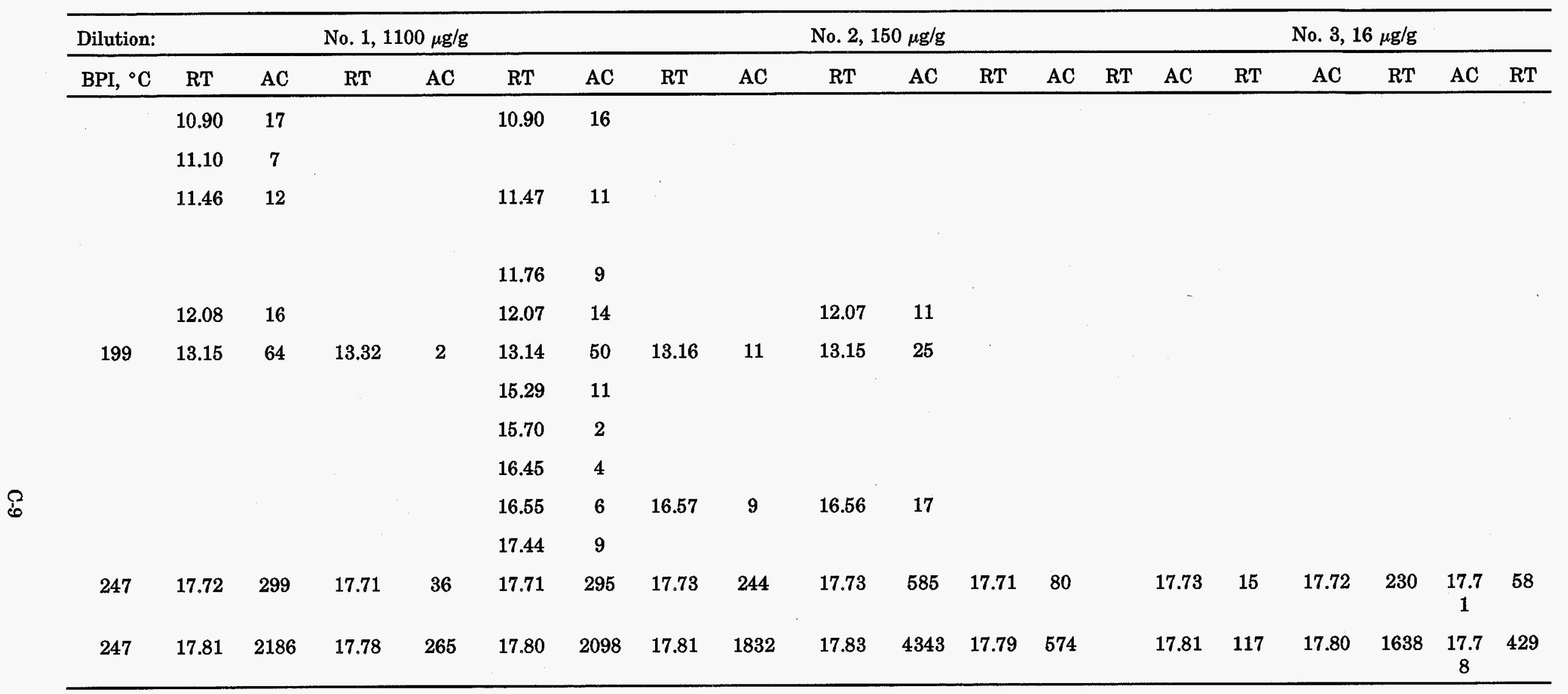

(continued...) 
APPENDIX D

CHLORINE CONCENTRATION DETERMINATION 


\section{CHLORINE CONCENTRATION DETERMINATION}

Chlorine from the decomposition of polyvinyl chloride (PVC) is removed from the overhead gas stream from the depolymerization reactor by fixation to $\mathrm{CaO}$. The following reaction exists in the $\mathrm{CaO}$ fixed-bed filter:

$$
\mathrm{nCaO}+m \mathrm{Cl}^{-} \rightarrow p \mathrm{CaCl}_{2}+(n-p) \mathrm{CaO}+(m-q) \mathrm{Cl}^{-}
$$

Because the $\mathrm{CaO}$ is not saturated, some $\mathrm{CaO}$ remains. The starting weight of $\mathrm{CaO}$ is known, as is the amount of chlorine introduced into the system and the final weight of material collected from the filter. Additionally, this final filter material will probably contain some condensed organics. To determine the efficiency of chlorine capture, a proximate analysis is first performed to determine the amount of volatile matter (condensed organics) on the filter material. Next, a calcium balance is performed. If this balance is satisfactory, the implication is that no $\mathrm{CaO}$ was lost (blown out of the fixed bed), and no sand from the depolymerization reactor was blown over into the fixed-bed filter. Since chlorine content is calculated as a percentage of the spent $\mathrm{CaO}$ filter material, a degree of validity is given to the chlorine content of the bed material.

The amount of calcium is known. The amount of chlorine (as ppm of the filter material) in the filter material is known, and is assumed to be exclusively in the form of $\mathrm{CaCl}_{2}$. The amount of $\mathrm{CaO}$ is the difference between the nonorganic filter material and the amount of $\mathrm{CaCl}_{2}$. These calculations are illustrated below, using M357 as an example.

Weight of Filter Material (measured) = 234 grams

Filter Material wt\% Ash (nonorganic material) $=95.12 \%$

Nonorganic Filter Material $\left(\mathrm{CaCl}_{2}+\mathrm{CaO}\right) 234 \times 95.12 \%=222.6$ grams

$\begin{array}{lr}\text { Cl Concentration in Filter Material } & =144,000 \text { ppm } \\ \text { Cl in Filter } \mathrm{Material} & 0.144 \times 234=33.7 \text { grams } \\ \text { Weight of } \mathrm{CaCl}_{2} & 52.96(33.7 / 35 / 2 \times 110) \\ \text { Weight of } \mathrm{CaO} & 169.64(222.6-52.96) \\ & \\ \text { Weight of } \mathrm{Ca} \text { in } \mathrm{CaCl}_{2} & 52.96 / 110 \times 40=19.3 \\ \text { Weight of } \mathrm{Ca} \text { in } \mathrm{CaO} & 169.6 / 56 \times 40=121.2 \\ \text { Total Ca in Filter Material } & 140.5 \text { grams }\end{array}$

Original Weight of Filter Material $=200$ grams

Weight of $\mathrm{Ca}$ in Starting $\mathrm{CaO} 200 / 56$ × $40=142.9$ grams

Ca Closure $140.5 / 142.9 \times 100 \%=98 \%$

Table D-1 below gives the proximate analysis results for Runs M357 through M364, and Table D-2 shows their calcium balances. It should be noted that the calcium content was not determined directly by analysis, but rather calculated indirectly. 
TABLE D-1

Proximate Analyses

\begin{tabular}{lccc}
\hline Run No. & Volatile Matter & Fixed Carbon & Ash \\
\hline M357 & 4.83 & 1.15 & 94.02 \\
M358 & 4.66 & 0.90 & 94.44 \\
M359 & 8.93 & 0.31 & 90.76 \\
M360 & 25.32 & 0.29 & 74.39 \\
M361 & 11.27 & 0.61 & 88.12 \\
M362 & 11.69 & 0.00 & 87.77 \\
M363 & 4.59 & 1.44 & 93.97 \\
M364 & 7.14 & 1.02 & 91.84 \\
\hline
\end{tabular}

TABLE D-2

Calcium Balances

\begin{tabular}{|c|c|c|c|c|c|c|c|c|}
\hline Run: & M357 & M358 & M359 & M360 & M361 & M362 & M363 & M364 \\
\hline Wt. of Filter Material & 234 & 614 & 487 & 553 & 539 & $535^{1}$ & 231 & 622 \\
\hline Wt\% Ash & 94.02 & 94.44 & 90.76 & 74.39 & 88.12 & 87.77 & 93.97 & 91.84 \\
\hline $\mathrm{CaCl}_{2}+\mathrm{CaO}, \mathrm{g}$ & 220.0 & 485.4 & 442.0 & 411.4 & 475.0 & 469.3 & 217.1 & 479.4 \\
\hline $\mathrm{Cl}, \mathrm{ppm}$ & 144,000 & 148,000 & 89,700 & 63,400 & 117,000 & 119,000 & 239,000 & 147,000 \\
\hline Cl out, $\mathrm{g}$ & 33.7 & 76.1 & 40.8 & 35.1 & 63.1 & 55.8 & 55.2 & 76.7 \\
\hline $\mathrm{CaCl}_{2}$ out, $\mathrm{g}$ & 63.0 & 119.6 & 64.1 & 55.2 & 99.2 & 87.8 & 86.7 & 120.6 \\
\hline $\mathrm{CaO}$ out, $\mathrm{g}$ & 121.2 & 365.8 & 377.9 & 356.2 & 375.8 & 381.5 & 130.4 & 358.9 \\
\hline $\mathrm{Ca}$ from $\mathrm{CaCl}_{2}, \mathrm{~g}$ & 19.3 & 43.5 & 28.3 & 20.1 & 36.1 & 31.8 & 31.5 & 43.8 \\
\hline $\mathrm{Ca}$ from $\mathrm{CaO}, \mathrm{g}$ & 121.2 & 261.3 & 269.9 & 254.4 & 268.4 & 272.5 & 93.1 & 256.4 \\
\hline Ca out, $\mathrm{g}$ & 140.5 & 304.8 & 293.2 & 274.5 & 304.5 & 304.3 & 124.6 & 300.2 \\
\hline Initial Filter Wt., g & 200 & 463 & 426 & 426 & 456 & 426 & 184 & 458.0 \\
\hline $\mathrm{Ca}$ in, $\mathrm{g}$ & 142.9 & 323.6 & 304.3 & 304.3 & 325.7 & 304.3 & 131.4 & 327.0 \\
\hline Ca closure, \% & 98 & 94 & 96 & 90 & 93 & $100^{1}$ & 95 & 92 \\
\hline $\mathrm{Cl}$ Capture by $\mathrm{CaO}$, & 83 & 93 & 107 & 43 & 103 & 91 & 90 & 94 \\
\hline
\end{tabular}

${ }^{1}$ No weight for spent-bed material was available, so the calcium balance was forced to $100 \%$, and a bed weight calculated. 


\section{THERMAL DEPOLYMERIZATION OF POSTCONSUMER PLASTICS}




\section{TABLE OF CONTENTS}

LIST OF FIGURES $\ldots \ldots \ldots \ldots \ldots \ldots \ldots \ldots \ldots \ldots \ldots \ldots \ldots \ldots$

LIST OF TABLES $\ldots \ldots \ldots \ldots \ldots \ldots \ldots \ldots \ldots \ldots \ldots \ldots \ldots \ldots \ldots \ldots$

EXECUTIVE SUMMARY $\ldots \ldots \ldots \ldots \ldots \ldots \ldots \ldots \ldots \ldots \ldots \ldots$

1.0 INTRODUCTION $\ldots \ldots \ldots \ldots \ldots \ldots \ldots \ldots \ldots \ldots \ldots \ldots \ldots \ldots \ldots \ldots$

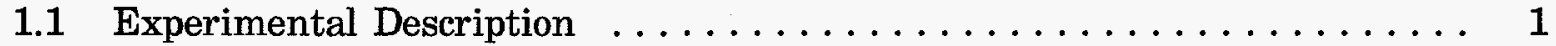

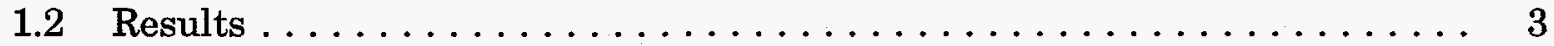

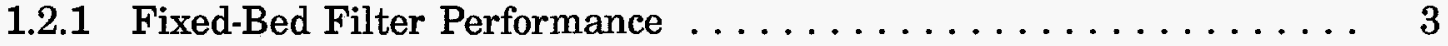

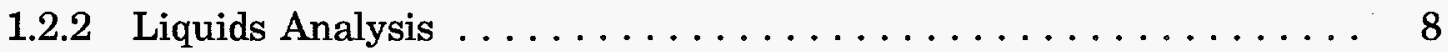

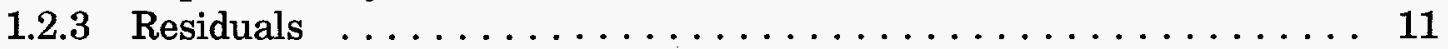

2.0 CONCLUSIONS $\ldots \ldots \ldots \ldots \ldots \ldots \ldots \ldots \ldots \ldots \ldots \ldots \ldots \ldots$

$3.0 \quad$ REFERENCES $\ldots \ldots \ldots \ldots \ldots \ldots \ldots \ldots \ldots \ldots \ldots \ldots \ldots \ldots \ldots$

\section{LIST OF FIGURES}

1 TGA proximate analyses from filter sections of $\mathrm{M} 367$ and $\mathrm{M} 368 \ldots \ldots 7$

2 Simulated boiling point distribution comparison for M367 . . . . . . . . . 10

3 Simulated boiling point distribution comparison for M368 . . . . . . . . 10 


\section{LIST OF TABLES}

1 Proximate Analysis for Postconsumer Plastics Stream $\ldots \ldots \ldots \ldots \ldots \ldots$

2 XRF Analysis of Equilibrium Cat Cracker Catalyst $\ldots \ldots \ldots \ldots \ldots$

3 Postconsumer Plastics Test Conditions $\ldots \ldots \ldots \ldots \ldots \ldots \ldots \ldots$

4 Filter Sections Proximate Analyses $\ldots \ldots \ldots \ldots \ldots \ldots \ldots \ldots \ldots$

$5 \quad$ Filter Sections Carbonate Analyses $\ldots \ldots \ldots \ldots \ldots \ldots \ldots \ldots \ldots \ldots$

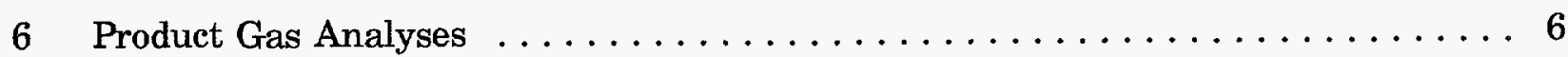

7 Filter Sections Chlorine Concentration $\ldots \ldots \ldots \ldots \ldots \ldots \ldots \ldots$

8 M367 and M368 Product Liquids Chlorine Concentrations . . . . . . . . . 9

9 M368 Product Liquids Characterization . . . . . . . . . . . . . . 9

10 PIANO Analysis of M368 Decomposition Liquids $\ldots \ldots \ldots \ldots \ldots \ldots \ldots$

11 Metals Analysis $\ldots \ldots \ldots \ldots \ldots \ldots \ldots \ldots \ldots \ldots \ldots \ldots \ldots$

$12 \mathrm{M} 368 \mathrm{Bed}$ Material TCLP $\ldots \ldots \ldots \ldots \ldots \ldots \ldots \ldots \ldots \ldots \ldots$

13 Proximate Analysis of M368 Bed Material . . . . . . . . . . . . . 12 


\section{EXECUTIVE SUMMARY}

After successful completion of the $\mathrm{CaO}$ fixed-bed tests with PP and PVC, similar tests were performed using a postconsumer plastics (PCP) stream to demonstrate the ability to process $\mathrm{PCP}$ and to evaluate chlorine capture efficiency of $\mathrm{CaO}$ with this type of feed material. Chlorine capture from postconsumer streams is complicated by the presence of water, $\mathrm{CO}_{2}$, metals, and organic acids, which can block sites used for chlorine fixation, and by particulates (carbon) produced from the decomposition of polyethylene terephthalate (PET). While chlorine removal remains a primary concern for a thermal depolymerization process, metals content of the product liquids and leachability of the bed material also need to be addressed. The process of acquiring product acceptability will need to begin with characterization of these products in terms familiar to end-users. For the product liquids, these specifications will include metals content and relevant characterizations. For example, some process conditions produce a liquid that is similar in boiling point distribution to a gasoline. For these liquids, a boiling point distribution, specific gravity, octane number, and PIANO (paraffins, isoparaffins, aromatics, naphthenes, and olefins) analyses might be appropriate. For liquids which resemble a gas oil, a MAT (microactivity) test might be appropriate.

Thermal depolymerization of postconsumer plastics proved to be generally more difficult than when using virgin resins as feed materials. The first attempts at processing the postconsumer blend were unsuccessful, so the postconsumer plastic feed material was blended with HDPE and PP resin. The most likely explanation for the difficulty in processing this material was the high content of PET. Previous attempts to process PET alone or in high concentrations with other polymers (1) also proved difficult. The issue of PET decomposition will need further scrutiny. However, using the postconsumer plastics material mixed with HDPE and PP, the tests were completed. In addition to the addition of polyolefin resin, PVC was added to the postconsumer material to bring chlorine levels up to a range expected in typical postconsumer streams. Total chlorine analysis of the raw postconsumer material showed that it contained negligible levels of chlorine, indicating PVC had been sorted from the stream.

Tests were completed using postconsumer plastics at temperatures of $440^{\circ}$ and $540^{\circ} \mathrm{C}$. In addition to dilution with HDPE and PP, because of the high concentration of PET, steam was added, affecting a de-esterification reaction. Results of the tests indicate a good quality liquid is produced at both temperatures; the liquid product from the $540^{\circ} \mathrm{C}$ test is similar to a gasoline or naphtha fraction (with $80 \%$ boiling below $235^{\circ} \mathrm{C}$ ) and that produced at $440^{\circ} \mathrm{C}$ is slightly lower in boiling point distribution to a diesel fuel. A PIANO analysis of the liquid produced at $540^{\circ} \mathrm{C}$, based on gas chromatography-flame ionization detection (GC-FID) results, revealed that this product is more aromatic than that of a cut of similar boiling point distribution from a petroleum refinery. Organic acids (probably terephthalic and benzoic) and acetophenone were some of the components identified as unique to liquids produced from postconsumer plastics.

In situ chlorine removal is not as efficient with the PCP as with pure polymers. Using virgin resin, in situ chlorine removal using $\mathrm{CaO}$ produced $<100$ to $500 \mathrm{ppm}$ chlorine in the product liquids (1). Similar conditions with postconsumer plastics yielded approximately $4000 \mathrm{ppm}$ chlorine in the product liquids. Postreactor chlorine removal in the fixed-bed unit produced chlorine levels in the product liquids comparable to those observed when processing pure polymers (PP/PVC) using $\mathrm{CaO}$ for in-bed capture. When 
processing postconsumer plastics, sorbent chemistry is complicated by the presence of water, $\mathrm{CO}_{2}$, and metals. Although organic acid fragments and carbon were speculated to be troublesome, they were not. It was determined that, because of the presence of $\mathrm{CO}_{2}$ from PET decomposition, calcium oxide is converted to calcium carbonate. Calcium carbonate is not effective for chlorine capture at the temperatures of interest (1). In the $440^{\circ} \mathrm{C}$ test, when minimal $\mathrm{CO}_{2}$ was produced, about $15 \%$ of the filter was $\mathrm{CO}_{2}$ (calcium was associated as carbonate). About $20 \%$ of the filter material occurred as $\mathrm{Ca}(\mathrm{OH})_{2}$. In the $540^{\circ} \mathrm{C}$ test, about $30 \%$ of the filter material was $\mathrm{CO}_{2}$, and no $\mathrm{Ca}(\mathrm{OH})_{2}$ was detected. These results suggest that when significant levels of PET are present in the feed material, a thermal depolymerization process will need to be carried out at low enough temperatures to minimize $\mathrm{CO}_{2}$ production, or alternatively, the sorbent regeneration rate will be fairly high.

A characterization of the residuals (spent bed material) from the tests was performed and showed higher than acceptable levels of several RCRA metals, although it is unclear whether these came from the starting bed material or from the postconsumer plastics. The difficulties experienced in the early tries with the postconsumer blend prompted use of a $\mathrm{CaO}$ /equilibrium cat cracker catalyst bed. Earlier work had shown some success with a cat cracker catalyst bed when PET was present (1). The equilibrium cat cracker catalyst, however, may have contained higher concentrations of metals than anticipated. This material was not analyzed alone, so it is unknown what contribution was made to the metals content of the products by the cat cracker catalyst. In future tests, if such bed materials are chosen, these materials will be analyzed beforehand to ensure that these substances are not introduced into the system by the choice of bed material. 


\section{THERMAL DEPOLYMERIZATION OF POSTCONSUMER PLASTICS}

\subsection{INTRODUCTION}

The fixed-bed concept, discussed in Section 1.0, Vol. I, of this report, proved to be successful when used with a PP/PVC feedstock. Postconsumer material presents a more complex situation than PP/PVC. Some postconsumer streams will be high in PET. Decomposition of PET produces $\mathrm{CO}_{2}$. A possibility exists for this $\mathrm{CO}_{2}$ to combine with the $\mathrm{CaO}$ to form $\mathrm{CaCO}_{3} \cdot \mathrm{CaCO}_{3}$ has been shown to be ineffective in chlorine capture at the temperatures of interest (1). Additionally, decomposition products of PET may contain some acid groups which could react with the $\mathrm{CaO}$, also blocking sights for chlorine capture. Metals, present in postconsumer plastic streams, have the potential to interfere with sorbent performance. Lastly, if sufficient carbon or other small solid materials are carried over into the fixed bed, large pressure drops may be created or the filter plugged off entirely.

In order to evaluate chlorine capture by $\mathrm{CaO}$ with a postconsumer blend, $\mathrm{CaO}$ was used as a bed material in the fluid-bed reactor using postconsumer plastics tests. Additionally, the fixed-bed filter was used on one of the condensation trains. Liquids were collected both before and after the fixed bed. After each test, liquid products were analyzed for total and organic chlorine levels, and a proximate analysis was performed on the filter material to determine moisture, volatile matter, fixed carbon, and ash content. Chlorine and carbonate analyses were also performed on the filter material.

The primary purpose of this set of tests was to demonstrate the ability to process postconsumer material successfully. Secondary concerns included the production of liquids for evaluation and characterization in terms of refinery standards, evaluation of previously demonstrated chlorine removal techniques (in situ and fixed bed) on postconsumer plastics, and a preliminary look at the metals content of the product liquids and bed material.

\subsection{Experimental Description}

Four runs were attempted in the CFBR using a postconsumer plastics/PP/HDPE/PVC mix. A rough approximation for this stream is $49 \% \mathrm{HDPE}, 21 \%$ $\mathrm{PP}, 24 \% \mathrm{PET}$, and 6\% PVC. A proximate analysis for this same stream is given in Table 1. Table 2 gives an XRF analysis of the equilibrium cat cracker catalyst and $\mathrm{CaO}$ blended for use as a bed material. $\mathrm{CaO}$ alone was used in the postreactor fixed bed.

A total chlorine analysis indicates a chlorine level of approximately $6000 \mathrm{ppm}$ in the starting postconsumer plastics material. To arrive at this figure, two samples were randomly taken from a representative feed sample and analyzed. Chlorine concentrations for the two samples were 4000 and $8000 \mathrm{ppm}$. These two numbers were averaged to arrive at the $6000 \mathrm{ppm}$ figure. For a more representative analysis, it is suggested that a sample of the feed material be melted, stirred, and very quickly cooled. This cooled sample could then be analyzed several times until a consistent number could be obtained. The figure of $6000 \mathrm{ppm}$ is an adequate estimate for our purposes in these tests. 
Postconsumer plastics were processed at the conditions listed in Table 3. Reactor temperature refers to the temperature of the fluid-bed reactor (thermal depolymerization temperature); filter temperature refers to the temperature of the fixed-bed filter located after the cyclone; and the $\mathrm{Ca} / \mathrm{Cl}$ ratio is a molar ratio of calcium (from $\mathrm{CaO}$ ) to chlorine in the feed material.

TABLE 1

Proximate Analysis ${ }^{a}$ for Postconsumer Plastics Stream

\begin{tabular}{lcc}
\hline Proximate, wt\% & As-Rec'd & Moisture-Free \\
\hline Moisture & 0.50 & N/A \\
Volatile Matter & 94.72 & 95.22 \\
Fixed Carbon & 3.93 & 3.93 \\
Ash & 0.85 & 0.85 \\
\hline
\end{tabular}

${ }^{\text {a }}$ ASTM method D-3172-89.

TABLE 2

XRF Analysis of Equilibrium Cat Cracker Catalyst ${ }^{\text {a }}$

\begin{tabular}{ccc}
\hline Oxides, wt\% & Equilibrium Cat Cracker Catalyst & $\mathrm{CaO}$ \\
\hline $\mathrm{SiO}_{2}$ & 65.96 & 0.47 \\
$\mathrm{Al}_{2} \mathrm{O}_{3}$ & 26.14 & 0.13 \\
$\mathrm{Fe}_{2} \mathrm{O}_{3}$ & 0.00 & 0.17 \\
$\mathrm{TiO}_{2}$ & 0.00 & 0.00 \\
$\mathrm{P}_{2} \mathrm{O}_{5}$ & 0.55 & 0.00 \\
$\mathrm{CaO}$ & 0.99 & $97.79^{\mathrm{a}}$ \\
$\mathrm{MgO}$ & 1.98 & 1.12 \\
$\mathrm{Na}_{2} \mathrm{O}$ & 2.97 & 0.05 \\
$\mathrm{~K}_{2} \mathrm{O}$ & 1.41 & 0.28 \\
Total & 100.00 & 100.00
\end{tabular}

${ }^{a} \mathrm{XRF}$ does not distinguish between $\mathrm{CaO}$ and $\mathrm{CaCO}_{3}$. 
TABLE 3

Postconsumer Plastics Test Conditions

\begin{tabular}{|c|c|c|c|c|}
\hline & M365 & M366 & M367 & M368 \\
\hline Reactor Temperature, ${ }^{\circ} \mathrm{C}$ & 440 & 440 & 440 & 540 \\
\hline System Pressure, psig & 10 & 10 & 10 & 10 \\
\hline Feed Material Mix & $\mathrm{PCP}^{\mathrm{a}} / \mathrm{PVC}$ & $\begin{array}{l}\mathrm{PCP} / \mathrm{PVC} / \\
\mathrm{HDPE}\end{array}$ & $\begin{array}{l}\mathrm{PCP} / \mathrm{PVC} / \\
\mathrm{HDPE}\end{array}$ & $\begin{array}{l}\text { PCP/PVC/ } \\
\text { HDPE }\end{array}$ \\
\hline Feed Rate & 2.0 & 2.0 & 1.3 & 1.3 \\
\hline Reactor Bed Material & $\begin{array}{l}\mathrm{CaO} / \text { cat } \\
\text { cracker } \\
\text { catalyst }^{\mathrm{b}}\end{array}$ & $\begin{array}{l}\mathrm{CaO} / \text { cat } \\
\text { cracker } \\
\text { catalyst }\end{array}$ & $\begin{array}{l}\mathrm{CaO} / \text { cat } \\
\text { cracker } \\
\text { catalyst }\end{array}$ & $\begin{array}{l}\mathrm{CaO} / \text { cat } \\
\text { cracker } \\
\text { catalyst }\end{array}$ \\
\hline Duration of Test, $\mathrm{hr}$ & -.- & -- & 6.0 & 6.5 \\
\hline Filter Bed Material & $\mathrm{CaO}$ & $\mathrm{CaO}$ & $\mathrm{CaO}$ & $\mathrm{CaO}$ \\
\hline Filter Bed Material Size & $\begin{array}{l}-1 / 4+12 \\
\text { mesh }\end{array}$ & $\begin{array}{l}-1 / 4+12 \\
\text { mesh }\end{array}$ & $\begin{array}{c}-1 / 4+ \\
12 \text { mesh }\end{array}$ & $\begin{array}{l}-1 / 4+ \\
12 \text { mesh }\end{array}$ \\
\hline $\mathrm{Ca} / \mathrm{Cl}$ Ratio & $4 / 1$ & $5 / 1$ & $5 / 1$ & $5 / 1$ \\
\hline Filter Temperature, ${ }^{\circ} \mathrm{C}$ & 440 & 440 & 440 & 540 \\
\hline Initial Filter Weight, Grams & -- & 382.8 & 421.2 & 367.5 \\
\hline
\end{tabular}

\subsection{Results}

\subsubsection{Fixed-Bed Filter Performance}

$\mathrm{CaO}$ was used in the fixed-bed cartridge to evaluate the ability to capture chlorine during the thermal depolymerization of postconsumer plastics. The cartridge, described in Section 3.0, Vol. I, is divided into 4 sections. These sections are divided by a stainless screen. The filter was divided into sections to facilitate the evaluation of filter performance. Proximate and carbonate analyses for the filter sections of Tests M367 and M368 are shown in Tables 4 and 5. As seen in Table 4, fixed carbon is a very small portion of the filter material. The ash content is assumed to be essentially all $\mathrm{CaO}$, although very small quantities of ash are found in the feed material (approximately $0.85 \%$ of the postconsumer plastics). Both M367 and M368 have high volatile contents compared with the PP/PVC tests (Table D-1). Filter sections from M367, the test at $440^{\circ} \mathrm{C}$, have about half of their volatile contents resulting from $\mathrm{CO}_{2}$, while the sections from the $540^{\circ} \mathrm{C}$ test (M368) have almost all their volatile content resulting from $\mathrm{CO}_{2}$. The remaining volatile content from M367 was initially thought to be either condensed organics or organic acid groups which attached to the $\mathrm{CaO}$. To determine what the remaining volatile matter was, a test similar to the carbonate analysis was performed. In the carbonate analysis, acid $(\mathrm{KOH})$ is added to the material to be tested and the mixture heated to evolve $\mathrm{CO}_{2}$. The $\mathrm{CO}_{2}$ is absorbed and measured. Results showed that no organic acid existed on the filter material. Examination of the gas analyses from M367 
and M368 (Table 6) show that the partial pressure of $\mathrm{CO}_{2}$ in the product gas stream (before the fixed-bed filter) is higher in M368 than in M367. It was then hypothesized that the volatile matter observed in the proximate analysis might be $\mathrm{Ca}(\mathrm{OH})_{2}$ in the $440^{\circ} \mathrm{C}$ test and $\mathrm{CaCO}_{3}$ for the $540^{\circ} \mathrm{C}$ test, since both water vapor and $\mathrm{CO}_{2}$ are present. Water is not given off from $\mathrm{Ca}(\mathrm{OH})_{2}$ until about $580^{\circ} \mathrm{C}(1)$. The following reactions are thought to be occurring in the filter:

$$
\begin{aligned}
& \text { (1) } \mathrm{CaO}+\mathrm{H}_{2} \mathrm{O} \rightarrow \mathrm{Ca}(\mathrm{OH})_{2} \\
& \text { (2) } \mathrm{CaO}+\mathrm{CO}_{2} \rightarrow \mathrm{CaCO}_{3}
\end{aligned}
$$

In the higher temperature $\left(540^{\circ} \mathrm{C}\right)$ test, more $\mathrm{CO}_{2}$ is present, and Reaction 2 is predominant. In the lower temperature test $\left(440^{\circ} \mathrm{C}\right)$, with the lower $\mathrm{CO}_{2}$ vapor pressure, Reaction 1 also occurs. This is shown graphically in Figure 1, which shows the TGA proximate analyses of the filter sections from M367 and M368. Volatile evolution from the four sections of $\mathrm{M} 368$ occurs after about $850^{\circ} \mathrm{C}$, indicating that the volatile evolution is due to $\mathrm{CO}_{2}$. Volatile evolution from M367 occurs at two temperatures. The first is at about the temperature of Reaction $1,580^{\circ} \mathrm{C}$, and the second at about the temperature of Reaction 2, approximately $850^{\circ} \mathrm{C}$. In Run M367, about twice as much volatile content was evolved due to $\mathrm{CO}_{2}$ as was evolved from $\mathrm{H}_{2} \mathrm{O}$. This agrees with the results of the $\mathrm{CO}_{2}$ tests shown in Table 5.

Table 7 shows the chlorine concentration for each of the filter sections from M367 and M368. Chlorine concentration decreases approximately 76\% from Section 1 to 4 (entrance to exit) for M367. Volatile and carbonate content do not vary significantly from section to section. By contrast, chlorine concentration decreased only $42 \%$ from Section 1 to 4 for M368. As with M367, volatile and carbonate contents of the filter sections do not vary significantly. Chlorine concentration in all sections for M368 was much lower than for M367. One possible cause for this is the higher carbonate content of the filter sections of M368 (31\%) compared to M367 (16\%).

TABLE 4

\begin{tabular}{|c|c|c|c|c|}
\hline & Section 1 & Section 2 & Section 3 & Section 4 \\
\hline \multicolumn{5}{|l|}{ M367 } \\
\hline Moisture & 0.20 & 0.20 & 0.10 & 0.10 \\
\hline Volatile Matter & 35.65 & 36.84 & 36.97 & 36.36 \\
\hline Fixed Carbon & 0.44 & 0.00 & 0.00 & 0.04 \\
\hline Ash & 63.71 & 62.99 & 62.95 & 63.50 \\
\hline \multicolumn{5}{|l|}{ M368 } \\
\hline Moisture & 0.20 & 0.20 & 0.10 & 0.10 \\
\hline Volatile Matter & 34.83 & 30.88 & 33.63 & 32.10 \\
\hline Fixed Carbon & 0.15 & 0.00 & 0.10 & 0.02 \\
\hline Ash & 64.82 & 68.95 & 66.17 & 67.78 \\
\hline
\end{tabular}

Filter Sections Proximate ${ }^{\mathrm{a}}$ Analyses, wt\%

a As-received basis. 
TABLE 5

Filter Sections Carbonate Analyses ${ }^{\mathrm{a}}$

\begin{tabular}{|c|c|}
\hline & $\mathrm{wt} \% \mathrm{CO}_{2}$ \\
\hline Starting $\mathrm{CaO}^{\mathrm{b}}$ & $4.02 \%$ \\
\hline \multicolumn{2}{|l|}{ M367 } \\
\hline Section 1 & 12.45 \\
\hline Section 2 & 17.48 \\
\hline Section 3 & 19.66 \\
\hline Section 4 & 15.86 \\
\hline \multicolumn{2}{|l|}{ M368: } \\
\hline Section 1 & 33.26 \\
\hline Section 2 & 29.16 \\
\hline Section 3 & 31.80 \\
\hline Section 4 & 31.26 \\
\hline
\end{tabular}

a Determined by ASTM D1756-89, "Standard Test for Carbon Dioxide in Coal."

b $1 / 4$ " $\times 20 \mathrm{~m} \mathrm{CaO}$ from the American Crystal Sugar plant in Grand Forks. 
TABLE 6

Product Gas Analyses

\begin{tabular}{|c|c|c|c|c|}
\hline & $\begin{array}{c}\text { M367 } \\
\text { Prefilter }\end{array}$ & $\begin{array}{c}\text { M367 } \\
\text { Postfilter }\end{array}$ & $\begin{array}{l}\text { M368 } \\
\text { Prefilter }\end{array}$ & $\begin{array}{c}\text { M368 } \\
\text { Postfilter }\end{array}$ \\
\hline $\mathrm{H}_{2}$ & 0.31 & 0.34 & 2.58 & 1.41 \\
\hline $\mathrm{CO}_{2}$ & 0.37 & & & 1.99 \\
\hline $\mathrm{C}_{3} \mathrm{H}_{8}$ & 0.06 & 0.09 & 0.38 & 0.45 \\
\hline $\mathrm{C}_{3}=$ & 0.25 & 0.25 & 1.66 & 1.43 \\
\hline iso- $\mathrm{C}_{4} \mathrm{H}_{10}$ & 0.03 & 0.04 & 0.13 & 0.11 \\
\hline Unidentified & 0.12 & 0.12 & 0.60 & 0.47 \\
\hline$n-\mathrm{C}_{4} \mathrm{H}_{10}$ & 0.05 & 0.05 & 0.19 & 0.17 \\
\hline $\mathrm{H}_{2} \mathrm{~S}$ & & & 0.05 & \\
\hline $1-\mathrm{C}_{4} \mathrm{H}_{8}$ & 0.04 & 0.04 & 0.27 & 0.22 \\
\hline$t-2-\mathrm{C}_{4} \mathrm{H}_{8}$ & 0.04 & 0.04 & 0.25 & 0.18 \\
\hline iso- $\mathrm{C}_{5} \mathrm{H}_{12}$ & 0.02 & 0.02 & 0.06 & 0.03 \\
\hline c- $2-\mathrm{C}_{4} \mathrm{H}_{8}$ & 0.03 & 0.03 & 0.18 & 0.13 \\
\hline$n-\mathrm{C}_{5} \mathrm{H}_{12}$ & 0.20 & 0.18 & 0.30 & 0.36 \\
\hline $\mathrm{C}_{2}=$ & 0.15 & 0.16 & 0.98 & 0.92 \\
\hline $\mathrm{C}_{2} \mathrm{H}_{6}$ & 0.13 & 0.12 & 0.90 & 0.97 \\
\hline $\mathrm{O}_{2}$ & 0.18 & 0.10 & 0.12 & 0.12 \\
\hline $\mathrm{N}_{2}$ & 94.74 & 94.83 & 85.49 & 85.36 \\
\hline $\mathrm{CH}_{4}$ & 0.19 & 0.21 & 1.99 & 1.66 \\
\hline $\mathrm{CO}$ & 0.11 & 0.13 & 0.38 & 0.28 \\
\hline \multicolumn{5}{|l|}{ Calc. Btu/scf } \\
\hline Sat. & 30.6 & 31.3 & 160.3 & 143.8 \\
\hline Dry & 31.2 & 31.9 & 163.1 & 146.4 \\
\hline Calc. Sp. Gr. & 0.973 & 0.970 & 0.962 & 0.984 \\
\hline Calc. Av. Mol. Wt. & 28.18 & 28.10 & 27.86 & 28.49 \\
\hline
\end{tabular}




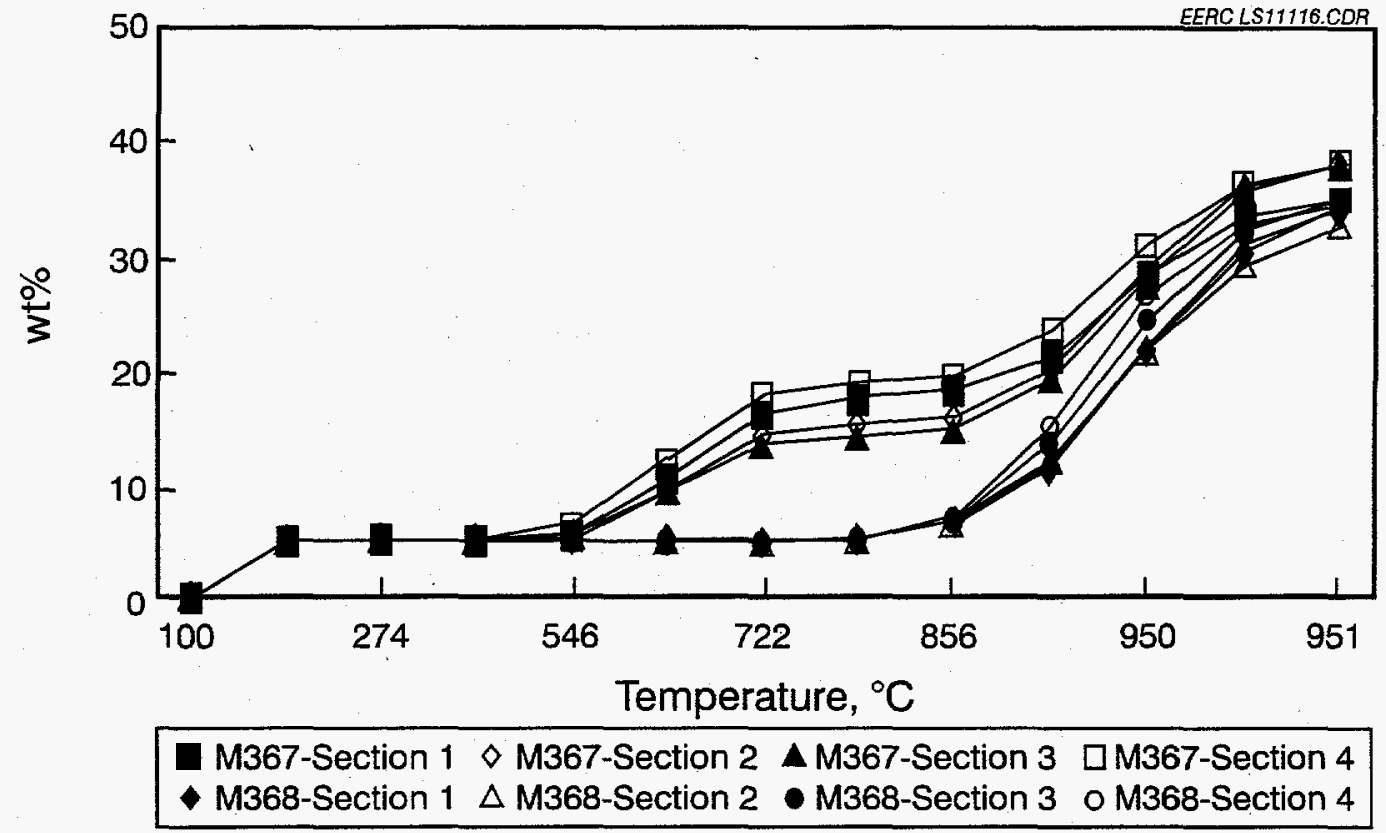

Figure 1. TGA proximate analyses from filter sections of M367 and M368.

TABLE 7

Filter Sections Chlorine Concentration

\begin{tabular}{lc}
\hline & Total Chlorine, ppm \\
\hline M367 & 100,000 \\
Section 1 & 52,000 \\
Section 2 & 37,000 \\
Section 3 & 24,000 \\
Section 4 & Unavailable \\
Bed Material & \\
M368 & 19,000 \\
Section 1 & 16,000 \\
Section 2 & 12,000 \\
Section 3 & 11,000 \\
Section 4 & 70,000 \\
Bed Material &
\end{tabular}

${ }^{a}$ Bed material from fluid-bed reactor. 


\subsubsection{Liquids Analysis}

Product liquids from M367 and M368 were collected both prior to the fixed-bed filter and after passing through the fixed-bed filter. Total and organic chlorine levels for these liquids are shown in Table 8 . As seen in Table 8, similar chlorine levels are achieved in liquids produced at $440^{\circ} \mathrm{C}$ and $540^{\circ} \mathrm{C}$, both with and without a postreactor sorbent. While a full chlorine balance was not performed, some information on the distribution is given in Table 8. While both product liquids (M367 and M368) showed similar chlorine concentrations, a much different distribution is seen for chlorine in the fixed-bed filter. Fixed-bed filter chlorine levels for M367 are much higher than for M368. The explanation for this might be that in the $440^{\circ} \mathrm{C}$ test, where only about $15 \%$ of the $\mathrm{CaO}$ is converted to $\mathrm{CaCO}_{3}$, a higher percentage of the chlorine is captured as $\mathrm{CaCl}_{2}$. In the $540^{\circ} \mathrm{C}$ test, about $35 \%$ of the $\mathrm{CaO}$ is converted to $\mathrm{CaCO}_{3}$. Earlier tests (M357-M364 Section 4.0, Vol. I) indicate that the higher the depolymerization temperature, the greater the amount of chlorine associated with the product liquids (as opposed to associating with the gas stream as $\mathrm{HCl})$.

All liquids have organically associated chlorine levels below detection limits. Appendix $\mathrm{C}$ of Vol. I details a detection limit and quality control study for the GC/AED technique used in organic chlorine determination performed at the EERC as a part of this contract.

Characteristics of the liquids from Run M368 are shown in Table 9. A simulated boiling point distribution, shown along with distributions for several common fuels in Figure 2, shows the liquids are similar in boiling point distribution to a naphtha fraction. Figure 3 shows the simulated boiling point distribution of the liquids resulting from the test at $440^{\circ} \mathrm{C}$, along with some common fuels for comparison. Table 10 gives a PIANO analysis for the M368 liquids, based on GC-FID information. Most notable is the high aromatic content and the presence of organic acids and acetophenone. The organic acid concentration is low, as these materials do not chromatograph very well. It is speculated that the organic acids observed consist mainly of terephthalic and benzoic acid, since these substances are potential products of PET decomposition.

Liquids produced in M368 were analyzed for several metals. These results are given in Table 11, along with an analysis of the plastics feed and bed material makeup for these same metals. It should be noted that the bed material makeup was a CaO/equilibrium cat cracker catalyst mix, used to ease processing of the high-PET plastic feed. The equilibrium cat cracker catalyst will likely contain quantities of metals and may not be the best choice for bed material. The cat cracker catalyst was not analyzed alone for these metals. 
TABLE 8

M367 and M368 Product Liquids Chlorine Concentrations

\begin{tabular}{|c|c|c|}
\hline & Total Chlorine, ppm & Organic Chlorine, ppm \\
\hline \multicolumn{3}{|l|}{ M367 } \\
\hline Unfiltered & 400 & $\mathrm{ND}^{\mathrm{a}}$ \\
\hline Filtered & 160 & ND \\
\hline \multicolumn{3}{|l|}{ M368 } \\
\hline Unfiltered & 3600 & ND \\
\hline Filtered & 120 & ND \\
\hline
\end{tabular}

a Not detected.

TABLE 9

M368 Product Liquids Characterization

\begin{tabular}{|c|c|}
\hline Sp. Gr. $\left(60 / 60^{\circ} \mathrm{F}\right)$ & 0.8194 \\
\hline API Gravity & 41.19 \\
\hline Density & $6.8224 \mathrm{lb} / \mathrm{gal}$ \\
\hline \multicolumn{2}{|l|}{ Simulated Distillation Data } \\
\hline Boiling Point Index, ${ }^{\circ} \mathrm{F}\left({ }^{\circ} \mathrm{C}\right)$ & Cumulative wt\% Distilled \\
\hline $81(27)$ & IBP \\
\hline $176(80)$ & 5 \\
\hline $201(94)$ & 10 \\
\hline $252(122)$ & 20 \\
\hline $280(138)$ & 30 \\
\hline $293(145)$ & 40 \\
\hline 328 (164) & 50 \\
\hline 369 (187) & 60 \\
\hline $396(202)$ & 70 \\
\hline $455(235)$ & 80 \\
\hline $563(295)$ & 90 \\
\hline $671(355)$ & 95 \\
\hline $910(488)$ & 100 \\
\hline
\end{tabular}




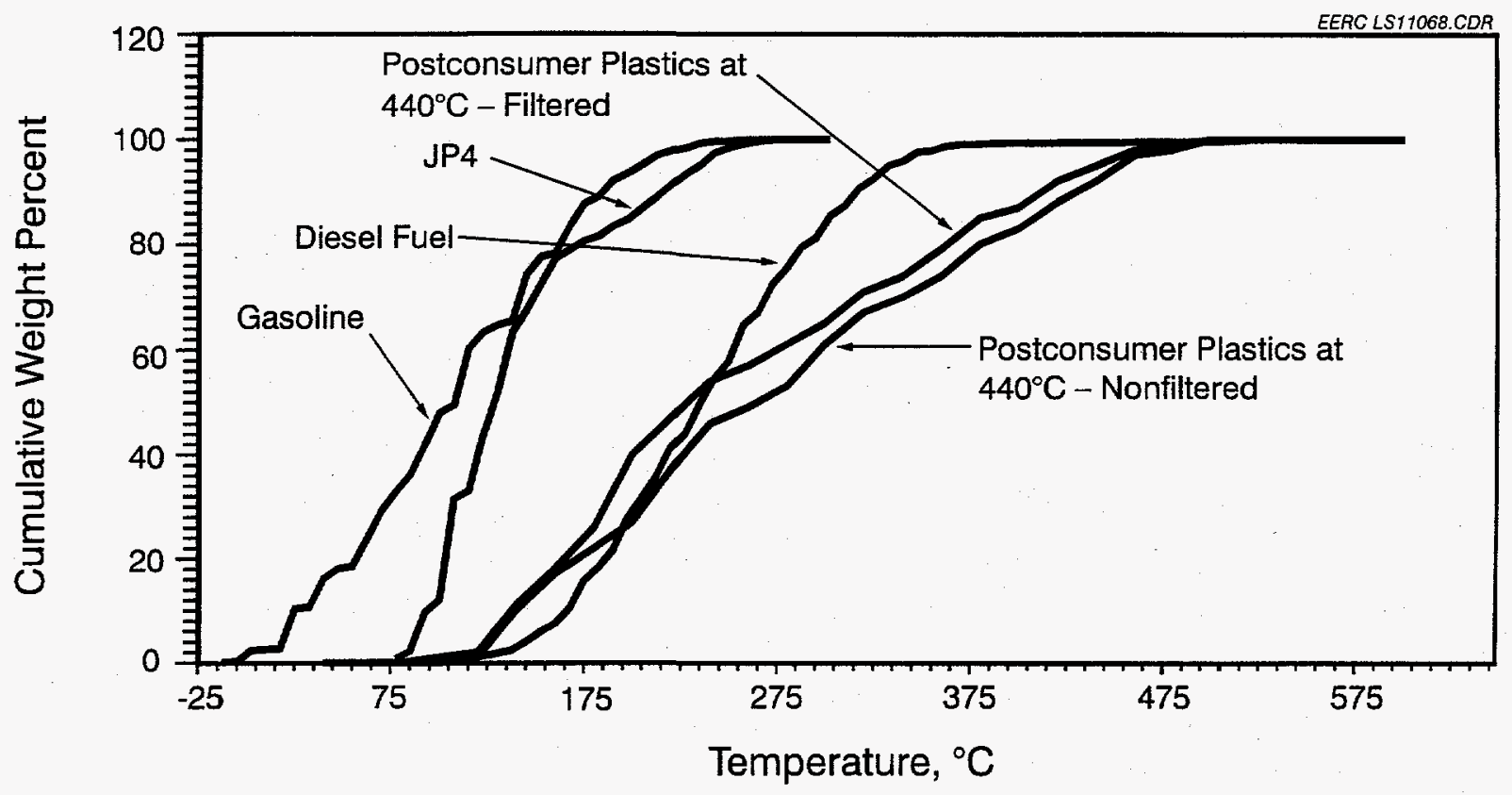

Figure 2. Simulated boiling point distribution comparison for M367.

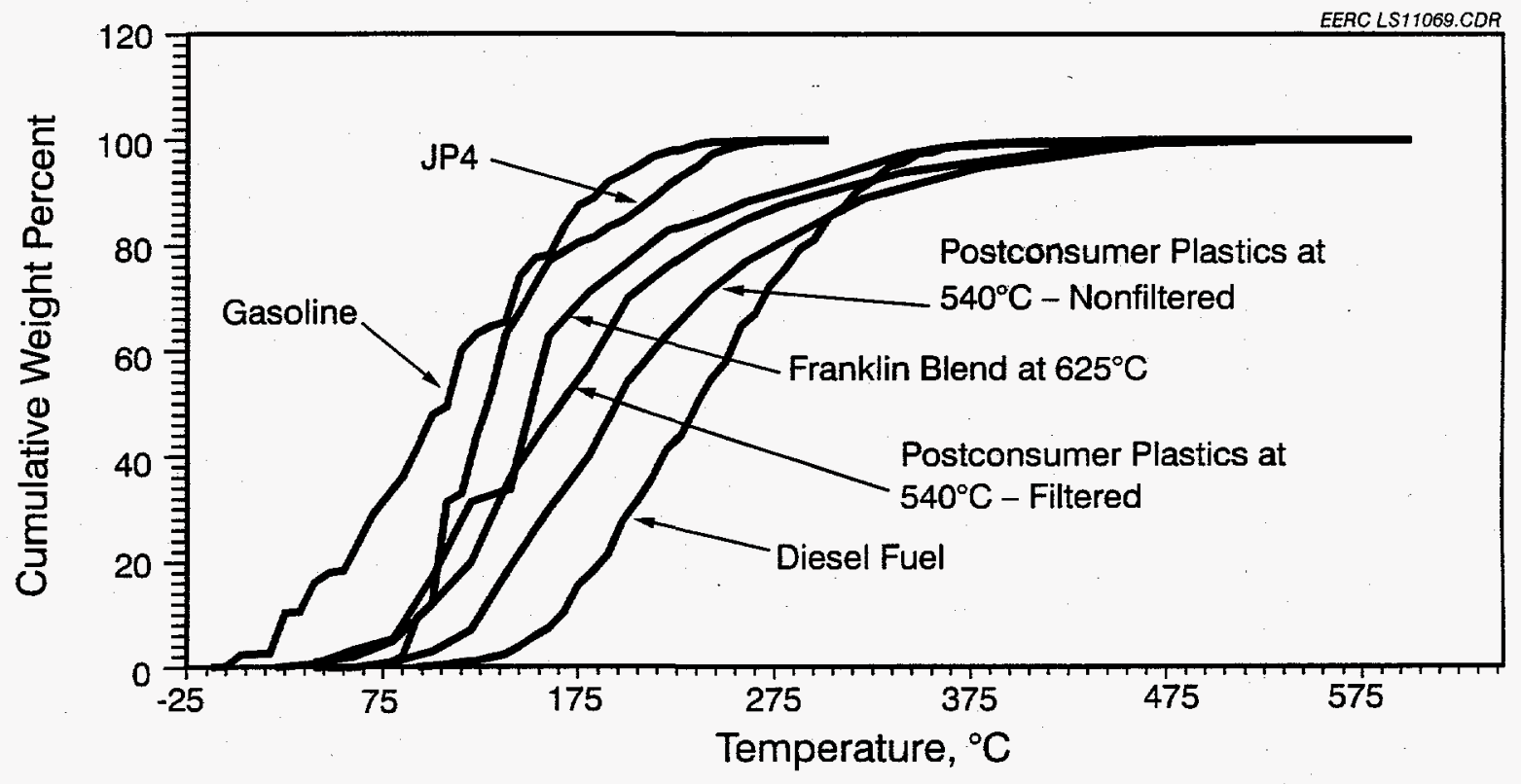

Figure 3. Simulated boiling point distribution comparison for M368. 
TABLE 10

PIANO Analysis of M368 Decomposition Liquids

\begin{tabular}{|c|c|c|}
\hline & Identified, wt\% & Normalized, wt\% \\
\hline Paraffins & 10.3 & 15.1 \\
\hline Isoparaffins & $\mathrm{NI}^{\mathrm{a}}$ & NI \\
\hline Aromatics & 24.0 & 35.1 \\
\hline Olefins/Naphthenes & 18.7 & 27.3 \\
\hline Acetophenone & 5.4 & 7.9 \\
\hline Organic Acid ${ }^{\mathbf{b}}$ & 10.0 & 14.6 \\
\hline Total Identified & 68.4 & 100.0 \\
\hline \multicolumn{3}{|c|}{$\begin{array}{l}\text { a Not identified. } \\
\text { b Estimated concentration-organic acids do not chromatograph well. }\end{array}$} \\
\hline \multicolumn{3}{|c|}{ TABLE 11} \\
\hline \multicolumn{3}{|c|}{ Metals Analysis } \\
\hline Constituent & $\begin{array}{l}\text { Post consumer Plastics }+ \text { Bed } \\
\text { Material, } \mu \mathrm{g} / \mathrm{L}^{1}\end{array}$ & $\begin{array}{c}\text { M368 Composite Liquid Sample, } \\
\mu \mathrm{g} / \mathrm{L}^{2}\end{array}$ \\
\hline Copper & 7 & 1.5 \\
\hline Iron & 140 & 6 \\
\hline Nickel & 4 & 0.5 \\
\hline Vanadium & 4 & $<50$ \\
\hline
\end{tabular}

${ }^{1} \mathrm{CaO}$ and equilibrium cat cracker catalyst.

${ }^{2}$ Collected after fixed-sorbent bed.

\subsection{3 $\underline{\text { Residuals }}$}

The bed material from M368 was analyzed by toxicity characteristic leaching procedure (TCLP). Analysis for RCRA elements are shown in Table 12, along with acceptable RCRA limits. A proximate analysis of the bed material is shown in Table 13. As previously mentioned, the equilibrium cat cracker catalyst used in the bed material contains unknown quantities of metals. If this catalyst is pursued, it will be analyzed for the RCRA metals before further use. 
TABLE 12

M368 Bed Material TCLP

\begin{tabular}{lcc}
\hline Constituent & M368 Bed Material, $\mu \mathrm{g} / \mathrm{L}$ & RCRA limit, $\mu \mathrm{g} / \mathrm{L}$ \\
\hline $\mathrm{As}$ & $<5$ & 5 \\
$\mathrm{Ag}$ & $<0.5$ & 5 \\
$\mathrm{Ba}$ & 300 & 100 \\
$\mathrm{Cd}$ & 10.2 & 1 \\
$\mathrm{Cr}$ & $<5$ & 5 \\
$\mathrm{~Pb}$ & 106 & 5 \\
$\mathrm{Hg}$ & 2.3 & 0.2 \\
$\mathrm{Se}$ & $<5$ & 1 \\
\hline
\end{tabular}

TABLE 13

Proximate Analysis of M368 Bed Material, wt $\%^{1}$

\begin{tabular}{lr}
\hline Moisture & 0.50 \\
Volatile Matter & 28.47 \\
Fixed Carbon & 6.59 \\
Ash & 64.44 \\
\hline${ }^{1}$ As-received basis.
\end{tabular}




\subsection{CONCLUSIONS}

Postconsumer plasties process differently than the resins attempted to date, most likely because of the difference in composition (i.e., PET content) between the virgin resin mixes tested and the postconsumer plastics streams obtained locally. PET produces $\mathrm{CO}_{2}$ upon decomposition, which will decrease the efficiency of chlorine capture by $\mathrm{CaO}$ when used either in situ or in a postreactor fixed bed. The implication is that more sorbent will be needed or conditions will have to be adjusted so that chlorine is removed prior to $\mathrm{CO}_{2}$ evolution. Options include chlorine removal before the main decomposition reaction (pretreatment) or decomposition at a low temperature $\left(\sim 440^{\circ} \mathrm{C}\right)$, followed by a highertemperature decomposition step. A two-step process may be beneficial for high-PET streams. Even in the presence of high PET concentrations, the chlorine removal by the $\mathrm{CaO}$ was excellent. In both tests, M367 and M368, no organic chlorine was detected. Total chlorine levels were $120 \mathrm{ppm}$ for the test at $\mathrm{M} 368\left(540^{\circ} \mathrm{C}\right)$ and $160 \mathrm{ppm}$ for M367 $\left(440^{\circ} \mathrm{C}\right)$.

Metals analysis of the liquids and solids was inconclusive because of questions concerning the choice of bed material. Equilibrium cat cracker catalyst, added to enable processing of the high-PET postconsumer material, was initially thought to contain minimal levels of metals. The cat cracker catalyst was not analyzed prior to its use as a bed material. The higher than expected levels of some RCRA metals lead us to suspect the cat cracker catalyst. If this material is pursued as a bed material for this process, it will be analyzed for RCRA metals prior to its further use.

The postconsumer plastics/HDPE/PP/PVC stream processed at $540^{\circ} \mathrm{C}$ resulted in a liquid stream of quality similar in boiling point distribution to a naphtha. While differences exist between the plastics-derived liquid produced and those of the type produced in a refinery, the liquids are generally similar, with no components seen thus far that would preclude their introduction to a refining process. 


\subsection{REFERENCES}

1. Sharp, L.L. "Thermal Recycling of Plastics," final report to the American Plastics Council; EERC publication, Aug. 1993. 